\title{
Seismic Stability Analysis of Liquefiable Earthdams
}

Submitted by

\section{Shahab Mehregani}

B.Sc, Baha'i Institute for Higher Education (BIHE), Iran

A thesis submitted to the Faculty of Graduate Studies and Research in partial fulfillment of the requirement for the degree of Master of Applied Science

\author{
Department of Civil and Environmental Engineering \\ Carleton University \\ Ottawa, Ontario, Canada
}

(C) Shahab Mehregani

January, 2006

The Master of Applied Science in Civil Engineering Program is a joint program with the University of Ottawa, administered by the Ottawa-Carleton Institute of Civil Engineering 


$\begin{array}{ll}\begin{array}{l}\text { Library and } \\ \text { Archives Canada }\end{array} & \begin{array}{l}\text { Bibliothèque et } \\ \text { Archives Canada }\end{array} \\ \begin{array}{l}\text { Published Heritage } \\ \text { Branch }\end{array} & \begin{array}{l}\text { Direction du } \\ \text { Patrimoine de l'édition }\end{array} \\ \begin{array}{l}\text { 395 Wellington Street } \\ \text { Ottawa ON K1A ON4 }\end{array} & \begin{array}{l}\text { 395, rue Wellington } \\ \text { Ottawa ON K1A ON4 } \\ \text { Canada }\end{array}\end{array}$

Your file Votre référence ISBN: 978-0-494-16462-4 Our file Notre référence ISBN: 978-0-494-16462-4

NOTICE:

The author has granted a nonexclusive license allowing Library and Archives Canada to reproduce, publish, archive, preserve, conserve, communicate to the public by telecommunication or on the Internet, loan, distribute and sell theses worldwide, for commercial or noncommercial purposes, in microform, paper, electronic and/or any other formats.

The author retains copyright ownership and moral rights in this thesis. Neither the thesis nor substantial extracts from it may be printed or otherwise reproduced without the author's permission.
AVIS:

L'auteur a accordé une licence non exclusive permettant à la Bibliothèque et Archives Canada de reproduire, publier, archiver, sauvegarder, conserver, transmettre au public par télécommunication ou par l'Internet, prêter, distribuer et vendre des thèses partout dans le monde, à des fins commerciales ou autres, sur support microforme, papier, électronique et/ou autres formats.

L'auteur conserve la propriété du droit d'auteur et des droits moraux qui protège cette thèse. $\mathrm{Ni}$ la thèse ni des extraits substantiels de celle-ci ne doivent être imprimés ou autrement reproduits sans son autorisation.
In compliance with the Canadian

Privacy Act some supporting forms may have been removed from this thesis.

While these forms may be included in the document page count, their removal does not represent any loss of content from the thesis.
Conformément à la loi canadienne sur la protection de la vie privée, quelques formulaires secondaires ont été enlevés de cette thèse.

Bien que ces formulaires aient inclus dans la pagination, il n'y aura aucun contenu manquant.

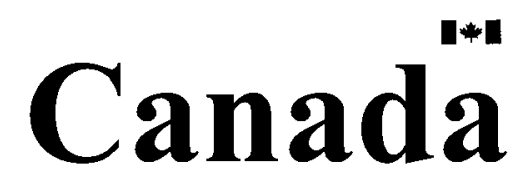




\section{This thesis is humbly dedicated to}

My beloved wife,

Dorna Rohani

and

All the Baha'i youth in Iran

who are deprived of higher education 


\begin{abstract}
Earthdams constructed from loose to compact, fine to medium sand fills might be susceptible to liquefaction during a seismic event. A deterministic stability analysis has been proposed and applied to such dams in this study.

There are two basic steps in the proposed method. First, the liquefaction triggering of a dam corresponding to a certain design earthquake is studied using the cyclic stress approach. This step involves initial static and dynamic analyses for identifying the regions where liquefaction could be triggered during the earthquake. Second, the overall slope stability under the static condition shortly after the earthquake is evaluated. For the liquefied regions, the residual undrained strength (steady-state strength) and for non-liquefied zones, the drained strength of the soil is applied. The residual undrained strength is determined from two different approaches. The results of these two approaches are compared to assist judgment on the stability of the dam.
\end{abstract}

The proposed method has been verified by examining its applicability of Lower San Fernando Dam which failed in liquefaction during the 1971 San Fernando earthquake. The proposed method is then applied to a Canadian dam and the results show that this dam is vulnerable to the flow slide type of failure under the design earthquake.

Finally, two remedial measures are considered for the dam which suffers a flow slide type of failure under the design earthquakes. The applied remedial techniques are the use of stabilizing berms and recompaction of the original fill layer of the dam. 


\section{Acknowledgments}

I would like to express my deepest and most sincere gratitude to my supervisor, Professor K.T. Law, whose patience, advice and encouragement throughout this research supported me to fulfill this accomplishment.

My warmest thanks go to the Civil and Environmental Engineering Department, especially Professor S. Sivathayalan for his kind support and cooperation in this research.

My most grateful acknowledgment is to my devoted parents, Soheil and Farangiz, and my beloved grandparents, Habib'u'llah and Golrokh for their extensive support, infinitive love and sympathetic motivation. Many thanks also to my parents-in-law, Gholam-Hossein and Pooran for their loving support and endless encouragement.

I am also deeply grateful to my cherished wife, Dorna, for her immense patience, continuous invigoration and loving assistance all through my studies. Without her sincere dedication and selfless sacrifice, none of my achievements would be accomplished.

My special acknowledgment goes to the Baha'i community of Canada for all their ceaseless support, love and encouragement during my studies in Canada. No words can truly express my cordial respect and appreciation to them. 


\section{Table of contents}

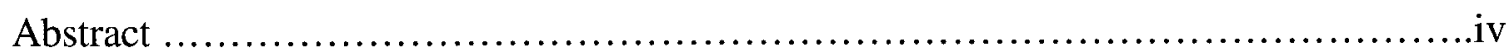

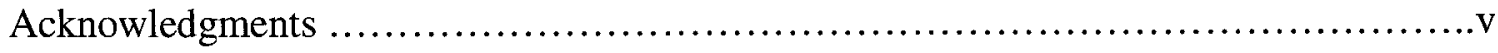

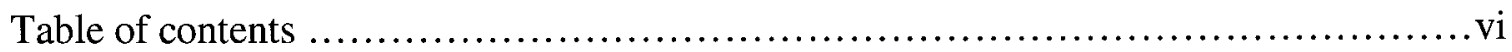

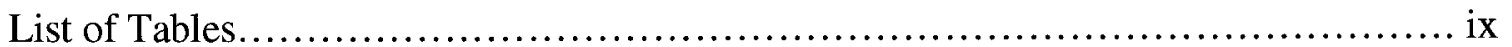

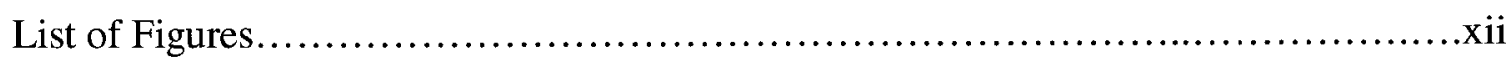

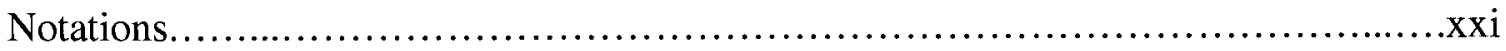

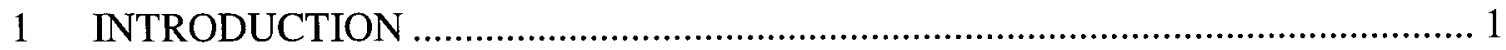

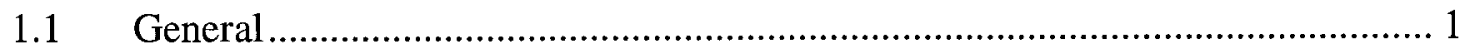

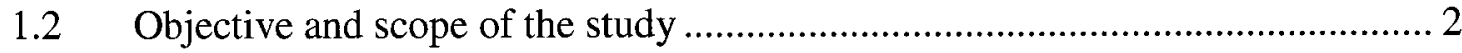

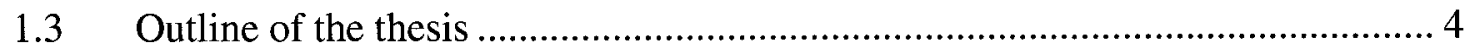

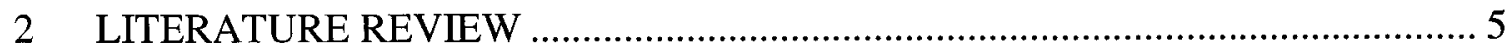

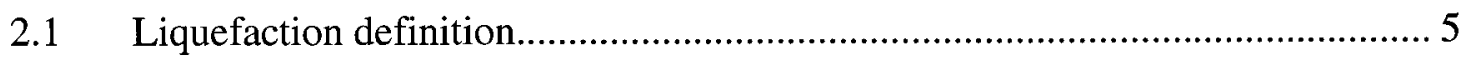

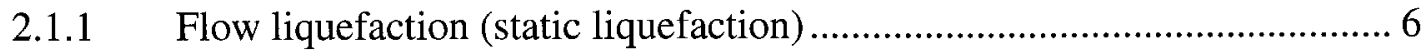

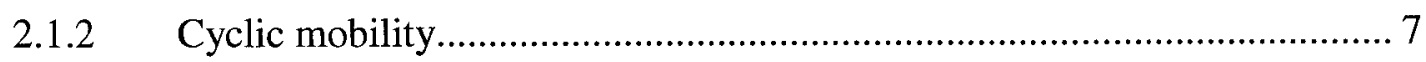

2.2 Liquefaction hazard evaluation ............................................................ 7

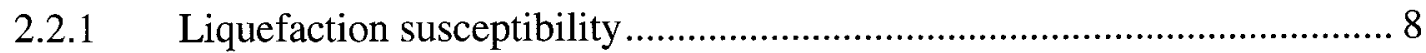

2.2.2 Evaluation of liquefaction triggering ............................................. 11

2.2.2.1 Cyclic stress approach............................................................ 11

2.2.2.2 Cyclic strain approach............................................................. 18

2.2.3 The liquefied shear strength of soils ..................................................... 18 
2.2.3.1 In-situ testing procedure ................................................................ 19

2.2.3.2 Normalized stress procedure ................................................................ 21

2.2.3.3 Laboratory-based procedure ……………………………………….... 23

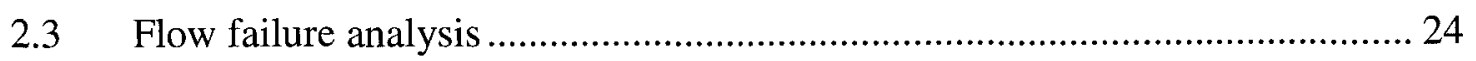

2.4 Applicable software packages for evaluation of liquefaction triggering and

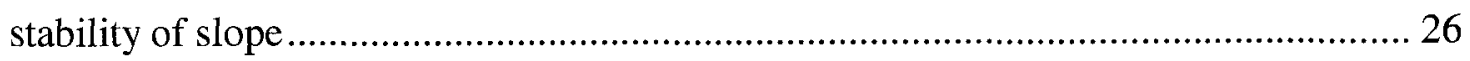

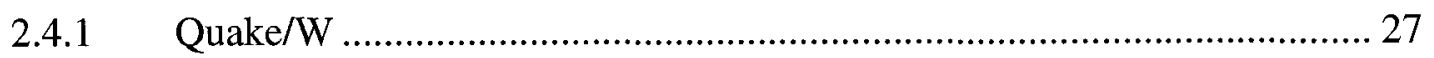

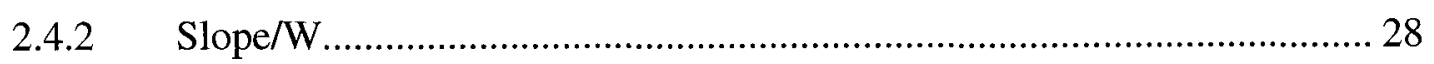

3 LOWER SAN FERNANDO DAM CASE HISTORY ………………………......... 39

3.1 Geometry and general characteristics of LSFD .............................................. 40

3.2 Applied earthquake record and Peak Ground Acceleration (PGA) .................. 41

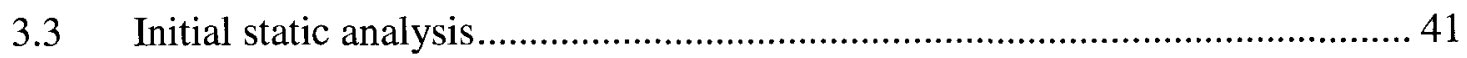

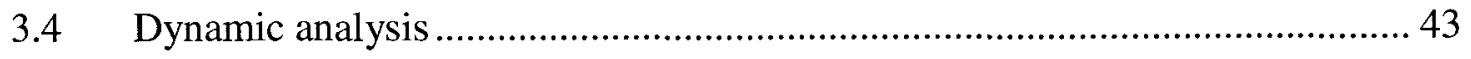

3.5 Evaluation of liquefaction initiation and determination of pore water pressure 48

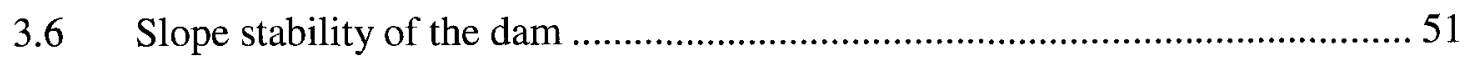

3.6.1 Establishment of Slope/W file ........................................................... 52

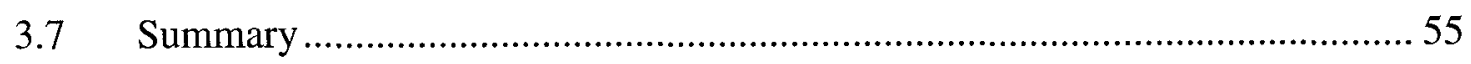

4 LIQUAFACTION ANALYSIS ON A DAM IN CANADA ……………………...... 76

4.1 Geometry and general characteristics of the dam ............................................ 77

4.2 Applied earthquake record and PGA ......................................................... 78

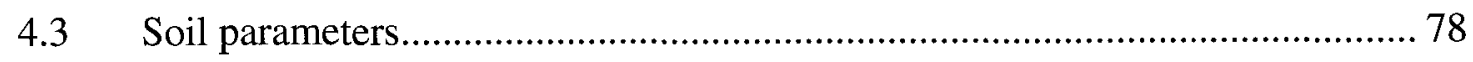

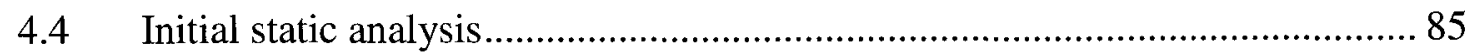

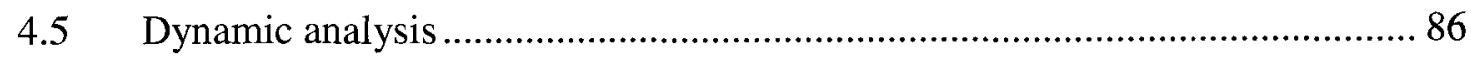

vii 


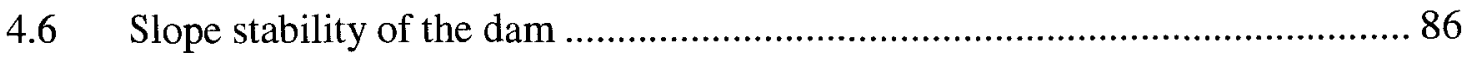

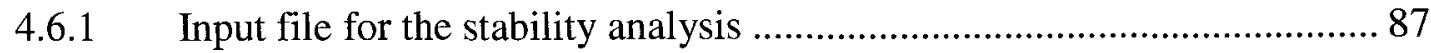

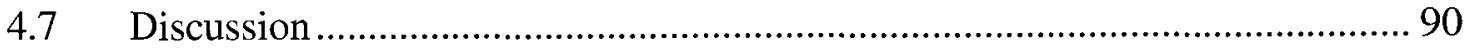

5 REMEDIATION OF THE CANADIAN DAM ............................................. 131

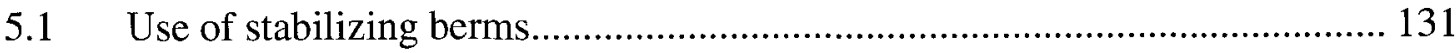

5.1.1 Evaluation of liquefaction initiation ............................................... 133

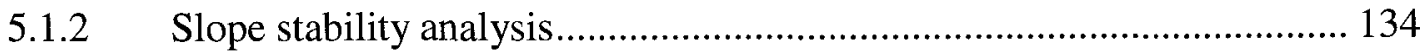

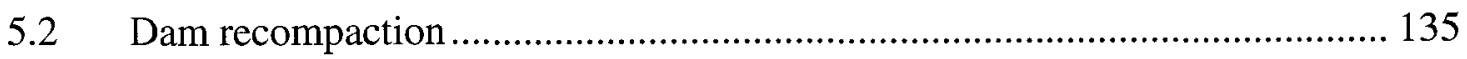

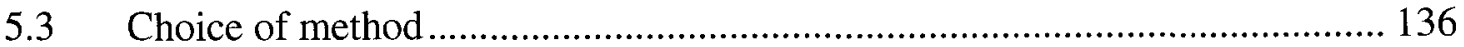

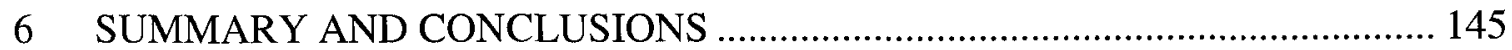

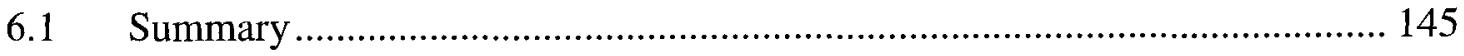

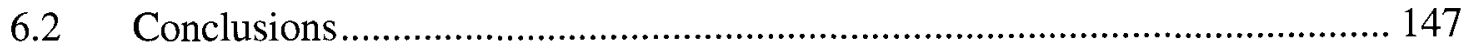

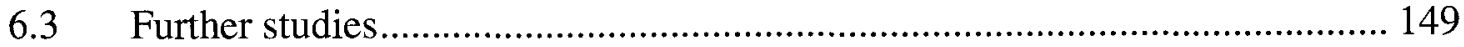

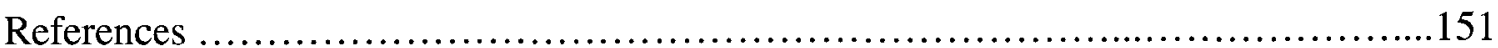




\section{List of Tables}

Table 2.1 Relationships for determination of $c_{r}$ correction factor (Kramer, 1996) ..... 30

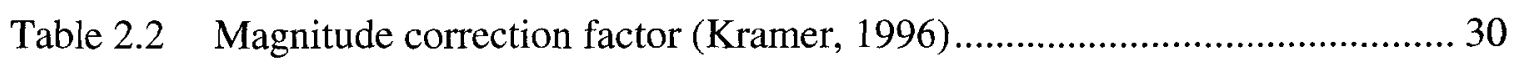

Table 2.3 Fines content correction factor suggested by Seed and Harder (1990) and

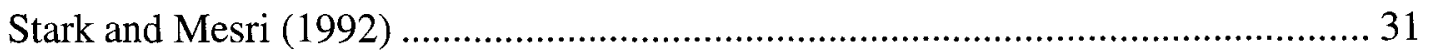

Table 3.1 Soil parameters for static analysis of LSFD (Seed et al., 1973; Lee et al., 1975) 56

Table 3.2 Soil parameters for dynamic analysis of LSFD (Seed et al., 1973).............56

Table 3.3 Values of $K_{2 \text {,max }}$ versus void ratio (e) or relative density $\left(\mathrm{D}_{\mathrm{r}} \%\right.$ ) (Seed and

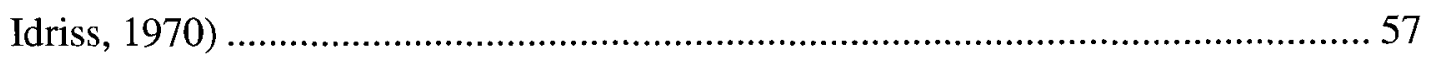

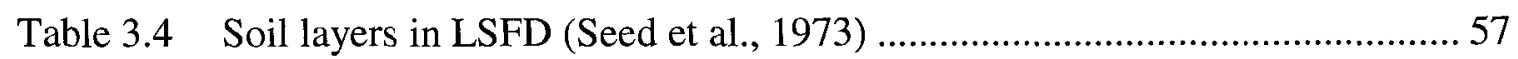

Table 3.5 Parameters of the soil inside the upstream hydraulic fill (from the static and dynamic analyses) for evaluation of liquefaction triggering and determination of

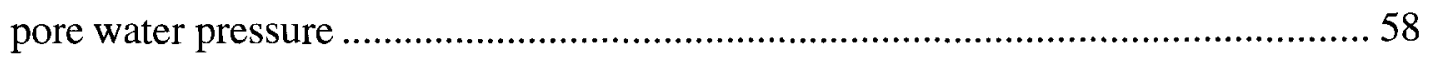

Table 3.6 Additional SPT blow-count $\left(\mathrm{N}_{\text {corr }}\right)$ corrected for fines content (Seed and Harder, 1990) 58

Table 4.1 Average $\mathrm{N}$ value from two the bore-hole data for different depths of the fill of the dam 94

Table 4.2 Characteristics of the critical records for both near- and far-field ground motions with $0.5 \%$ exceedance in 50 years .95

Table 4.3 Characteristics of the critical records for both Short- and long-period ground

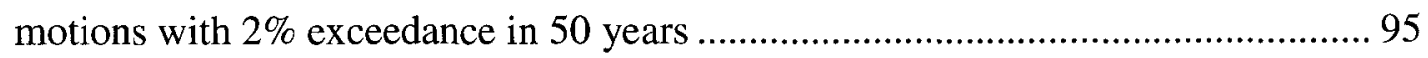

Table 4.4 Determination of $\left(\mathrm{N}_{1}\right)_{60}$ and the friction angle ................................. 96 
Table 4.5 Variation of $K_{2 \max }$ with respect to relative density (Seed and Idriss, 1970). 96

Table 4.6 Correlation between $\left(\mathrm{N}_{1}\right)_{60}$ and relative density (Tokimatsu and Seed, 1987) 97

Table 4.7 Determined relative densities and $\mathrm{K}_{2 \max }$ in each depth interval of the fill layer 98

Table 4.8 Procedure of damping ratio determination ......................................... 99

Table $4.9 \quad\left(\mathrm{~N}_{1}\right)_{60}$ value and friction angle determination of lower layer .................... 100

Table 4.10 Damping ratio calculation for lower layer ....................................... 101

Table 4.11 Required soil parameters for static and slope stability analysis ............ 102

Table 4.12 Dynamic parameters of soils in Canadian dam.................................. 102

Table 4.13 Results of the stability analysis of the Canadian dam for the ground motions with 10,000 years return period 103

Table 4.14 Results of the stability analysis of the Canadian dam for ground motions with 2500 years return period 103

Table 4.15 Factors of safety of the upstream side of the dam with different shear modulus based on the far-field ground motion (the bolded column represents the values of the overall stability analysis of the dam.) 104

Table 4.16 Comparison of the factor of safety based on the new Poisson's Ratio of 0.25 with the factor of safety based on the applied Poisson's Ratio of 0.40 . 104

Table 4.17 Comparison of the factor of safety based on the new Plasticity Index of 5 with the factor of safety based on the applied Plasticity Index of zero 104

Table 5.1 Soil properties and slope stability results of the dam for different dimensions of the upstream berm corresponding to $\mathrm{N}=15$ and $\mathrm{N}=20$ blows $/ 30 \mathrm{~cm}$ 137 
Table 5.2 Soil parameters for the material compacted to $\mathrm{N}=7,12,15,20$ blows $/ 30 \mathrm{~cm}$; $\mathrm{N}=7$ corresponds to the original loose fill. 


\section{List of Figures}

Figure 2.1 Soil behaviour under undrained monotonic loading (Kuerbis, 1989)....... 32

Figure 2.2 Liquefaction caused by monotonic and cyclic loadings (Poulos et al., 1985) 32

Figure 2.3 Determination of depth reduction factor (Seed and Idriss, 1971)............ 33

Figure 2.4 Cyclic stresses required to produce initial liquefaction $\left(\mathrm{N}_{\mathrm{L}}\right)$ and $20 \%$ axial strain in isotropically consolidated triaxial specimens of Sacramento River Sand (Seed and Lee, 1965) 33

Figure 2.5 Cyclic resistance ratio, $\mathrm{CRR}$, vs. $\left(\mathrm{N}_{1}\right)_{60}$ for clean and silty sands based on reference earthquake of $M=7.5$ (Seed et al., 1985).

Figure 2.6 Variation of $\mathrm{K}_{\alpha}$ with respect to $\alpha$ (Seed and Harder, 1990) 35

Figure 2.7 Values of $\mathrm{K}_{\sigma}$ with respect to vertical effective stress (Youd and Idriss, 2001) 35

Figure 2.8 Range of recommended magnitude correction factors by Youd and Idriss (2001) 36

Figure 2.9 Variation of undrained Residual Strength, $\mathrm{S}_{\mathrm{r}}$ versus the equivalent clean sand SPT blow-count, $\left(\mathrm{N}_{1}\right)_{60-\mathrm{cs}}$ (Seed and Harder, 1990) 36

Figure 2.10 Relationship between residual excess pore pressure ratio and the factor of safety against liquefaction (Marcuson and Hynes, 1990). 37

Figure 2.11 Procedure of estimating undrained steady-state strength of in-situ liquefied soil from laboratory-based data (Poulos et al., 1985) 37

Figure 2.12 Number of uniform stress cycles, $\mathrm{N}_{\mathrm{eq}}$, vs. earthquake magnitude, $\mathrm{M}$ (Seed et al., 1975) 38 
Figure 2.13 Pore pressure ratio vs. cyclic number ratio in cyclic simple shear test

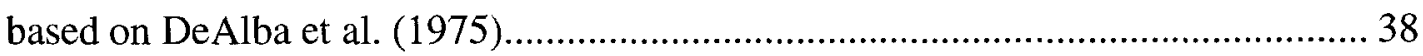

Figure 3.1 Cross-section of LSFD (Seed et al., 1975c) ....................................59

Figure 3.2 (a) Cross-section and water table and (b) Finite element mesh of LSFD for

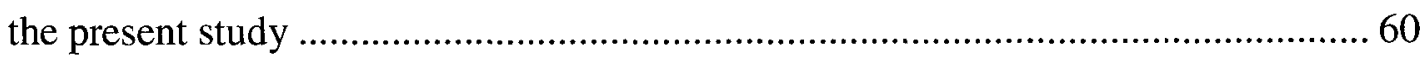

Figure 3.3 Pacoima Dam earthquake records for stability analysis of LSFD .......... 61

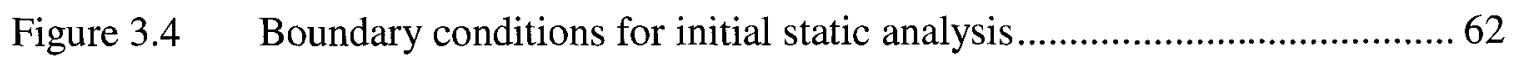

Figure 3.5 Relationship between initial shear stress ratio, $\alpha$, and $\mathrm{K} \alpha$ correction factor 62

Figure 3.6 Ko correction function for the soil layers susceptible to liquefaction ...... 63

Figure 3.7 Cyclic number function for the hydraulic sand fill of LSFD (Seed et al., 1973) 64

Figure 3.8 Cyclic number function for the alluvium foundation of LSFD (Seed et al., 1973) 64

Figure 3.9 G-reduction function for cohesionless soils in LSFD (Seed et al., 1973). 65

Figure 3.10 G-reduction function for cohesive soils in LSFD (Seed et al., 1973) ...... 65

Figure 3.11 Damping ratio function of cohesionless soils in LSFD (Seed et al., 1973) 66

Figure 3.12 Damping ratio function of cohesive soils (Seed et al., 1973) .................. 66

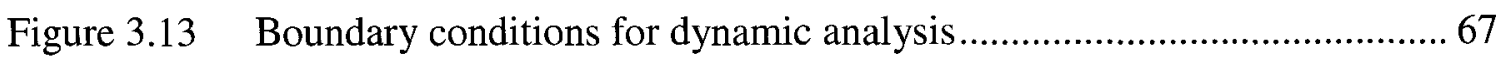

Figure 3.14 Result of the evaluation of liquefaction triggering; shadowy regions indicate liquefied zones. 68 
Figure 3.15 Shear stresses-time histories of representative locations (Seed et al., 1973) 69

Figure 3.16 Analysis of soil liquefaction along one of the potential zones of LSFD after 8 seconds of shaking, using Pacoima ground motion records (Seed et al., 1973) 70

Figure 3.17 Computed liquefied zones in LSFD based on Pacoima ground motion records (Seed et al. 1973). 71

Figure 3.18 Result of slope stability analysis based on average residual strength from Seed and Harder (1990) 72

Figure 3.19 Result of slope stability analysis based on upper bound residual strength from Seed and Harder (1990) 72

Figure 3.20 Result of slope stability analysis based on lower bound residual strength from Seed and Harder (1990) 72

Figure 3.21 Factor of safety for upstream side of LSFD (Seed et al., 1973) 73

Figure 3.22 Factor of safety for the slip surface closely resembling what was considered by Seed et al. (1973) (from Seed and Harder (1990)) 73

Figure 3.23 Result of slope stability analysis based on average liquefied shear strength from Olson and Stark (2002) 74

Figure 3.24 Result of slope stability analysis based on upper bound liquefied shear strength from Olson and Stark (2002) 74

Figure 3.25 Result of slope stability analysis based on lower bound liquefied strength from Olson and Stark (2002) 74 
Figure 3.26 Factor of safety for the slip surface closely resembling what was considered by Seed et al. (1973) (from Olson and Stark (2002)) .......................... 75

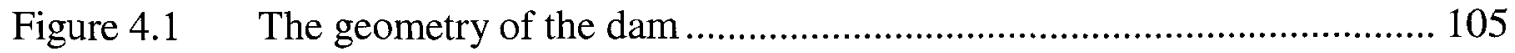

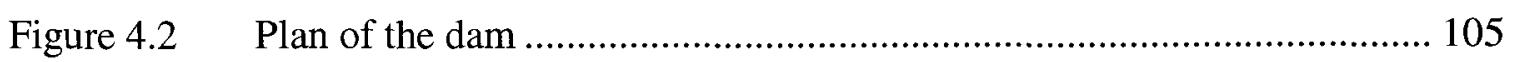

Figure 4.3 SPT data of bore-hole number one in referenced cross section from Figure $4.1 \quad 107$

Figure 4.4 SPT data of bore-hole number two in referenced cross section from Figure $4.1 \quad 109$

Figure 4.5 Acceleration time history of near-field ground motion with $0.5 \%$ exceedance in 50 years... 110

Figure 4.6 Acceleration time history of far-field ground motion with $0.5 \%$ exceedance in 50 years. 110

Figure 4.7 Acceleration spectra (5\% damping) for both near- and far-field ground motions with $0.5 \%$ exceedance in 50 years 111

Figure 4.8 Acceleration time history of short-period ground motion (M6) with 2\% exceedance in 50 years. 111

Figure 4.9 Acceleration time history of long-period ground motion (M7) with 2\% exceedance in 50 years.

Figure 4.10 Acceleration spectra (5\% damping) for both short-period (M6) and longperiod (M7) ground motions with $2 \%$ exceedance in 50 years 112

Figure 4.11 $\mathrm{K}_{\sigma}$ correction function for the fill layer 113

Figure 4.12 $\mathrm{K}_{\alpha}$ correction function versus the initial shear stress ratio, $\alpha$ for the fill layer $\quad 113$ 
Figure 4.13 Cyclic number function for the fill layer

Figure 4.14 Pore pressure function for both the fill and the till layers...................... 114

Figure $4.15 \quad \mathrm{G}$ reduction function for the fill layer.......................................... 115

Figure 4.16 Damping ratio function for the fill layer........................................ 115

Figure $4.17 \mathrm{~K}_{\sigma}$ correction function for the till layer......................................... 116

Figure 4.18 Cyclic number function for the till layer........................................ 116

Figure 4.19 G reduction function for the till layer .......................................... 117

Figure 4.20 Damping ratio function for the till layer ......................................... 117

Figure 4.21 Finite element mesh of the typical liquefiable dam in Canada.............. 118

Figure 4.22 Variation of vertical effective stress with depth; "h" shows the depth of the contour lines from the crest in metre.

Figure 4.23 Liquefied regions due to the near-field ground motion with $0.5 \%$ exceedance in 50 years.

Figure 4.24 Liquefied regions due to the far-field ground motion with $0.5 \%$ exceedance in 50 years.

Figure 4.25 Liquefied regions due to the short-period (M6) ground motion with 2\% exceedance in 50 years 120

Figure 4.26 Liquefied regions due to the long-period (M7) ground motion with $2 \%$ exceedance in 50 years

Figure 4.27 Factor of safety of the upstream side of the dam with the average liquefied strength from the Seed and Harder (1990) approach and based on the near-field ground motion

xvi 
Figure 4.28 Factor of safety of the upstream side of the dam with the average liquefied strength from the Seed and Harder (1990) approach and based on the far-field ground motion 121

Figure 4.29 Factor of safety of the downstream side of the dam with the average liquefied strength from the Seed and Harder (1990) approach and based on the nearfield ground motion. 122

Figure 4.30 Factor of safety of the downstream side of the dam with the average liquefied strength from the Seed and Harder (1990) approach and based on the farfield ground motion

Figure 4.31 Factor of safety of the upstream side of the dam with the lower bound liquefied strength, according to the Seed and Harder (1990) approach, and based on the near-field ground motion

Figure 4.32 Factor of safety of the upstream side of the dam with the lower bound liquefied strength, according to the Seed and Harder (1990) approach, and based on the far-field ground motion 123

Figure 4.33 Factor of safety of the downstream side of the dam with the lower bound liquefied strength, according to the Seed and Harder (1990) approach, and based on the near-field ground motion

Figure 4.34 Factor of safety of the downstream side of the dam with the lower bound liquefied strength, according to the Seed and Harder (1990) approach, and based on the far-field ground motion.

Figure 4.35 The pre-earthquake vertical effective stress and the liquefied area due to the far-field ground motion. 125 
Figure 4.36 Factor of safety of the upstream side of the dam with the average liquefied strength, according to the Olson and Stark (2002) approach, and based on the nearfield ground motion. 126

Figure 4.37 Factor of safety of the upstream side of the dam with the average liquefied strength, according to the Olson and Stark (2002) approach, and based on the farfield ground motion. 126

Figure 4.38 Factor of safety of the downstream side of the dam with the average liquefied strength, according to the Olson and Stark (2002) approach, and based on the near-field ground motion 127

Figure 4.39 Factor of safety of the downstream side of the dam with the average liquefied strength, according to the Olson and Stark (2002) approach, and based on the far-field ground motion. 127

Figure 4.40 Factor of safety of the upstream side of the dam with the average liquefied strength, according to the Olson and Stark (2002) approach, and based on the shortperiod ground motion (M6) 128

Figure 4.41 Factor of safety of the upstream side of the dam with the average liquefied strength, according to the Olson and Stark (2002) approach, and based on the longperiod ground motion (M7) 128

Figure 4.42 Factor of safety of the downstream side of the dam with the average liquefied strength, according to the Olson and Stark (2002) approach, and based on the short-period ground motion (M6) 129 
Figure 4.43 Factor of safety of the downstream side of the dam with the average liquefied strength, according to the Olson and Stark (2002) approach, and based on the long-period ground motion (M7) 129

Figure 4.44 Comparing the liquefied shear strength based on approaches of Seed and

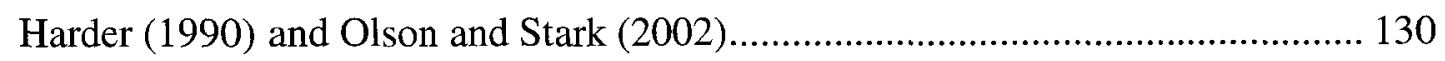

Figure $5.1 \quad$ Geometry of the dam with the added berms .................................... 139

Figure 5.2 $\mathrm{K}_{\sigma}$ correction function for the berm material compacted to $\mathrm{N}=15$ blows $/ 30 \mathrm{~cm}$. 139

Figure 5.3 $\mathrm{K}_{\alpha}$ correction factor for the berm material compacted to $\mathrm{N}=15$ and $\mathrm{N}=20$ blows $/ 30 \mathrm{~cm}$. 140

Figure 5.4 $\mathrm{K}_{\sigma}$ correction function for the berm material compacted to $\mathrm{N}=20$ blows $/ 30 \mathrm{~cm}$ 140

Figure 5.5 Cyclic number function of the berm material compacted to $\mathrm{N}=15$ blows $/ 30 \mathrm{~cm}$ 141

Figure 5.6 Cyclic number function of the berm material compacted to $\mathrm{N}=20$ blows $/ 30 \mathrm{~cm}$ 141

Figure 5.7 Dynamic analysis of the dam with the berm material compacted to $N=15$ blows $/ 30 \mathrm{~cm}$ 142

Figure 5.8 Result of slope stability analysis for the upstream berm with $H=3.30 \mathrm{~m}$, $\mathrm{W}=10.00 \mathrm{~m}$, material compacted to $\mathrm{N}=15$ blows $/ 30 \mathrm{~cm}$ 142

Figure 5.9 Result of slope stability analysis for the downstream berm with $H=2.70 \mathrm{~m}$, $\mathrm{W}=3.50 \mathrm{~m}$, material compacted to $\mathrm{N}=15$ blows $/ 30 \mathrm{~cm}$ 143

Figure 5.10 Cyclic number function of the soil with respect to $\mathrm{N}=12$ blows $/ 30 \mathrm{~cm}$.. 143

xix 
Figure $5.11 \mathrm{~K}_{\sigma}$ correction functions with respect to $\mathrm{N}=12$ blows $/ 30 \mathrm{~cm} \ldots \ldots \ldots \ldots \ldots \ldots . . . . . .144$

Figure 5.12 Variation of factor of safety of the fill layer of the dam with respect to SPT N values.. 144 


\section{Notation}

$a_{\max } \quad$ Maximum horizontal acceleration at ground surface

$\mathrm{C}_{\mathrm{M}} \quad$ Magnitude correction factor

$\mathrm{C}_{\mathrm{N}} \quad$ Correction factor for overburden pressure

CPT Cone Penetration Test

$\mathrm{c}_{\mathrm{r}} \quad$ Correction factor to relate the CSR due to simple shear test and CSR

due to triaxial test

CRR Cyclic Resistance Ratio

$\left(C R R_{\text {field }}\right) \quad$ Liquefaction resistance of a soil in the field

CSR Cyclic Stress Ratio

$\mathrm{CSR}_{\mathrm{ss}} \quad$ Cyclic Stress Ratio in simple shear test

$\mathrm{CSR}_{t x} \quad$ Cyclic Stress Ratio in triaxial test

$\mathrm{D}_{\mathrm{r}} \quad$ Relative density

$\mathrm{e}_{\mathrm{f}} \quad$ In-situ void ratio

f Exponent estimate from site conditions used in calculation of $\mathrm{K}_{\sigma}$

g Acceleration of gravity

$\mathrm{G}_{\max } \quad$ Maximum shear modulus

G Secant shear modulus

$\mathrm{H} \quad$ Head of water

$\mathrm{K}_{0} \quad$ Coefficient of earth pressure at rest

$\mathrm{K}_{\alpha} \quad$ Correction factor for initial shear stresses on a horizontal plane 


\begin{tabular}{|c|c|}
\hline $\mathrm{K}_{\sigma}$ & Correction factor for effective overburden pressure \\
\hline LL & Liquid limit \\
\hline $\mathrm{M}_{\mathrm{w}}$ & Moment earthquake magnitude \\
\hline$\left(\mathrm{N}_{1}\right)_{60}$ & Corrected standard penetration resistance \\
\hline$\left(\mathrm{N}_{1}\right)_{60-\mathrm{cs}}$ & Equivalent clean sand blow-count \\
\hline $\mathrm{N}_{\text {corr }}$ & Correction factor for fines content \\
\hline $\mathrm{N}_{\mathrm{eq}}$ & $\begin{array}{l}\text { Number of equivalent uniform stress cycles for an earthquake } \\
\text { magnitude }\end{array}$ \\
\hline $\mathrm{N}_{\mathrm{L}}$ & Number of cycles required for liquefaction \\
\hline OCR & Over consolidation ratio \\
\hline $\mathrm{P}_{a}$ & Atmospheric pressure \\
\hline PGA & Peak Ground Acceleration \\
\hline PI & Plasticity index \\
\hline $\mathrm{q}_{\mathrm{cl}}$ & Normalized cone penetration resistance \\
\hline $\mathrm{r}_{\mathrm{d}}$ & Depth reduction factor to account for flexibility on soil profile \\
\hline $\mathrm{r}_{\mathrm{u}}$ & Pore pressure ratio \\
\hline SPT & Standard Penetration Test \\
\hline SSL & Steady-State Line \\
\hline $\mathrm{u}_{\mathrm{excess}}$ & Excess pore pressure \\
\hline$u_{i}$ & Initial pore water pressure \\
\hline $\mathrm{z}$ & Depth of soil below the interested surface \\
\hline$\alpha$ & Initial shear stress ratio \\
\hline$\gamma_{c}$ & Cyclic shear strain \\
\hline
\end{tabular}




$\begin{array}{ll}\xi & \text { Damping ratio } \\ \sigma_{3 c}^{\prime} & \text { Initial effective confining pressure in triaxial test } \\ \sigma_{d c} & \text { Maximum cyclic shear stress in triaxial test } \\ \sigma_{f c}^{\prime} & \text { Initial effective normal stress } \\ \sigma_{m}^{\prime} & \text { Effective confining pressure } \\ \sigma_{v} & \text { Total vertical stress } \\ \sigma_{v o}^{\prime} & \text { Static (initial) vertical effective stress } \\ \Sigma S_{r} & \text { Mobilized resisting shear force along a slip surface } \\ \Sigma S_{m} & \text { Induced shear forces along that slip surface } \\ \tau_{\mathrm{cyc}} & \text { Cyclic shear stress } \\ \tau_{\mathrm{hv}} & \text { Static driving shear stress on horizontal plane } \\ \phi & \text { Friction angel } \\ \Psi & \text { Energy correction factor }\end{array}$




\section{CHAPTER 1}

\section{INTRODUCTION}

\subsection{General}

After spectacular damages due to Good Friday's earthquake in Alaska and Niigata (1964), the phenomenon of earthquake-induced liquefaction of soils became a noteworthy topic of study for geotechnical engineers. A great deal of investigations were initiated to explain the liquefaction behaviour of the soil. Relative density, stress path, static shear stresses, field behaviour structure (or soil fabric), consolidation pressure, and cyclic stress ratio are some factors that affect the resistance of soil against liquefaction.

After the 1971 San Fernando earthquake, which caused a flow failure on the upstream side of Lower San Fernando Dam, some investigators paid attention to the effect of liquefied shear strength of the soil on the stability of slopes. They developed different procedures, either based on in-situ investigations or laboratory studies, to assess this parameter. Poulos et al. (1985), Seed and Harder (1990), Stark and Mesri (1992), 
Ishihara (1993), Konrad and Watts (1995), and Olson and Stark (2002) are some researchers who have worked on the shear strength of liquefied soils and presented some correlations for its determination. Olson (2001) defines the shear strength of liquefied soils as, "the shear strength mobilized at large deformation after liquefaction ..... in saturated, contractive sandy soils."

One of the important applications of shear strength of liquefied soils is in post liquefaction stability analysis of earthdams. Earthdams with loose to compact, fine to medium sand fills are susceptible to liquefaction during a seismic event. Since earthdams are categorized as critical structures, it is necessary to confirm their stability even after their construction. This research deals with the stability analysis of one of such liquefiable earthdams with its existing geometry. As the results of analysis show that the dam will fail after the design seismic event, this research goes on to examine measures to stabilize the dam.

\subsection{Objective and scope of the study}

The purpose of this study is the evaluation of seismic stability of a liquefiable earthdam in Canada. The dam material is generally composed of loose to compact, fine to medium sand with little to some silt and therefore, is susceptible to liquefaction. The overall stability analysis of the dam has been performed using a two-dimensional plane strain finite element method and consists of two steps. Firstly, using the cyclic stress approach, the liquefaction triggering of the dam during the design earthquake is investigated. Secondly, under static conditions shortly after the termination of the earthquake, the stability analysis of the liquefied dam is evaluated. 
Prior to analysis of the Canadian dam, the slope stability analysis of Lower San Fernando Dam (LSFD) is conducted and the results of this analysis are compared with the previous researches in order to verify the applied procedure for the stability analysis of liquefiable earthdams under seismic events. Moreover, this analysis of LSFD helps to appraise the capability of two commercially available computer programs, Quake/W and Slope/W.

The evaluation of liquefaction triggering involves two steps: static and dynamic analysis. Both of these analyses are carried out with Quake/W. During the static analysis, the pre-earthquake stress conditions of the body and the foundation of the dam are determined. A linear elastic soil model is used for this analysis. The resulting stresses of static analysis are applied in the dynamic analysis in order to determine the dynamic response of the dam and the foundation. An equivalent-linear soil model is utilized for the dynamic analysis.

Slope stability analysis of the liquefied earthdam is conducted with Slope/W. This program uses the results from the dynamic analysis of Quake/W with liquefied shear strengths (residual strength) being mobilized in the liquefied zones in the dam. Two methods of determining the liquefied shear strength are utilized in this study: one by Seed and Harder (1990) and the other by Olson and Stark (2002). The slope stability results based on these two methods have been compared to permit an evaluation of the stability of the dam under the design earthquakes.

As the results of stability analysis show that flow failure in the dam is likely under the design earthquakes, some remedial measures have been considered. Two common techniques to improve the seismic dam stability have been considered in this study. The 
first involves the use of stabilizing berms and the second is by recompacting the original loose material of the dam.

\subsection{Outline of the thesis}

Chapter 2 presents the review of literature including liquefaction hazard analysis and stability analysis of earthdams. Stability analysis of Lower San Fernando Dam with the two mentioned geotechnical computer programs and based on Seed and Harder (1990) and Olson and Stark (2002) methods is presented in Chapter 3. Chapter 4 deals with the overall stability analysis of the Canadian dam including liquefaction triggering and postliquefaction slope stability analysis. Considerations of the remedial measures for the dam are presented in Chapter 5. Lastly, a summary and conclusions of the analysis and remedial measures are discussed in Chapter 6. 


\section{CHAPTER 2}

\section{LITERATURE REVIEW}

\subsection{Liquefaction definition}

The term liquefaction was first coined by Casagrande in 1936 for the response of loose saturated sand to static or dynamic disturbance that resulted in flow slides (Casagrande, 1936). Along the same thought, Mogami and Kubo in 1953 (quoted by Kramer, 1996) associated the phenomenon of liquefaction involving large soil deformation in saturated cohesionless soil due to monotonic, transient or repeated disturbance under undrained conditions. When a loose saturated soil is subjected to a rapid loading under undrained conditions, there is a tendency to densify. As the undrained condition does not allow densification to occur, the pore water pressure of the soil will increase and consequently, the effective stress and the shear strength will decrease. When this process continues to the point that the shear strength drops below the driving shear stress in the soil, the soil mass will fail and start to flow that would modify 
the geometry of the soil mass and the driving shear stress. This flow continues until the driving shear stress becomes lower than the shear strength of the soil. Figure 2.1 shows the behaviour of the soil under undrained monotonic loading. In this figure, three different types of soil behaviour are recognized. Soil type 1 represents the behaviour of loose sand that is strain softening or contractive. Soils with this behaviour are considered liquefiable in which the shear strength of the soil reaches a very low value after straining beyond the peak. In this post peak state, the soil continues to deform at constant void ratio, constant confining pressure and constant shear stress. Soil type 2 in Figure 2.1 represents limited liquefaction in which strain softening occurs in a limited strain interval beyond which strain hardening occurs. Soil type 3 represents a dilative soil where work hardening behaviour prevails. This soil type is safe against liquefaction (Kuerbis, 1989).

According to the type of loading and deformation, liquefaction phenomenon can be divided into two different categories: flow liquefaction (i.e., soil type 1 in Figure 2.1) and cyclic mobility (Kramer, 1996).

\subsubsection{Flow liquefaction (static liquefaction)}

Flow liquefaction occurs when the shear strength of the soil mass in its liquefied state (liquefied strength) is less than the shear stress in that soil required for static equilibrium. Figure 2.2 schematically shows the condition for flow liquefaction that might be caused by monotonic or cyclic loading. Liquefaction normally leads to large drop of soil strength. Therefore, slope failures following liquefaction may happen suddenly and flow over large distances at high speed. Lower San Fernando Dam (LSFD) is a good sample of liquefaction flow failure. 


\subsubsection{Cyclic mobility}

Another kind of liquefaction phenomenon is earthquake-induced softening or cyclic mobility. There is a main difference between triggering of this kind of liquefaction and flow liquefaction regarding shear stresses and shear strength of the soil. Opposite to flow liquefaction, cyclic mobility is triggered when the static shear stress is less than the shear strength in the soil in a liquefied state (Kramer, 1996).

Sand boiling at level ground, also known as level ground liquefaction, is a special case of cyclic mobility that occurs when loose saturated sands in flat or nearly flat deposits are subjected to sufficiently large shaking. Shaking of the ground causes the void ratio of sand to decrease and, subsequently, the pore pressure in the voids increases, creating a hydraulic gradient causing the pore water to flow towards the surface. The out flow of pore water carries with it the sand particles which are deposited on the ground surface (Poulos et al., 1985; Kramer, 1996).

As both of these two types of liquefaction can cause serious damage, it is important that the hazards due to both flow liquefaction and cyclic mobility be evaluated.

\subsection{Liquefaction hazard evaluation}

Since liquefaction does not occur in all soils, the first step for evaluating liquefaction hazard of a specific site is to assess the liquefaction susceptibility of the soil at a site. If it is concluded that the soil is not susceptible to liquefaction, the liquefaction hazard evaluation will be finished. However if the soil is liquefiable, a second step is needed to evaluate the potential of liquefaction initiation under the perceived earthquake conditions. After demonstrating liquefaction failure is likely, the next task is to assess the 
extent of damage due to liquefaction. Therefore, a liquefaction hazard evaluation consists of examining the following:

- Liquefaction susceptibility,

- Liquefaction initiation, and

- Liquefaction effects.

\subsubsection{Liquefaction susceptibility}

Kramer (1996) suggested that a good judgment for liquefaction susceptibility of a soil should consider several criteria, including historical, geologic, compositional, and the state criterion.

Studying the liquefaction case histories provides useful information on the soil behaviour of a site and helps to identify liquefaction. Youd (1991) has mapped large number of these historical cases.

Youd and Hoose (1977) indicated that the depositional and hydrological environment of a deposit and its age are the main geological factors that have to be considered in the investigation of liquefaction susceptibility of a deposit. Considering these factors, Kramer (1996) has listed some susceptible deposits regarding their natural or man-made origin.

Some of the main compositional characteristics of soil, such as the size, shape, and gradation of soil particles, have influence on the volume change behaviour of that soil, which in turn can control its liquefaction susceptibility. In contrast to coarser-grained soils that are too permeable to be liquefied, sands that are capable to generate high pore water pressure are susceptible to liquefaction. Also, the capability of fine-grained soils to generate high pore pressure is much less than sands and are considered less susceptible to 
liquefaction than sands. Ishihara $(1984,1985)$ showed that the plasticity characteristics of a fine-grained soil have more effect on its liquefaction susceptibility than its grain size. The shape of particles in finer silts has a significant effect on their liquefaction susceptibility. Silts with flaky or plate-like particles are not liquefiable because of sufficient cohesion among their particles. In sands, rounded particles show more tendencies for volume change than angular-grained soils and therefore, have a higher chance to liquefy. Well-graded soils, in which small particles fill the voids between larger particles, show lower volume change under the drained conditions as compared with uniformly graded soils. Therefore, these soils show lower excess pore pressure under undrained conditions and are less susceptible to liquefaction (Kramer 1996).

The most important factors that should be considered in assessing the liquefaction susceptibility of a soil are the stresses it carries and its density just before the earthquake. These factors describe the initial state of the soil. When a soil has a tendency to increase in volume during shearing, i.e., dilative soils, it is not considered liquefiable because its undrained strength is greater than its drained strength (Poulos et al., 1985). Numerous investigations have been developed on the state criteria and most define a susceptibility boundary line to separate contractive soils from dilative soils. According to investigations by Casagrande (1936) and Castro (1969), the steady-state concept is the most useful model to evaluate the flow liquefaction susceptibility based on a state criterion (Kramer, 1996).

Using the steady-state concept and laboratory test data, Fear and Robertson (1995) proposed a method to determine a boundary line between dilative and contractive soils applicable to in-situ data (i.e., Standard Penetration Test, SPT, and Cone Penetration Test, CPT data). They recommended Equations 2.1 and 2.2 to approximate the boundary line: 
$\left(\sigma_{v 0}^{\prime}\right)_{\text {boundary }}=9.58 \times 10^{-4}\left[\left(N_{1}\right)_{60}\right]^{4.79}$

$\left(\sigma_{v 0}^{\prime}\right)_{\text {boundary }}=1.10 \times 10^{-2}\left(q_{c 1}\right)^{4.79}$

where:

$\sigma_{v 0}^{\prime}$ is the initial vertical effective stress in $\mathrm{kPa}$.

$\left(N_{1}\right)_{60}$ is the representative standard penetration blow-count $\mathrm{N}$, corrected for field testing procedures, energy efficiency, and overburden pressure and it is given by:

$\left(N_{1}\right)_{60}=C_{N} N_{60}=\left(\frac{100}{\sigma_{v 0}^{\prime}}\right)^{0.5} N_{60}$

where:

$C_{N}$ is the correction factor for overburden pressure.

and:

$N_{60}=\Psi N$

$\Psi$ is the energy factor and for the safety and the donut hammers, it is approximately equal to 1.0 and 0.75 , respectively (Seed et al., 1985), $q_{c 1}$ is the cone resistance corrected for overburden pressure in MPa.

Seed and Harder (1990) suggested that Equation 2.3 is not suitable for freshly-placed soils or for soils that are coarser than fine or medium sands.

To evaluate the liquefaction susceptibility of a soil, for a specific $\left(N_{1}\right)_{60}$ or $q_{c 1}$ values, the actual value of $\sigma_{v 0}^{\prime}$ is determined and then is compared with $\sigma_{v 0}^{\prime}$ calculated from Equations 2.1 and 2.2. If this actual $\sigma_{v 0}^{\prime}$ is less than that calculated $\sigma_{v 0}^{\prime}$, then the soil is susceptible to flow liquefaction, i.e. the soil is contractive (Olson and Stark, 2003). 


\subsubsection{Evaluation of liquefaction triggering}

Soils that have tendency to decrease in volume during shearing and therefore, suffer reduction in shear resistance are susceptible to liquefaction. However, liquefaction may not necessarily be triggered in all soils susceptible to liquefaction. There are two frameworks to evaluate liquefaction triggering: cyclic stress approach and cyclic strain approach. Since the first approach is the most common among alternatives, this method will be discussed first. Sometimes, both of these techniques or even more methods are used together for important projects.

\subsubsection{Cyclic stress approach}

The basis of the cyclic stress approach is to compare the liquefaction resistance of the soil with the seismic stresses induced during an earthquake. Both the resistance of the soil and the seismic induced stresses are expressed in terms of cyclic shear stresses. The factor of safety against liquefaction is obtained by dividing the resistance by the driving seismic stress. Usually the resistance of the soil is obtained from SPT or CPT data while seismic induced stresses are obtained from the maximum peak ground acceleration, PGA, at the ground surface (Seed and Idriss, 1971).

\section{Evaluation of driving loadings}

Seed and Idriss (1971) proposed a simple method to predict the value of seismic loading. This method, named the simplified method, has been used commonly by engineers and researchers. In this method, it is assumed that the seismic loading can be expressed in terms of the cyclic shear stresses which in turn is related to the PGA at the ground surface as follows: 
$\tau_{c y c}=0.65 \frac{a_{\max }}{g} \sigma_{v}$

where:

$a_{\max }$ is the maximum peak horizontal acceleration (PHA) at ground surface $\left(\mathrm{m} / \mathrm{s}^{2}\right)$.

$\mathrm{g}$ is the acceleration of gravity $\left(\mathrm{m} / \mathrm{s}^{2}\right)$.

$\sigma_{v}$ is the total vertical stress $(\mathrm{kPa})$.

Day (2002) has addressed some usual methods to determine PHA at the site. Some of these methods use historical earthquakes, local building code or other regulatory requirements, maximum credible earthquake, maximum probable earthquake, or U.S. Geological Survey (USGS) earthquake maps. He also suggested the minimum $a_{\max }$ value and earthquake magnitude for liquefaction triggering are $0.1 \mathrm{~g}$ and 5 , respectively.

During an earthquake, the behaviour of soil column is deformable. To account for this flexibility effect, Seed and Idriss (1971) added another factor to Equation 2.5 as a depth reduction factor to arrive at the following:

$\tau_{c y c}=0.65 \frac{a_{\max }}{g} \sigma_{v} r_{d}$

The value of the depth reduction factor can be determined from Figure 2.3.

Normalizing $\tau_{c y c}$ by the initial effective overburden pressure, $\sigma_{v 0}^{\prime}$, results in the cyclic stress ratio, CSR, where:

$C S R=\frac{\tau_{c y c}}{\sigma_{v 0}^{\prime}}=0.65\left(\frac{a_{\max }}{g}\right)\left(\frac{\sigma_{v}}{\sigma_{v 0}^{\prime}}\right) r_{d}$

In 1996 and 1998, two workshops were held by the National Center for Earthquake Engineering Research (NCEER) to standardize, simplify and develop the 
approaches that were applied to determine the liquefaction resistance of the soils. According to Seed and Idriss's (1971) investigation, Youd and Idriss (2001) suggested Equation 2.7 for determining the value of CSR. To facilitate the calculation of $r_{d}$, they suggested Equations 2.8, 2.9 and 2.10:

$r_{d}=1.0-0.00765 z \quad$ for $\mathrm{z} \leq 9.15 \mathrm{~m}$

$r_{d}=1.174-0.0267 z \quad$ for $9.15 \mathrm{~m}<\mathrm{z} \leq 23 \mathrm{~m}$

$r_{d}=\frac{\left(1.000-0.4113 z^{0.5}+0.4052 z+0.001753 z^{1.5}\right)}{\left(1.000-0.4177 z^{0.5}+0.05729 z-0.006205 z^{1.5}+0.001210 z^{2}\right)}$

where $\mathrm{z}$ in these equations is the depth of soil below the surface in metres where the CSR is to be evaluated. Equation 2.10 gives nearly the same result as the other two equations (Youd and Idriss, 2001).

\section{Evaluation of liquefaction resistance}

- Laboratory based approach:

In the early approaches to characterize liquefaction resistance, many isotropically consolidated undrained triaxial tests or $\mathrm{K}_{0}$-consolidated simple shear tests were performed by applying the number of uniform cyclic loading on the soil specimens. During these tests, the liquefaction resistance of a soil is expressed by a cyclic strength curve which shows the relationship between soil density, cyclic stress amplitude, and the number of cycles required to initiate liquefaction. Figure 2.4 shows that a sample of these curves has been obtained by the triaxial tests. The cyclic strength curve is commonly normalized by the effective overburden pressure to yield the cyclic stress ratio (CSR). Considering the differences in the definition of CSR in the simple shear test and 
the triaxial test and according to the suggestion of Seed et al. (1975), Kramer (1996) suggested Equation 2.11 for the evaluation of liquefaction resistance of a soil in the field. $(C S R)_{\text {field }}=0.9(C S R)_{s s}=0.9 c_{r}(C S R)_{r x}$

where: $c_{r}$ is a correction factor to relate the CSR from simple shear test (Equation 2.12) and CSR from triaxial test (Equation 2.13) and can be estimated from Table 2.1.

$$
(\operatorname{CSR})_{s s}=\frac{\tau_{c y c}}{\sigma_{v 0}^{\prime}}
$$

and:

$$
(\operatorname{CSR})_{t x}=\frac{\sigma_{d c}}{2 \sigma_{3 c}^{\prime}}
$$

where

$\tau_{c y c}$ is the cyclic shear stress,

$\sigma_{v 0}^{\prime}$ is the initial vertical effective stress,

$\sigma_{d c}$ is the maximum cyclic shear stress,

$\sigma_{3 c}^{\prime}$ is the initial effective confining pressure.

There are some factors such as differences in soil fabric in different methods of soil specimen preparation, prior seismic straining, over-consolidation ratio, lateral earth pressure coefficient, and the length of time under sustained pressure, that can affect the characterization of liquefaction resistance of a specimen in laboratory tests. These factors can render the determination of liquefaction resistance extremely difficult so that many engineers and researchers prefer to replace laboratory based methods with methods based on in-situ test results. 
- In-situ based approach

The earthquake-induced stresses are compared with the mobilized resistances of the soil to calculate the factor of safety against liquefaction initiation. The earthquakeinduced stresses have already been characterized in terms of CSR. The mobilized resistance can be expressed in terms of the cyclic resistance ratio (CRR). Seed et al. (1975) proposed an SPT based method to characterize the CRR of the soil in the field. Ten years later, Seed et al. (1985) provided more data as shown in Figure 2.5 for the determination of CRR based on $\left(\mathrm{N}_{1}\right)_{60}$ data and the fines content of the soil. Some other symbols have also been employed for the cyclic resistance ratio, such as: CSR $\ell$ (Seed and Harder., 1990), CSRL (Youd, 1993), and CSR $_{\mathrm{L}}$ (Kramer, 1996). Figure 2.5 gives the CRR values for the earthquake magnitude of 7.5 as reference. The value obtained from this figure should be corrected by a scaling factor as listed in Table 2.2 to account for magnitudes other than 7.5. The resulted value of CRR in this step corresponds to relatively shallow deposits (i.e. $\sigma_{v 0}^{\prime} \leq 100 \mathrm{kPa}$ ) for level-ground sites. Two more correction factors have been proposed to consider the effects of high effective overburden pressures and the static horizontal shear stresses in sloping ground conditions. Finally, the CRR of a site can be estimated by Equation 2.14 .

$$
\left(C R R_{\text {field }}\right)_{\alpha, \sigma, M}=\left(C R R_{\text {field }}\right)_{\alpha=0, \sigma^{\prime}<100 k P a, M=7.5} K_{\alpha} K_{\sigma} C_{M}
$$

where:

$\left(C R R_{\text {field }}\right)_{\alpha=0, \sigma^{\prime}<100 k P a, M=7.5}$ is the CRR of the site for level ground and shallow deposits for earthquake magnitude 7.5 . 
$K_{\alpha}$ is the correction factor for initial shear stresses acting on horizontal plane (i.e., sloping ground conditions) which is determined from Figure 2.6. The parameter of $\alpha$ is defined as the static shear stress on the horizontal plane $\left(\tau_{h v}\right)$ normalized by the initial vertical effective stress (i.e., $\frac{\tau_{h v}}{\sigma_{v 0}^{\prime}}$ ). It should be noted that Seed and Harder (1990) emphasise this correlation is valid only for $\sigma_{v 0}^{\prime} \leq 300 \mathrm{kPa}$.

$K_{\sigma}$ is the correction factor for the vertical effective stress larger than $100 \mathrm{kPa}$ and is estimated from Figure 2.7 (Youd and Idriss, 2001).

$C_{M}$ is magnitude correction factor from Table 2.2 .

Finally, the factor of safety against liquefaction $\left(\mathrm{FS}_{\mathrm{L}}\right)$ is calculated using Equation 2.15:

$F S_{L}=\frac{\left(C R R_{\text {field }}\right)_{\alpha, \sigma, M}}{C S R}$

where CSR is determined from Equation 2.7.

The recommended method by Youd and Idriss (2001) to evaluate the value of CRR, whose framework is based on Seed and Idriss's (1971) simplified method, comprises some field tests such as SPT, CPT, shear wave velocity $\left(V_{s}\right)$ measurement, and Becker Penetration Test (BPT). In general, Youd and Idriss (2001) recommend SPT and CPT for the evaluation of CRR, as there are more extensive databases and past experience for these tests.

Similar to the simplified method by Seed and Idriss (1971), both SPT and CPT data in Youd and Idriss's (2001) method give the CRR for an earthquake with a magnitude of 7.5 and should be corrected for other magnitudes by applying a correction 
coefficient. The range of recommended values for the magnitude correction factors by Youd and Idriss (2001) is shown in Figure 2.8. Also, Equation 2.16 can be utilized to define the lower bound of the recommended range. $M_{w}$ in this equation is the moment earthquake magnitude.

$$
C_{M}=\frac{10^{2.24}}{M_{w}^{2.56}}
$$

Like the simplified method (Seed and Idriss, 1971), Youd and Idriss (2001) suggested using a correction coefficient (i.e., $\mathbf{K}_{\sigma}$ ) for soils with overburden pressure greater than $100 \mathrm{kPa}$ this coefficient is defined as:

$$
K_{\sigma}=\left(\frac{\sigma_{v o}^{\prime}}{P_{a}}\right)^{(f-1)}
$$

where $\sigma_{v o}^{\prime}$ is the initial vertical effective stress, $P_{a}$ is the atmospheric pressure, and $f$ is a coefficient that is related to the relative density, over-consolidation ratio, and age of the deposits. The value of this coefficient varies between $0.7-0.8$ for soils with relative densities between $40-60 \%$ and $0.6-0.7$ for relative densities between $60-80 \%$.

Considering the effect of the static driving shear stresses that act on a horizontal plane and incorporating their effects on the CRR within dams and embankments, Youd and Idriss (2001) suggested applying a correction factor of $K_{\alpha}$ for sloping grounds. To determine the value of $K_{\alpha}$, Youd and Idriss (2001) referred to the published curve by Harder and Boulanger (1997). They strongly recommended that this curve should not be used by non-specialists in geotechnical engineering or in routine engineering projects. 


\subsubsection{Cyclic strain approach}

In 1980, Dobry and Ladd and in 1982, Dobry et al. proposed another approach to evaluate the liquefaction initiation by means of the cyclic strain. They showed that cyclic strains have more effect on densification of dry sands than cyclic stresses. Since the tendency of dry sand to densify directly relates to its tendency to generate excess pore pressure when saturated, they suggested the generation of pore water pressure is strongly related to cyclic shear strain. This robust relationship can be considered as the main advantage of this approach and it helps researchers to evaluate excess pore pressure more precisely from using the cyclic strain approach. On the other hand, the main problem in using this method is that the prediction of cyclic strains is more difficult than predicting cyclic stresses (Kramer, 1996). The cyclic stress approach is therefore, used most commonly in liquefaction evaluation in geotechnical earthquake engineering practice and it is also used in this thesis.

\subsubsection{The liquefied shear strength of soils}

After an incidence of liquefaction, large deformation occurs in the soil until the shear stresses drop below the current shear strength of the soil. The amount of deformation controls the stability and depends on the difference between the shear strength of the liquefied soil and the shear stresses for equilibrium. The larger the difference, the larger is the deformation. To evaluate the stability of a slope, the liquefied shear strength of the soil should be estimated. The undrained steady-state shear strength, $\mathrm{S}_{\mathrm{us}}$, (Poulos et al., 1985), the undrained residual shear strength, $\mathrm{S}_{\mathrm{r}}$, (Seed, 1987), the undrained critical shear strength, $S_{\mathrm{u}}$ (critical), (Stark and Mesri, 1992), and the liquefied shear strength, $\mathrm{S}_{\mathrm{u}}(\mathrm{LIQ})$, (Olson and Stark, 2002) are different names that are selected by 
different researchers in different methods for the shear strength of liquefied soils (Olson and Stark, 2002).

Kramer (1996) defines three different approaches to be used to estimate the in-situ liquefied shear strength of a soil.

- In-situ testing procedure

- Normalized strength procedure

- Laboratory-based procedure

\subsubsection{In-situ testing procedure}

The well-known research in this method was done by Seed and Harder (1990) to estimate the in-situ undrained residual strength, $S_{r}$, of liquefied soils based on Standard Penetration Test (SPT) data. In their method, the undrained residual strength can be estimated from Figure 2.9. $\left(N_{1}\right)_{60-c s}$ in this figure is the corrected $\left(N_{1}\right)_{60}$ with an additional correction factor for fines content (Equation 2.18) and is called the equivalent clean sand SPT blow-count.

$$
\left(N_{1}\right)_{60-c s}=\left(N_{1}\right)_{60}+N_{c o r r}
$$

where $N_{c o r r}$ is the correction factor for fines content and is obtained from Table 2.3 for different fines content.

For stability analyses right after the earthquake, different shear strengths would be mobilized in different parts of the dam. Seed and Harder (1990) suggested the following strength mobilization based on the local factor of safety against liquefaction $\left(F S_{L}\right)$ expressed by $F S_{L}=\mathrm{CRR} / \mathrm{CSR}$.

- For the regions with $F S_{L} \leq 1.1$, the undrained residual strength is assigned. 
- For the regions with $F S_{L} \geq 1.4$, a large fraction of the drained static strength is applied.

- For the regions with $1.1 \leq F S_{L} \leq 1.4$, a strength interpolated as a function of $F S_{L}$ between the two above conditions is used.

Figure 2.10 shows the applied pore water pressure function by Seed and Harder (1990) for the level ground conditions. In this figure, the residual excess pore pressure ratio is defined as the ratio of the excess pore pressure over the initial confining pressure. This function is applicable for the determination of static drained strength.

Seed and Harder (1990) suggested two advantages to their method. Firstly, this procedure increases reliance on in-situ tests for evaluation of soil conditions. Secondly, their practice to evaluate the undrained residual strength can be used as part of the overall slope stability analysis. On the other hand, Olson and Stark (2002) mentioned that there are several uncertainties in Seed and Harder's (1990) approach. First, Seed and Harder (1990) have not taken note of the fact that 6 out of the 17 case histories were lateral spreading cases, which were completely different from flow liquefaction. Secondly, in 7 out of the 17 case histories, SPT blow-counts were not available and Seed and Harder (1990) had to estimate the SPT values based on the relative density. Thirdly, Seed and Harder (1990) recommended that, due to data scatter and uncertainty and the limited number of case studies, the lower bound or near lower bound of the correlation between undrained residual shear strength, $\mathrm{S}_{\mathrm{r}}$, and $\left(N_{1}\right)_{60-c s}$ in Figure 2.9 be used. According to Olson and Stark (2002), applying this lower bound to appraise the liquefied shear strength of the cases, especially large structures with large static shear stresses, gives conservative factors of safety. 
While Olson and Stark (2002) are correct in saying that Seed and Harder's (1990) method may lead to conservative estimate of the liquefied strength for large structures, the opposite may be true when dealing with small structures where the vertical effective stress is small. In that case, Seed and Harder's method may overestimate the liquefied shear strength. Studies presented in this thesis through Chapter 4 support this statement.

\subsubsection{Normalized stress procedure}

\section{Stark and Mesri (1992) approach}

Knowing that pre-failure vertical effective stress $\left(\sigma_{v 0}^{\prime}\right)$ has influence on liquefied shear strength, Stark and Mesri (1992) proposed Equation 2.19 to estimate the liquefied (residual) strength ratio of a soil from its SPT data.

$\frac{S_{r}}{\sigma_{v 0}^{\prime}}=0.0055\left(N_{1}\right)_{60-c s}$

where $\left(N_{1}\right)_{60-c s}$ has the same definition as what was employed in Seed and Harder (1990) approach and can be determined from Table 2.3.

\section{Olson and Stark (2002) approach}

Olson and Stark (2002) presented improved relationships to estimate the liquefied strength ratio from CPT and SPT data. Their approach is based on the back-analysis of thirty-three case histories of liquefaction flow failure excluding the lateral spreading cases. They used the following three levels of stability analysis in studying the case histories:

- Simplified stability analysis of post-failure geometry

- Rigorous stability analysis of post-failure geometry 
- Stability analysis incorporating the kinetics of the failure mass

They incorporated appropriate drained and undrained strength of non-liquefied soils in their kinetics analysis to determine the liquefaction strength of the soil. They did not explain how they determined pore water pressure and how they calculated the drained strengths. They tried to reduce the uncertainties in Seed and Harder (1990) and Stark and Mesri (1992) methods by using more rigorous methods of analysis. They considered the kinetics of failure, potential hydroplaning and mixing effects, and the shear strength of non-liquefied soils. Equation 2.20 gives the liquefied strength ratio for CPT data of $q_{c 1}$ less than 6.5 MPa and Equation 2.21 for SPT data of $\left(N_{1}\right)_{60}$ less than 12.

$$
\begin{aligned}
& \frac{s_{u}(L I Q)}{\sigma_{v 0}^{\prime}}=0.03+0.0143\left(q_{c 1}\right) \pm 0.03 \\
& \frac{s_{u}(L I Q)}{\sigma_{v 0}^{\prime}}=0.03+0.0075\left[\left(N_{1}\right)_{60}\right] \pm 0.03
\end{aligned}
$$

Despite Seed and Harder (1990) and Stark and Mesri (1992) who considered fines content correction factor to determine the liquefied shear strength or the liquefied strength ratio, Olson and Stark (2002) have not incorporated fines content adjustment in their study. Soils with higher fines contents have lower values of penetration resistance. On the other hand, these soils are more likely to maintain an undrained condition during flow. They explained that these two phenomena may offset the effect of each other. Therefore, the difference between the liquefied strength ratio of the clean sands and the sands with higher fines contents can be neglected.

Olson and Stark (2002) remarked some sources of uncertainties in back-calculated strength ratios during their studies. "(i) Limits of zones of liquefaction, (ii) shear strength 
of nonliquefied zones, (iii) location of initial and final surface sliding, (iv) location of phreatic surface within the slope, (v) potential of drainage or pore-water pressure redistribution occurring during flow, and (vi) location of post failure slope toe in a few cases" are some of the factors that cause uncertainties in their approach in estimating the liquefied shear strength ratio.

The potential of drainage or pore-water pressure redistribution during flow failure usually exists in all liquefaction case histories. The uncertainty due to this potential arose in their approach because there was no simplified method at that time to account for this potential effect.

\subsubsection{Laboratory-based procedure}

\section{Poulos et al. (1985) method}

Assuming the same slopes of the critical strength line for undisturbed and reconstituted samples and that the slope is independent of the methods of reconstituting the samples, Poulos et al. (1985) developed a procedure for estimating the undrained steady-state shear strength (liquefied strength), $S_{u s}$, of liquefied soils via monotonically loaded, consolidated-undrained triaxial compression tests (Stark and Mesri, 1992). They recommended a four-step process to correct laboratory test results to estimate the in-situ steady-state strength. This four-step procedure considers that sampling, transportation, handling, and consolidation change the density of a laboratory specimen from its in-situ value (Stark and Mesri, 1992). Figure 2.11 shows this process for estimating the undrained steady-state strength of in-situ soil from a laboratory triaxial compression test. According to this figure: 
1. The in-situ void ratio, $e_{f}$, from one or more undisturbed specimens should preferably be obtained via (1) fixed-piston sampling, (2) freezing of the ground and coring, or (3) sampling in test pits.

2. From the reconstituted specimens, the steady-state line is determined.

3. The undrained steady-state strength of an undisturbed specimen at laboratory void ratio is calculated.

4. A line from the undrained steady-state strength obtained in step 3 is drawn parallel to the Steady State Line (SSL) determined in step 2. From the calculated in-situ void ratio, $\mathrm{e}_{\mathrm{f}}$, on the ordinate axis, a horizontal line is drawn to intersect the parallel line. The abscissa of this point is the estimated in-situ undrained steady-state strength of that soil.

Since the slope of SSL is small, any slight deviation in calculating the in-situ void ratio causes significant difference in the calculated value of the laboratory steady-state strength of that specimen (Olson and Stark, 2002).

\subsection{Flow failure analysis}

Flow slide occurrence is usually evaluated through conventional static slope stability analysis using strength conditions at the end of an earthquake (Marcuson et al., 1990). In fine grained cohesionless soils, the critical stability condition may not always arise during the earthquake shaking but may occur some time after the shaking has stopped (Seed, 1979). After this critical time, the factor of safety increases. Seed and Harder (1990) stated that for liquefiable earthdams such as Lower San Fernando Dam, loss of strength due to liquefaction is the main factor for instability of the dam rather than inertia forces induced by the earthquake shaking. Therefore, to asses flow slide 
occurrence, a static stability analysis incorporating liquefied zones caused by the earthquake should be carried out. Hence, in this research, the purpose of the dynamic analyses is to determine the induced shaking stresses and the zones of liquefaction at the end of the earthquake.

The important point in the flow slide analysis is assigning the appropriate strength to the liquefied and non-liquefied areas. After the earthquake stops, the water flows from regions with high pore pressures (liquefied zones) to the areas with low pore water pressure (non-liquefied zones) caused by the dynamic shaking. Therefore, the strength of the non-liquefied zones would be closely equal to the drained strength under the hydrostatic pressure (Seed, 1979). The potential of drainage or pore water redistribution can occur in the liquefiable earthdams. On the other hand, simplified methods to account for this potential effect have not been developed yet (Olson and Stark, 2002).

Considering the above facts, the following assumption is employed for the seismic stability analysis of liquefied earthdams in this thesis. The liquefied shear strength is assigned to liquefied regions and the strength value based on the effective stresses at the end of the earthquake is applied for the non-liquefied zones

For the determination of the drained strength, the pore pressures generated during the earthquake are used. These pressures can be determined from the specified pore pressure function during the dynamic analysis. The applied pore water pressure functions in this study have been derived from Equation 2.22 presented by DeAlba et al. (1975)

$$
r_{u}=\frac{1}{2}+\frac{1}{\pi} \sin ^{-1}\left[2\left(\frac{N}{N_{L}}\right)^{1 / \alpha}-1\right]
$$


$r_{u}$ is the pore pressure ratio and is defined as the excess pore pressure over the initial static effective minor principal stress (i.e., $r_{u}=u_{\text {excess }} / \sigma_{3 c}^{\prime}$ ).

$\frac{N}{N_{L}}$ is the cyclic ratio and is defined as the ratio of the number of equivalent uniform stress cycles for an earthquake magnitude (e.g. Figure 2.12) divided by the number of cycles required for liquefaction (e.g. Figure 2.4).

$\alpha$ in this equation depends on the soil properties and the conditions of laboratory tests. To generate average values for this equation, $\alpha$ can be considered equal to 0.7 . The rate of the excess pore pressure build-up, for different values of $\alpha$, lies within a narrow range. Figure 2.13 shows this range and the average value.

The factor of safety of a slip surface is defined as the ratio of the mobilized resisting shear forces along a slip surface $\left(\Sigma S_{r}\right)$ to the induced shear forces along that slip surface $\left(\Sigma S_{m}\right)$ (Equation 2.23).

$$
F S=\frac{\Sigma S_{r}}{\Sigma S_{m}}
$$

If the factor of safety is less than 1.0, the slope is considered unsafe against flow failure.

\subsection{Applicable software packages for evaluation of liquefaction triggering and stability of slope}

Quake/W and Slope/W, developed by GEO-SLOPE International Ltd., are two applicable geotechnical programs for evaluation of the liquefaction triggering and the stability of slope in this research. 


\subsubsection{Quake/W}

Quake/W is a geotechnical finite element program for computing the static plus dynamic ground stresses of an embankment or slope at specified intervals during an earthquake. It can also compute the excess pore water pressure generated during shaking. The resulting stresses and pore water pressures can then be exported to Slope/W to analyze the stability based on the limit equilibrium method.

To determine the local factor of safety against liquefaction in each element, Quake/W compares the number of equivalent uniform stress cycles for the design earthquake magnitude $\left(\mathrm{N}_{\mathrm{eq}}\right)$ with the number of cycles required for liquefaction $\left(\mathrm{N}_{\mathrm{L}}\right)$. If $N_{\text {eq }}$ is larger than $N_{L}$, liquefaction will be expected to occur. $N_{\text {eq }}$ corresponds to the design earthquake and can be determined with the help of Figure 2.12. The $\mathrm{N}_{\mathrm{L}}$ value is associated with the cyclic resistance ratio that can be computed in Quake/W using the applicable correction factors such as $\mathrm{K}_{\sigma}$ and $\mathrm{K}_{\alpha}$.

When the local factor of safety is equal or less than 1.0 , the element is considered liquefied and is marked for recognition so that liquefied shear strength is applied to it in the Slope/W analysis to determine the overall factor of safety against flow failure.

The finite element analysis in Quake/W consists of two steps. Firstly, the problem is simulated by drawing the mesh, defining the material parameters, choosing the appropriate constitutive soil model, and defining the boundary conditions. This step has to be done by the user. Secondly, the simulated problem is formulated and the associated finite element equations are solved. This process can be done by Quake/W, based on the defined correlations and procedures. 


\subsubsection{Slope/W}

Slope/W is a geotechnical software to evaluate the stability of an embankment or slope by using the limit equilibrium method. It has been formulated for most common methods of stability analysis such as Ordinary (or Fellenius) method, Bishop Simplified method, Janbu Simplified method, Spencer method, Morgenstern-Price method, Corps of Engineers method, Lowe-Karafiath method, Generalized Limit Equilibrium (GLE) method, and finite element stress method. The stability analyses in this thesis have been carried out using the finite element stress method.

By using the finite element stress method, Slope/W can analyse the stability of a slope subjected to seismic shaking based on the imported results from Quake/W.

There are some factors that have to been considered for computing the safety factor based on the finite element stress method in Slope/W.

- In most cases, pore water pressure conditions are determined during Quake/W analysis and there is no need to specify new pore pressure conditions for Slope/W. However, it is possible to specify a different pore pressure condition in Slope/W independent of Quake/W.

- Except for no strength materials such as water, the whole geometric region defined in Slope/W should lie within the finite element mesh in Quake/W.

- All forces such as line loads, anchor loads, and surface surcharge pressures, which may act on the slope, should be considered in the stress analysis in Quake/W. This means that these forces cannot be ignored in Quake/W analysis and then later they are added in Slope/W analysis. 
In the next chapter, one of the most famous dams, Lower San Fernando Dam, damaged due to the Lower San Fernando Earthquake shaking in 1971, will be analyzed based on the proposed approach in this thesis to verify the mechanism of analysis through comparison of the results of this analysis with those of previous investigations. 
Table 2.1 Relationships for determination of $c_{\mathrm{r}}$ correction factor (Kramer, 1996)

\begin{tabular}{|c|c|c|c|}
\hline \multicolumn{2}{|c|}{} & \multicolumn{2}{|c|}{$\mathrm{c}_{\mathrm{r}}$ for: } \\
\hline Reference & Equation & $\mathrm{K}_{0}=0.4$ & $\mathrm{~K}_{0}=1.0$ \\
\hline Finn et al. (1971) & $c_{r}=\left(1+K_{0}\right) / 2$ & 0.7 & 1.0 \\
\hline Seed and Peacock (1971) & Varies & $0.55-0.72$ & 1.0 \\
\hline Castro (1975) & $c_{r}=2\left(1+2 K_{0}\right) / 3 \sqrt{3}$ & 0.69 & 1.15 \\
& & & \\
\hline
\end{tabular}

Table 2.2 Magnitude correction factor (Kramer, 1996)

\begin{tabular}{cc}
\hline Magnitude, $\mathrm{M}$ & $\mathrm{CRR}_{\mathrm{M}} / \mathrm{CRR}_{\mathrm{M}=7.5}$ \\
\hline 5.25 & 1.50 \\
6.00 & 1.32 \\
6.75 & 1.13 \\
7.50 & 1.00 \\
8.50 & 0.89 \\
\hline
\end{tabular}


Table 2.3 Fines content correction factor suggested by Seed and Harder (1990) and Stark and Mesri (1992)

\begin{tabular}{ccc}
\hline & \multicolumn{2}{c}{$\mathrm{N}_{\text {corr }}$ (blows/30cm) } \\
\cline { 2 - 3 } Percent fines & Seed and Harder (1990) & Stark and Mesri (1992) \\
\hline 0 & 0 & 0 \\
10 & - & 2.5 \\
15 & - & 4 \\
20 & 2 & 5 \\
25 & - & 6 \\
30 & - & 7 \\
35 & 4 & 7 \\
75 & 5 & 7 \\
\hline
\end{tabular}




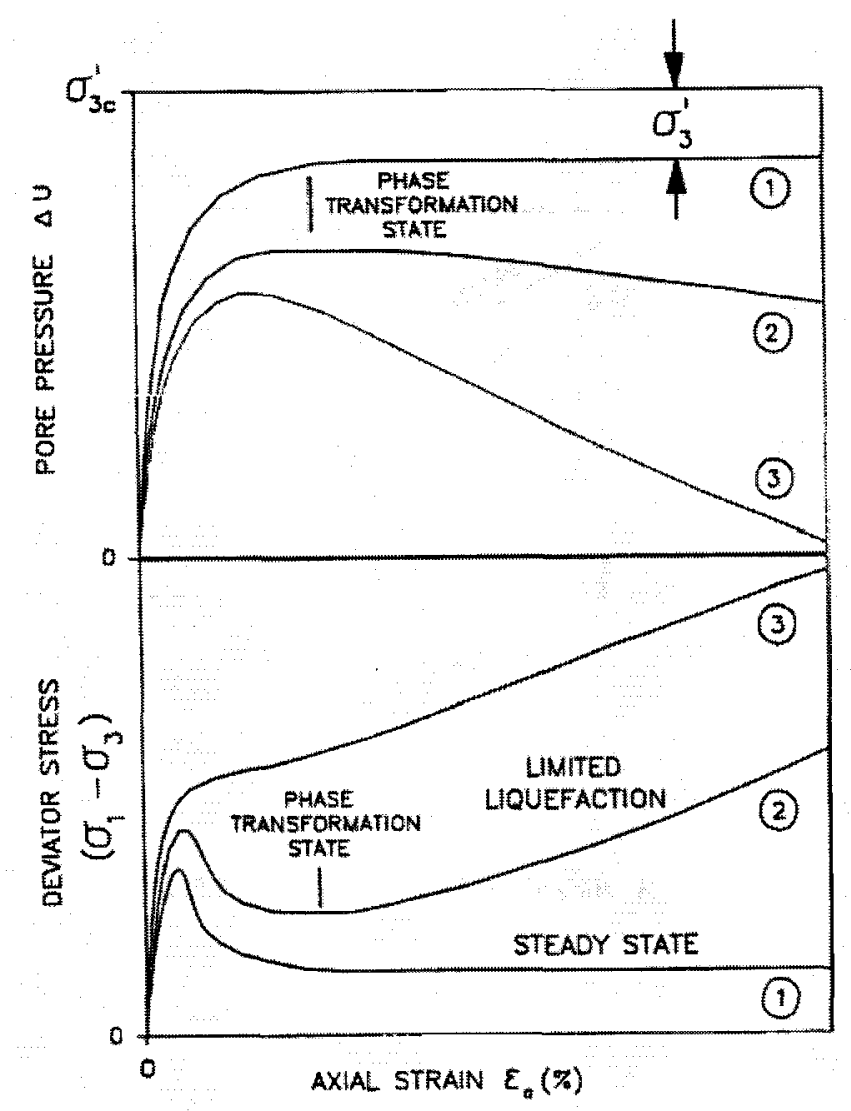

Figure 2.1 Soil behaviour under undrained monotonic loading (Kuerbis, 1989)

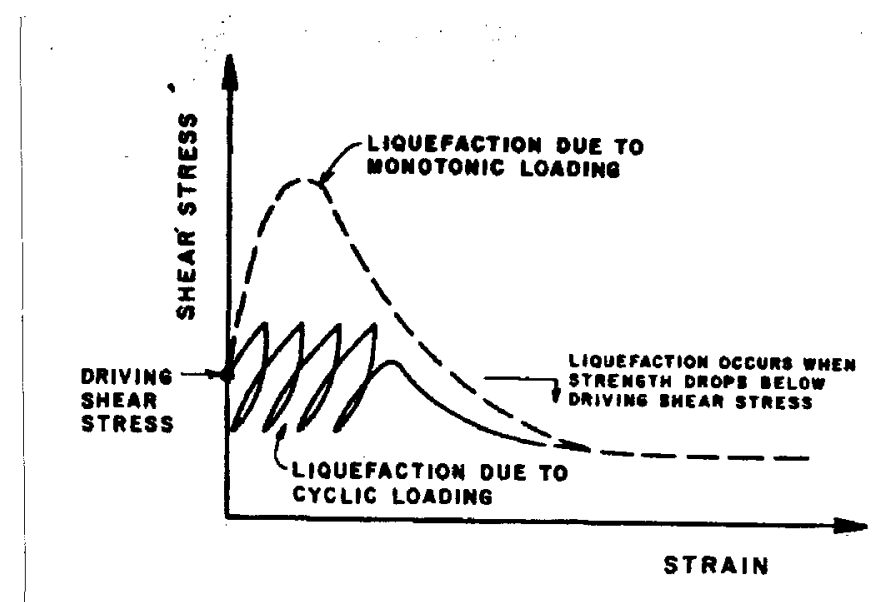

Figure 2.2 Liquefaction caused by monotonic and cyclic loadings (Poulos et al., 1985) 


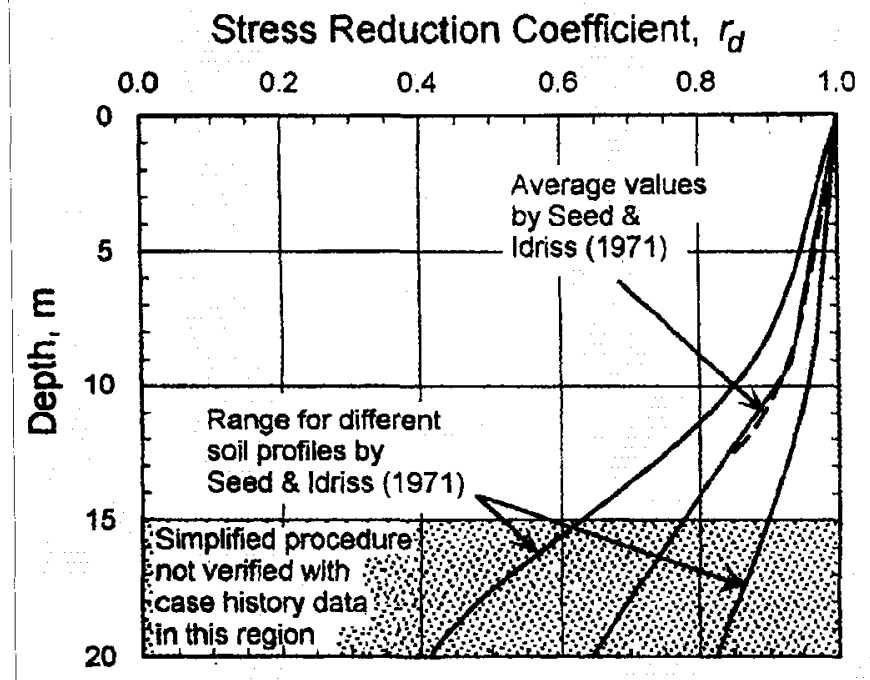

Figure 2.3 Determination of depth reduction factor (Seed and Idriss, 1971)

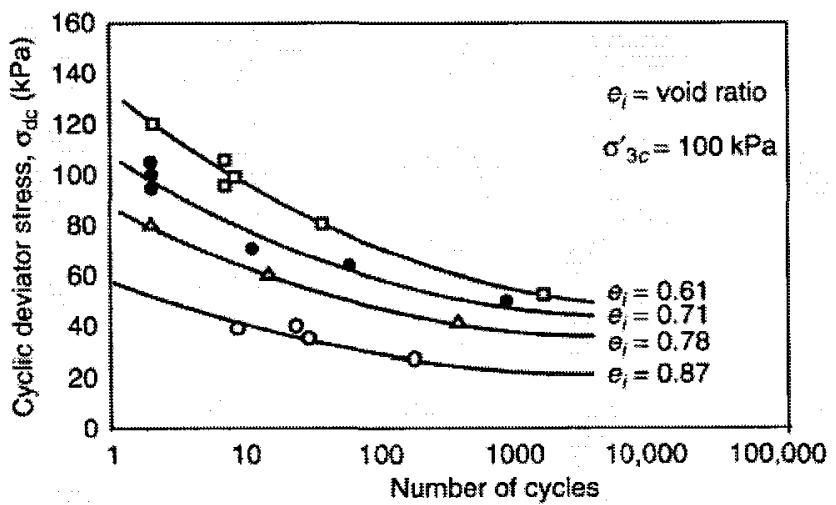

Figure 2.4 Cyclic stresses required to produce initial liquefaction $\left(\mathrm{N}_{\mathrm{L}}\right)$ and $20 \%$ axial strain in isotropically consolidated triaxial specimens of Sacramento River Sand (Seed and Lee, 1965) 


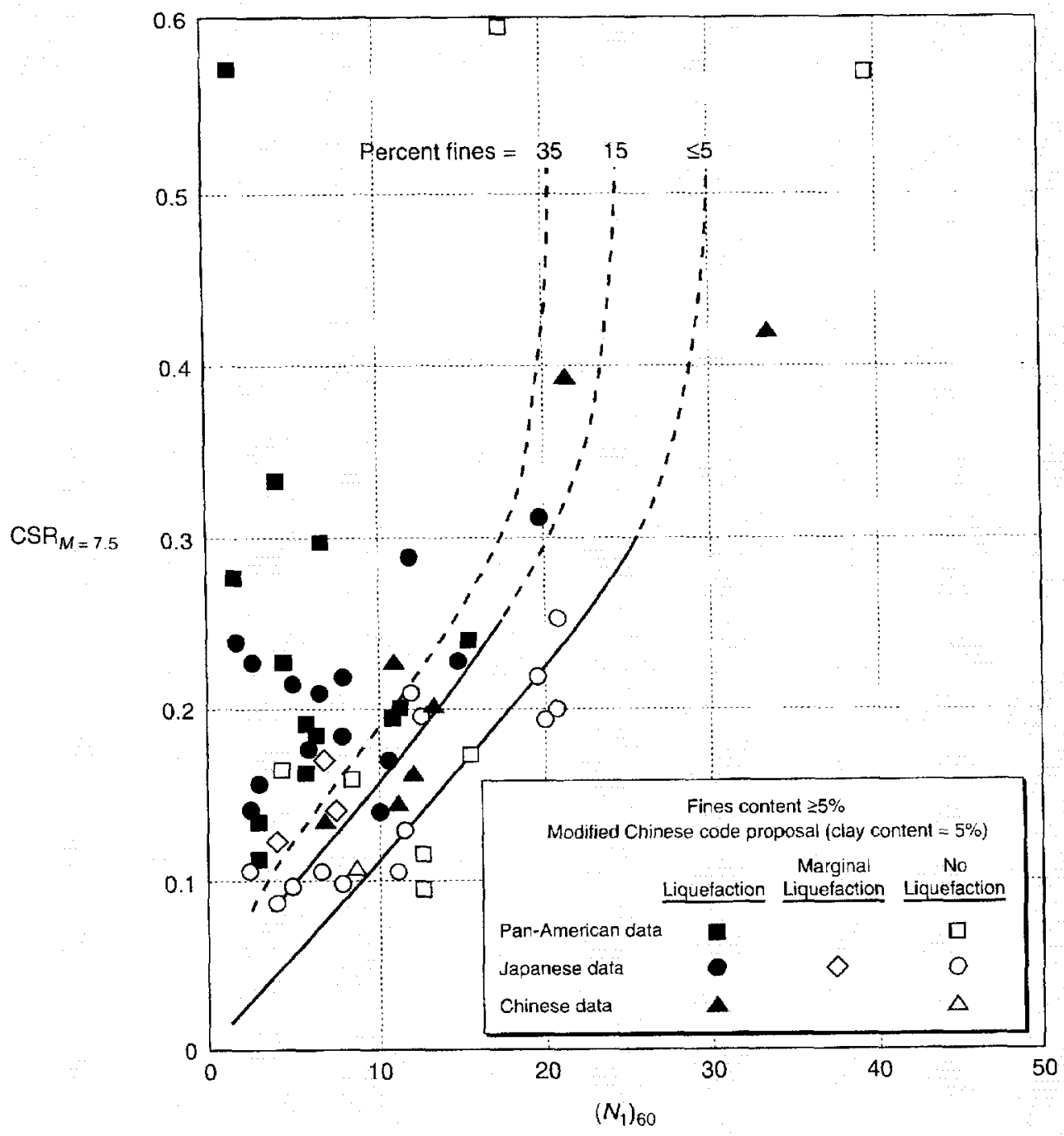

Figure 2.5 Cyclic resistance ratio, $\mathrm{CRR}$, vs. $\left(\mathrm{N}_{1}\right)_{60}$ for clean and silty sands based on reference earthquake of $\mathrm{M}=7.5$ (Seed et al., 1985) 


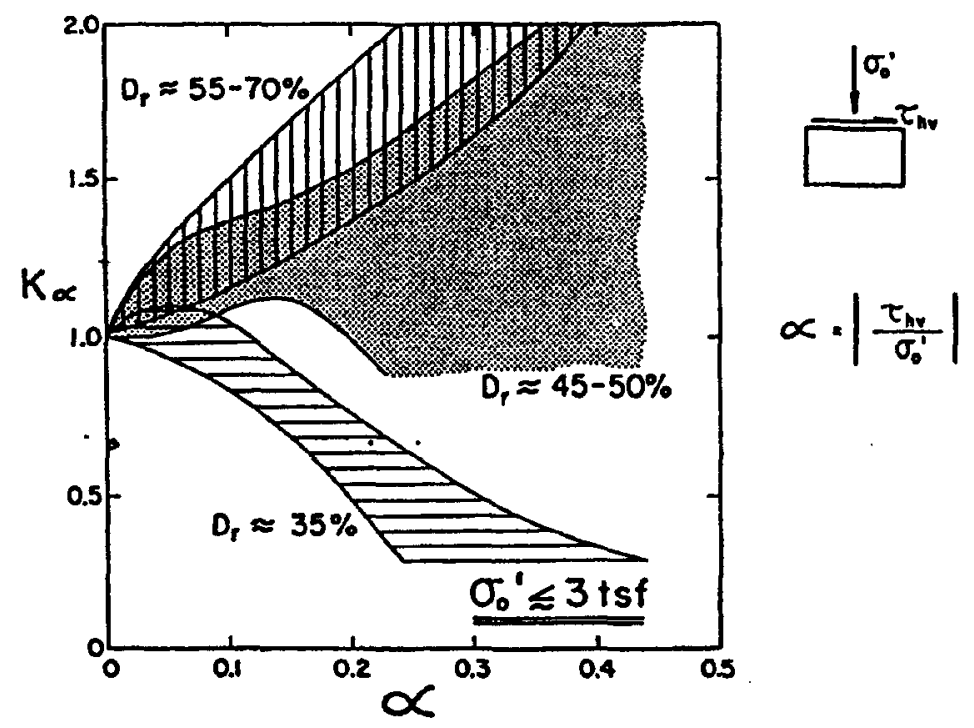

Figure 2.6 Variation of $\mathrm{K}_{\alpha}$ with respect to $\alpha$ (Seed and Harder, 1990)

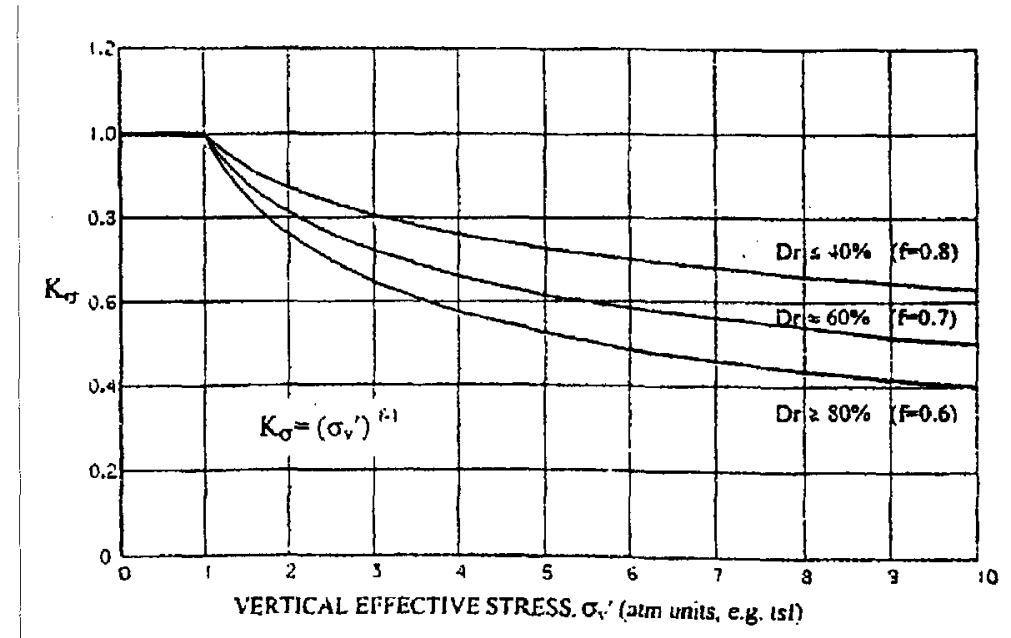

Figure 2.7 Values of $\mathrm{K}_{\sigma}$ with respect to vertical effective stress (Youd and Idriss, 2001) 


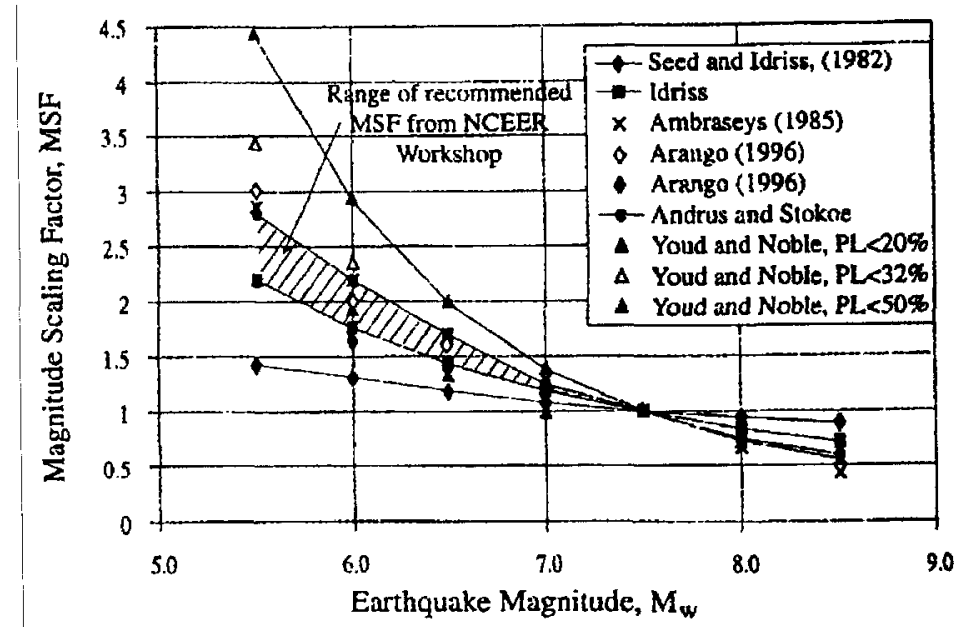

Figure 2.8 Range of recommended magnitude correction factors by Youd and Idriss (2001)

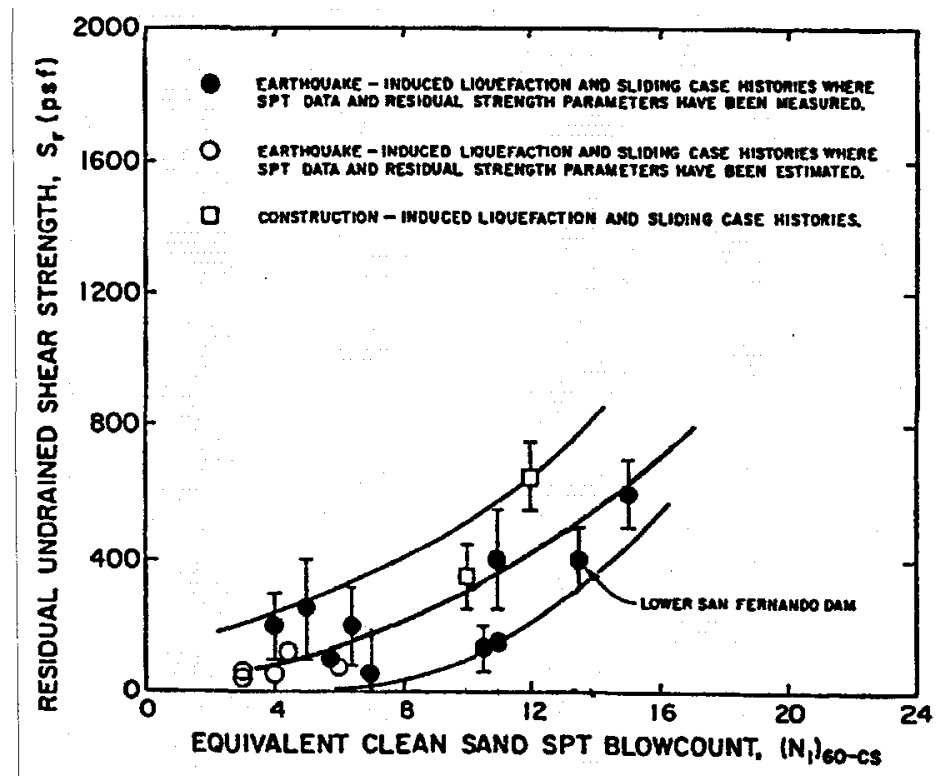

Figure 2.9 Variation of undrained Residual Strength, $\mathrm{S}_{\mathrm{r}}$ versus the equivalent clean sand SPT blow-count, $\left(\mathrm{N}_{1}\right)_{60-\mathrm{cs}}$ (Seed and Harder, 1990) 


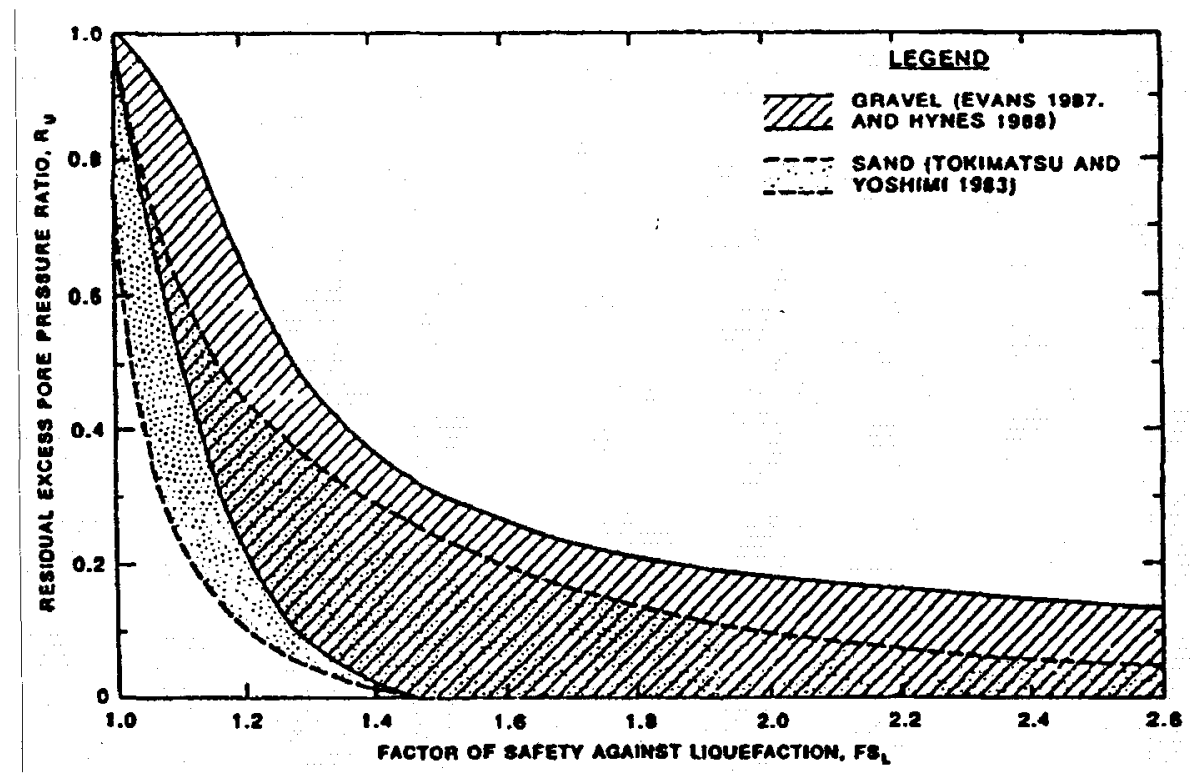

Figure 2.10 Relationship between residual excess pore pressure ratio and the factor of safety against liquefaction (Marcuson and Hynes, 1990)

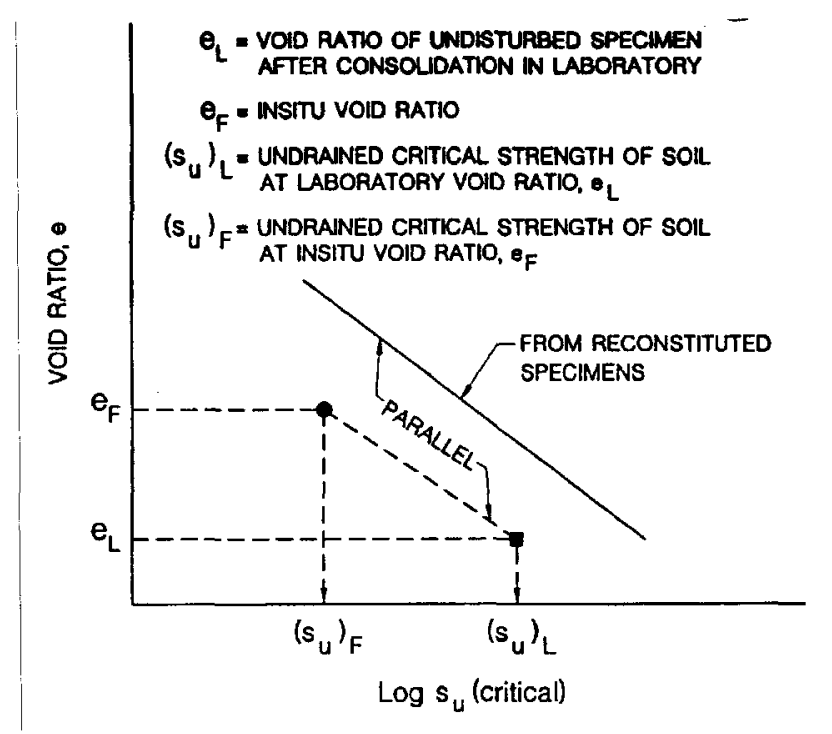

Figure 2.11 Procedure of estimating undrained steady-state strength of in-situ liquefied soil from laboratory-based data (Poulos et al., 1985) 


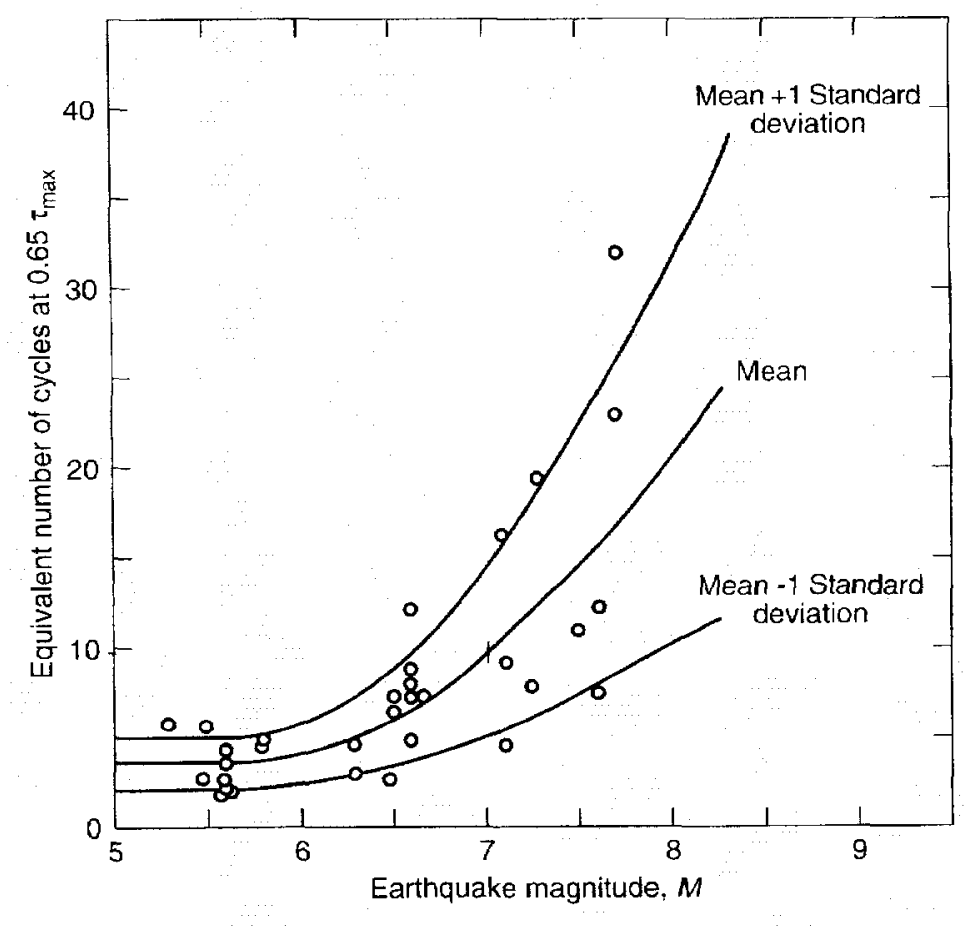

Figure 2.12 Number of uniform stress cycles, $\mathrm{N}_{\mathrm{eq}}$, vs. earthquake magnitude, $\mathrm{M}$ (Seed et al., 1975)

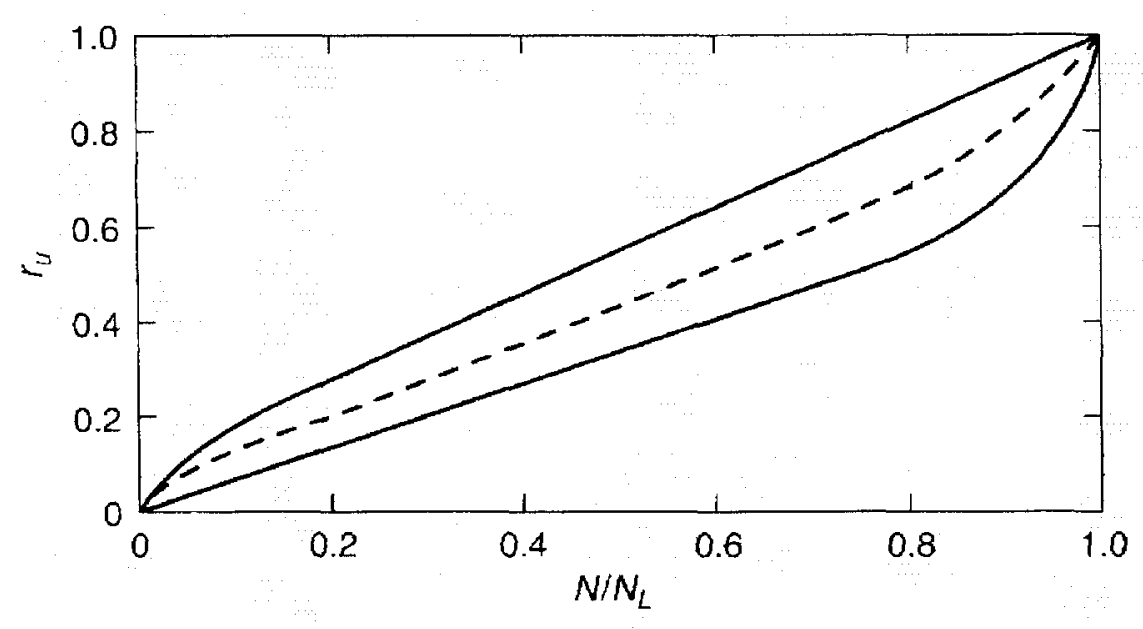

Figure 2.13 Pore pressure ratio vs. cyclic number ratio in cyclic simple shear test based on DeAlba et al. (1975) 


\section{CHAPTER 3}

\section{LOWER SAN FERNANDO DAM CASE HISTORY}

In this chapter, the Lower San Fernando Dam (LSFD) failure is analyzed to establish a method for assessing slope failure due to soil liquefaction caused by the San Fernando earthquake of February 9, 1971. The method proposed here is based on new concepts published recently in the literature on post-liquefaction strength (liquefied shear strength) of granular sands and using commercial software as a tool to identify liquefied zones.

The proposed method is conceptually similar to that proposed by Seed and Harder (1990) with a difference in the evaluation of liquefaction occurrence and the software used for the computation. In the method proposed in this thesis, the assessment of liquefaction occurrence is based on combining the work of Seed et al. (1973) and Seed 
and Harder (1990). Two commercial computer programs are used: Quake/W and Slope/W of GEO-SLOPE International Ltd.

The proposed method consists of the following steps.

1. The geometry of the dam and the foundation is determined.

2. Through geological and seismologic data, the most severe or maximum time history of the design earthquake is determined.

3. By using Quake/W, the pre-earthquake stresses (initial static stresses) are determined. This is a two-dimensional analysis, which is adequate for this dam with long crest length relative to the dam height according to Seed and Harder (1990).

4. The acceleration and dynamic shear stresses induced during the design earthquake are computed with Quake/W.

5. The liquefaction resistance of the soil within the dam and the foundation is determined.

6. By comparing the liquefaction resistance and the earthquake-induced stresses, liquefaction initiation is identified.

7. If the previous step reveals some liquefied zones, the overall slope stability of the dam is investigated using the liquefied shear strength (undrained residual strength) in the liquefied zones and the drained strength in the non-liquefied regions.

\subsection{Geometry and general characteristics of LSFD}

Lower San Fernando Dam is located on natural alluvium foundation and the body of the dam has been constructed mainly from hydraulic filling using similar borrow 
material (Seed et al., 1975c). The water level in the reservoir at the time of the earthquake was $35 \mathrm{ft}$ (11 metre) below the crest. Figure 3.1 shows the cross section of the dam with the maximum height and Figure 3.2 shows the conditions of the dam at the time of the earthquake for the analysis using Quake/W in this thesis.

\subsection{Applied earthquake record and Peak Ground Acceleration (PGA)}

The Pacoima Dam earthquake records, which were applied in the stability analysis of Lower San Fernando Dam by Seed and his colleagues in 1973, are also employed in this thesis and have been modified for PGA of $0.55 \mathrm{~g}$ (Figure 3.3) based on the suggestion by Scott (1973).

\subsection{Initial static analysis}

The next step involves the appraisal of the pre-earthquake stresses in the foundation and the body of the dam. This static analysis is essential in two ways. Firstly, the static stresses, especially the effective confining stress, can affect the dynamic response characteristics. Therefore, they influence the cyclic stress calculation. Secondly, static vertical effective stress (i.e. $\sigma_{v o}^{\prime}$ ) and static driving shear stress on horizontal plane (i.e. $\tau_{h v}$ ) have influence on pore pressure generation, which in turn have influence on the liquefaction resistance of the soil (Seed and Harder, 1990).

The initial static stresses are evaluated using Quake/W. Most of the necessary data for the analysis have been obtained from the works of Seed et al. (1973), Lee et al. (1975), and Seed and Harder (1990) on this dam. The following paragraphs describe the selected parameters for the static analysis. 


\section{Soil model}

A linear-elastic model is applied to assess the stresses under static conditions which stress level is low and this concept is applicable.

\section{Soil parameters of embankment and foundation}

The required soil parameters for linear-elastic model, including Young's modulus, Poisson's ratio, unit weight, drained cohesion and friction angle of all soil strata of the embankment and the foundation, are presented in Table 3.1.

\section{Initial water table}

There are several methods to specify pore water pressure in Quake/W. The first method is drawing the initial water table using Quake/W's command. The second way is determining the head of water $(\mathrm{H})$ by seepage analysis software and importing the file of results to Quake/W. The first method is used in this research with, the initial water table identical to what has been applied by Seed et al. (1973). Figure 3.2 shows the groundwater table defined in this analysis.

\section{Node boundary conditions}

As shown in Figure 3.4, the boundary conditions for this problem are:

- Displacement is zero in both the $\mathrm{X}$ and the $\mathrm{Y}$ directions along the bottom horizontal boundary (fixed boundary).

- Along the vertical boundaries, the soil cannot move in the $\mathrm{X}$ direction but is free to move in the $\mathrm{Y}$ direction.

- Along the exposed ground surface, the soil is free to move in both the $\mathrm{X}$ and the Y directions. 
After defining all necessary parameters for the static analysis, the problem will be solved for static loadings and the results are saved in a specific file.

\subsection{Dynamic analysis}

In the dynamic analysis, the response of the dam and the foundation during the earthquake is computed. The determined pre-earthquake (static) stresses and pore water pressure are imported from the initial static analysis. The required parameters to simulate the dynamic properties of the dam and the foundation are selected from the applied parameters by Seed et al. (1973). The procedure of dynamic simulation of the soils is described in the following.

\section{Soil model}

The selected soil model in the dynamic analysis is different from the soil model in the static analysis. To determine the dynamic response of the dam and the foundation for the design earthquake, the generation of excess pore pressure is calculated. As soil properties during linear-elastic method remain constant, this model inherently, cannot result in realistic excess pore water pressure. In order to consider the non-linearity of the soil property during the shaking, the equivalent-linear model is applied in the dynamic analysis. This model is actually non-linear as the shear modulus reduces with respect to the shear strain and the updated value of $\mathrm{G}$ after each dynamic loading analysis makes the total procedure non-linear. It is equivalent to linear model because in each iteration, the value of shear modulus $(G)$ remains constant.

\section{Soil parameters of embankment and foundation}

From the works of Seed et al. $(1973,1975 b)$ on this dam, all dynamic parameters of the different soil layers are available and listed in Table 3.2. 


\section{Equivalent number of cycles $\left(\mathbf{N}_{\mathrm{eq}}\right)$}

This parameter is applicable to determine the factor of safety against liquefaction initiation. The earthquake magnitude for this case is 6.6. Therefore, from Figure 2.12 this parameter is determined to be 8 .

\section{$\mathrm{K}_{\alpha}$ correction function}

The suggested correlation by Seed and Harder (1990) shown in Figure 2.6, is applied in the analysis to take into account the static driving shear stresses acting on horizontal plane. Since, according to Seed et al. (1973), the relative density of the soil layers susceptible to liquefaction ranges from 51 to $58 \%$, the function relevant to relative densities between $55-70 \%$ is selected and shown in Figure 3.5. The initial shear stress ratio $(\alpha)$ in this figure is defined as the normalized static shear stress on a horizontal plane with respect to static vertical effective stress (i.e. $\frac{\tau_{h v}}{\sigma_{v 0}^{\prime}}$ ).

\section{$\mathbf{K}_{\sigma}$ correction factor}

$\mathrm{K}_{\sigma}$ correction function is defined to consider the influence of effective overburden pressures higher than $100 \mathrm{kPa}$. Similar to $\mathrm{K}_{\alpha}$ factor, the suggested function by Seed and Harder (1990) (Figure 3.6) is applied to the soil layers susceptible to liquefaction.

\section{Cyclic number functions}

This function defines the necessary number of cycles to cause liquefaction for each stress level. The data of this function are used in the pore pressure function to determine the earthquake-induced pore water pressure. All required data are available in the literature (Seed et al., 1973). Figure 3.7 and Figure 3.8 show the functions of the hydraulic fill and the alluvium foundation, respectively. The symbol of $\sigma_{d}$ in these figures is the maximum cyclic shear stress. 


\section{Pore pressure function}

The pore pressure function is used to estimate the excess pore pressure generated in the non-liquefied soils. The function used in this study is based on Equation 2.22 as suggested by DeAlba et al. (1975)

The value of $\mathrm{N}_{\mathrm{L}}$ in this equation is determined from the cyclic stress function (i.e. Figure 3.7 and Figure 3.8) associated with the type of the soil. The value of $\mathrm{N}$ in the equation is the equivalent number of cycles $\left(\mathrm{N}_{\mathrm{eq}}\right)$. The way to determine the induced pore pressure during earthquake is described later in this chapter.

\section{G reduction function}

Under cyclic loading conditions, the secant shear modulus of the soil, $\mathrm{G}_{\mathrm{sec}}$, decreases with increasing cyclic shear strain amplitude, $\gamma_{c}$. This effect, therefore, should be considered in dynamic analysis. In Quake/W the variation of secant shear modulus versus cyclic shear strain can be defined through "G reduction function". Using this function and knowing $\mathrm{G}_{\max }$ or $\mathrm{K}_{2 \text {,max }}$, the value of $\mathrm{G}$ corresponding to the computed cyclic shear strain is determined in each iteration. The maximum shear modulus of sands is determined from Equation 3.1 which is an empirical relationship (Seed and Idriss, 1970).

$G_{\max }=1000 K_{2, \max }\left(\sigma_{m}^{\prime}\right)^{0.5}$

In this equation, $\sigma_{m}^{\prime}$ is the mean effective stress in $\mathrm{lb} / \mathrm{ft}^{2}$ and $K_{2, \max }$ is a soil constant and can be determined from Table 3.3 presented by Seed and Idriss (1970) and is a function of the void ratio or the relative density of the soil. If the coefficient 1000 is replaced with 218.8 , the equation will be appropriate for the metric units. $G_{\max }$ has the same unit as $\sigma_{m}^{\prime}$. 
Like other functions, all necessary data for defining this function for different layers of LSFD are available in the literature (Seed et al., 1973). Figure 3.9 and Figure 3.10 show the variation of modulus reduction, $G / G_{\max }$, with respect to the cyclic shear strain for cohesionless and cohesive soils, respectively. In order to apply these functions to the different layers of the dam concerning with their cohesion properties, Table 3.4 (Seed et al. 1973) is employed.

This function can also be estimated from Equation 3.2, presented by Ishibashi and Zhang's (1993). The equation shows how the $G$ reduction function correlates with plasticity index (PI), confining pressure $\left(\sigma_{m}^{\prime}\right)$, and cyclic shear strain $(\gamma)$.

$\frac{G}{G_{\max }}=K(\gamma, P I)\left(\sigma_{m}^{\prime}\right)^{m(\gamma, P I)-m_{0}}$

where:

$$
\begin{aligned}
& K(\gamma, P I)=0.5\left\{1+\tanh \left[\ln \left(\frac{0.000102+n(P I)}{\gamma}\right)^{0.492}\right]\right\} \\
& m(\gamma, P I)-m_{0}=0.272\left\{1-\tanh \left[\ln \left(\frac{.000556}{\gamma}\right)^{0.4}\right]\right\} \exp \left(-0.0145 P I^{1.3}\right) \\
& n(P I)= \begin{cases}0.0 & \text { for } P I=0 \\
3.37 \times 10^{-6} P I^{1.404} & \text { for } 0<P I \leq 15 \\
7.0 \times 10^{-7} P I^{1.976} & \text { for } 15<P I \leq 70 \\
2.7 \times 10^{-5} P I^{1.115} & \text { for } P I>70\end{cases}
\end{aligned}
$$

In Lower San Fernando Dam, however, there is enough information to individually define the function. 


\section{Damping ratio function}

The damping ratio is an index of energy dissipation during cyclic loading. Therefore, its consideration for problems related to liquefaction is important. Like the G reduction function, the variation of damping ratio with respect to the cyclic shear strain can be defined with the damping ratio function as suggested by Seed et al. (1973) for this dam. This function can also be estimated through Equation 3.3 proposed by Ishibashi and Zhang (1993).

$$
\xi=0.333 \frac{1+\exp \left(-0.0145 P I^{1.3}\right)}{2}\left[0.586\left(\frac{G}{G_{\max }}\right)^{2}-1.547 \frac{G}{G_{\max }}+1\right]
$$

Figure 3.11 and Figure 3.12 show the related functions for cohesionless and cohesive layers, according to Table 3.4 , respectively.

\section{Node boundary conditions}

In this dynamic analysis, it is reasonable to consider the following boundary conditions (Figure 3.13):

- Displacement is zero in both the $\mathrm{X}$ and the $\mathrm{Y}$ directions along the bottom horizontal boundary (fixed boundary).

- Along the vertical boundaries, the soil cannot move in the $\mathrm{Y}$ direction but is free to move in the $\mathrm{X}$ direction. To reduce the effect of wave reflection in dynamic analysis, these boundaries are applied in a distance of around 100 metres from the toe of the dam.

- Along the exposed ground surface, the soil is free to move in both the $\mathrm{X}$ and the $\mathrm{Y}$ directions (no boundary condition needs to be specified). 


\subsection{Evaluation of liquefaction initiation and determination of pore water pressure}

Built-up excess pore water pressure in a saturated soil under cyclic loading reduces the effective stress in the soil even to zero. Liquefaction occurs when the increase in pore water pressure is equal to the effective confining pressure. According to Equation 2.22 by DeAlba et al. (1975) for cyclic tests with uniform stress cycles, the pore pressure ratio (i.e. $u_{\text {excess }} / \sigma_{3 c}^{\prime}$ ) is related to the cyclic number ratio (i.e. $N / N_{L}$ ). Therefore, liquefaction initiation can be predicted by comparing two cyclic number parameters as illustrated in the following.

Consider the region located inside the upstream hydraulic fill. Table 3.5 shows the summary of the necessary parameters for the evaluation of liquefaction triggering and determination of pore water pressure.

From the initial static analysis:

$\sigma_{y}^{\prime} / P_{a}=138.70 / 101.3=1.37$ (Equation 2.17)

From the $\mathrm{K}_{\sigma}$ function (Figure 3.6) one obtains:

$\mathrm{K}_{\sigma}=0.94$

Initial shear stress ratio:

$\alpha=\tau_{\mathrm{hv}} / \sigma_{\mathrm{v} 0}^{\prime}=26.28 / 138.7=0.19$

From $\mathrm{K}_{\alpha}$ function (Figure 3.5) for above ratio, one obtains:

$\mathrm{K}_{\alpha}=1.34$

The CSR of an element of soil in the field is determined from Equation 3.4: 
$\left(C R R_{\text {field }}\right)=\frac{0.65 \times \frac{\sigma_{d}}{2 \sigma_{3}^{\prime}}}{\left(K_{\sigma} \times K_{\alpha}\right)}$

In this equation, $\sigma_{d} / 2$ is the peak maximum cyclic shear stress and has been determined from the dynamic analysis.

$$
\left(C R R_{\text {field }}\right)=\frac{0.65 \times \frac{155.16}{(2 \times 85.80)}}{(0.94 \times 1.34)}=0.47
$$

From the cyclic number function in Figure 3.7 for $\operatorname{CSR}=0.47$, one obtains:

$\mathrm{N}_{\mathrm{L}}=3$

The equivalent number of cycles $\left(\mathrm{N}_{\mathrm{eq}}\right)$ for the $\mathrm{M}=6.6$ earthquake that failed LSFD is found to be 8 , Figure 2.12 .

Since the number of cycles required to produce initial liquefaction $\left(\mathrm{N}_{\mathrm{L}}=3\right)$ is less than the number of equivalent uniform stress cycles involved in the earthquake $\left(\mathrm{N}_{\mathrm{eq}}=8\right)$ liquefaction should occur in this region and

$\mathrm{r}_{\mathrm{u}}=\mathrm{u}_{\mathrm{excess}} / \sigma_{3 \mathrm{c}}^{\prime}=1$ or

$u_{\text {excess }}=r_{u} \times \sigma_{3 c}^{\prime}=1.0 \times 85.8=85.8 \mathrm{kPa}$

From the initial static analysis:

$\mathrm{u}_{\mathrm{i}}=150.11 \mathrm{kPa} \quad$ (Table 3.5 )

The total pore pressure at liquefaction failure is therefore, equal to:

$85.8+150.11=235.91 \mathrm{kPa}$

Based on the above procedure, the liquefied regions of the dam are identified in the dynamic analysis and are shown in Figure 3.14. 
The framework of the method used in this thesis to evaluate the liquefaction triggering is nearly similar from what was applied by Seed et al. (1973) who employed the following procedures:

1. The embankment was divided into four potential zones of liquefaction, located in four elevations of the hydraulic fill. Elements along the average elevation of each zone were selected as representative to be used for evaluating the liquefaction potential.

2. The initial effective normal stress, $\sigma_{\mathrm{fc}}^{\prime}$, the initial shear stress, $\tau_{\mathrm{hv}}$, and $\alpha$ along the potential failure plane of the dam before the earthquake were first determined. This $\alpha$ can then be used to determine the liquefaction resistance of the soils in step 6 .

3. The response of the embankment to the bedrock excitation of the target earthquake motion was evaluated and the dynamic stresses induced in representative elements of the embankment were computed. Figure 3.15 shows the dynamic shear stress-time histories of the indicated representative elements along the base of the embankment. It should be noted that these records as suggested by Scott (1973) are different from the Pacoima dam ground motion records which have been applied in this thesis.

4. According to Lee and Chan (1972), the shear stress time histories of each representative location were converted to an equivalent series of uniform cyclic stress applications. This then yielded the magnitude and the number of uniform cyclic stresses.

5. The representative soil samples of the dam were subjected to the combination of pre-earthquake stress conditions and the dynamic stresses in the laboratory 
study to determine the effects of the earthquake-induced stresses in soil elements of the embankment.

6. Based on the laboratory results from step 5 , the required cyclic shear stresses to cause liquefaction for each liquefiable region were determined. To determine the cyclic shear stresses corresponding to the equivalent cyclic number, they used the calculated $\alpha$ from step 2 .

7. The equivalent cyclic stresses induced during the earthquake (from step 4) were compared to the stresses to cause liquefaction (from step 6). The length of the liquefied zone was determined as those regions in which the induced cyclic stresses exceed the required cyclic shear stress to cause liquefaction (Figure 3.16). Figure 3.17 shows the results of liquefaction analysis by Seed et al., (1973) which is comparable with the result of dynamic analysis shown in Figure 3.14.

The difference between the method of Seed et al. and the method proposed in this thesis is that in this thesis some parameters are determined based on more recent relationships and correction factors.

\subsection{Slope stability of the dam}

After determining the liquefied regions using Quake/W, the results are imported to Slope/W for stability analysis. To assess the possibility of a flow slide to occur, the undrained residual strength (liquefied shear strength) is used in the liquefied zones and the drained strength in non-liquefied regions. 
In order to calculate the liquefied shear strength, two different techniques have been applied, one being proposed by Seed and Harder (1990), and the other by Olson and Stark (2002). These methods are described later in this chapter.

\subsubsection{Establishment of Slope/W file}

\section{Analysis setting}

After importing the file from the Quake/W dynamic analysis, the operation of Slope/W is set to static finite element. In the last time sequence in the dynamic analysis, the pore pressure reaches its highest value. Accordingly, the pore pressures of this time sequence are applied for the stability analysis.

\section{Soil parameters}

For the liquefied zones the undrained residual strength and for the non-liquefied regions the drained strength of the soil with pore pressure associated with the last time sequence of the dynamic analysis are applied. All required soil parameters are available in the literature (Seed at al. 1973; Lee et al. 1975) and shown in Table 3.1.

\section{Method of Seed and Harder (1990)}

Seed and Harder (1990) proposed an approach to determine the undrained residual strength based on SPT data. Their method has been described in section 2.2.3.1. The main reason for selecting this method is that it has gained some general acceptance by the geotechnical community (Kramer, 1996; Youd and Idriss, 2001).

Representative pre-earthquake $\left(\mathrm{N}_{1}\right)_{60}$ value in the upstream section in the liquefied zones is found to be 11.5 (Seed and Harder, 1990; Stark and Mesri, 1992; Olson and Stark, 2002). After correction for fine contents between $25 \%$ and $35 \%$, as mentioned in the literature review, this value becomes 13.5 . From Figure 2.9 , the average undrained 
residual strength is determined to be $24.0 \mathrm{kPa}$ with upper and lower bounds at 36.0 and 14.0 $\mathrm{kPa}$, respectively. The factor of safety corresponding to the average undrained residual strength of $24 \mathrm{kPa}$ is 0.92 . Based on the upper bound and the lower bound of the undrained residual strength the factors of safety are 1.07 and 0.75 , respectively. The results of the analysis have been shown in Figure 3.18 to Figure 3.20.

The calculated factor of safety in this study is different from that of Seed et al. (1973). There are a number of reasons for the difference. First, the slip surfaces in the present study have been defined with various centers and surface tangents which may result in a different critical slip surface from what determined by Seed et al., 1973. Second, in this research, the applied liquefied shear strength is determined from the method of Seed and Harder (1990) which is based on empirical relationship between SPT data and the residual shear strength. Seed et al. (1973), however, did not consider any liquefaction for the liquefied zones. Third, there is the possibility that differences in the details and formulation between the finite element analyses of Seed et al. (1973) and the method used here may give rise to some difference in results. As shown in Figure 3.21, the factor of safety in upstream part of LSFD for average strength value is 1.06 (Seed et al., 1973). In this thesis, the computed FS for the slip surface nearly similar to what is shown in Figure 3.21, is 1.08 (Figure 3.22).

\section{Method of Olson and Stark (2002)}

Olson and Stark (2002) proposed a method to determine the liquefied shear strength based on SPT and CPT data. This method is selected as it is the most recent method for the appraisal of liquefied shear strength. The main points and equations of this approach have been discussed in section 2.2.3.2. 
Determination of the liquefied shear strength and the stability analysis based on this strength are described in the following paragraphs.

With $\left(\mathrm{N}_{1}\right)_{60}=11.5$, the average liquefied strength ratio (i.e., $\left.\frac{s_{u}(L I Q)}{\sigma_{v 0}^{\prime}}\right)$ can be calculated using Equation 2.21:

$\frac{s_{u}(L I Q)}{\sigma_{v 0}^{\prime}}=0.03+0.0075 \times 11.5=0.1163$

The liquefied strength is obtained by multiplying the liquefied strength ratio by the representative vertical effective stress of the liquefied zones $\left(\sigma_{\nu 0}^{\prime}\right)$. Stark and Mesri (1992) define this representative $\sigma_{v 0}^{\prime}$ as "the initial effective vertical stress at the mid-depth of the layer that was reported as having liquefied". Based on the static analysis, $\sigma_{v 0}^{\prime}$ associated with the liquefied regions in the upstream side of the dam is found to be 158 $\mathrm{kPa}$. Therefore, the liquefied strength is:

$0.1163 \times 158=18.4 \mathrm{kPa}$

With this liquefied strength, the minimum factor of safety is found to be 0.82 for the upstream side of LSFD (Figure 3.23). Similar to Seed and Harder (1990), they also considered the upper and lower bounds for the liquefied strength ratio given by $(0.1163+0.03=0.1463)$ and $(0.1163-0.03=0.0863)$, respectively. The factors of safety associated with these ratios are shown in Figure 3.24 and Figure 3.25. Like the analysis based on Seed and Harder (1990) approach, the determined factors of safety do not correspond to the same slip surface considered by Seed and his staff in 1973. As shown in Figure 3.26, the factor of safety of the slip surface identical to that considered by Seed et al. (1973) is 1.01 (1.06 by Seed et al. (1973)) 


\subsection{Summary}

The dynamic analyses to identify the liquefied zone and the subsequent stability analysis to determine the occurrence of flow slides in this study appear to give results agreeable with field observations and the results of previous investigation by Seed and his colleagues in 1973 . Therefore, the proposed analysis technique can be used to assess the potential of flow sliding as a result of liquefaction of a Canadian dam in a seismic area. This is described in the next chapter. 
Table 3.1 Soil parameters for static analysis of LSFD (Seed et al., 1973; Lee et al., 1975)

\begin{tabular}{l|c|c|c|c|c|c} 
Soil parameters & Symbol & Unit & Rolled & Hydraulic & Clay & Foundation \\
& & & fill & fill & core & alluvium \\
\hline Total unit weight & $\gamma$ & $\mathrm{kN} / \mathrm{m}^{3}$ & 21 & 20 & 20 & 20 \\
Young's modulus & $\mathrm{E}$ & $\mathrm{MPa}$ & 143.64 & 244.19 & 244.19 & 158.00 \\
Poisson's ratio & $v$ & - & 0.30 & 0.41 & 0.41 & 0.40 \\
Cohesion & $\mathrm{c}$ & $\mathrm{kPa}$ & 0 & 0 & 124 & 0 \\
Drained friction angle & $\phi$ & $\mathrm{Deg}$ & 25 & 37 & 37 & 38
\end{tabular}

Table 3.2 Soil parameters for dynamic analysis of LSFD (Seed et al., 1973)

\begin{tabular}{|c|c|c|c|c|c|}
\hline $\begin{array}{l}\text { Material } \\
\text { number }\end{array}$ & Description & $\left(\mathrm{K}_{2}\right)_{\max }$ & $\begin{array}{l}\text { Undrained shear } \\
\text { strength }(\mathrm{kPa})\end{array}$ & $\begin{array}{c}\text { Damping } \\
\text { ratio }\end{array}$ & $\mathrm{n}$ \\
\hline 1 & Lower alluvium & 22974 & - & 0.02 & 0.5 \\
\hline 2 & Upper alluvium & 11377 & - & 0.02 & 0.5 \\
\hline 3 & Clayey core & - & 95 & 0.04 & 0.5 \\
\hline 4 & Ground shale & 11377 & - & 0.04 & 0.5 \\
\hline 5 & $\begin{array}{l}\text { Hydraulic sand } \\
\text { fill }\end{array}$ & 9408 & - & 0.04 & 0.5 \\
\hline 6 & $\begin{array}{l}\text { Hydraulic sand } \\
\text { fill }\end{array}$ & 9408 & - & 0.04 & 0.5 \\
\hline 7 & Rolled fill berm & 10502 & - & 0.04 & 0.5 \\
\hline 8 & Rolled fill & 12034 & - & 0.04 & 0.5 \\
\hline
\end{tabular}


Table 3.3 Values of $\mathrm{K}_{2, \max }$ versus void ratio (e) or relative density ( $\mathrm{D}_{\mathrm{r}} \%$ ) (Seed and Idriss, 1970)

\begin{tabular}{lllll}
\hline $\mathrm{e}$ & $\mathrm{K}_{2, \max }$ & & $\mathrm{D}_{\mathrm{r}} \%$ & $\mathrm{~K}_{2, \max }$ \\
\cline { 1 - 2 } \cline { 5 - 5 } 0.4 & 70 & & 30 & 34 \\
0.5 & 60 & & 40 & 40 \\
0.6 & 51 & & 45 & 43 \\
0.7 & 44 & & 60 & 52 \\
0.8 & 39 & & 75 & 59 \\
0.9 & 34 & & 90 & 70
\end{tabular}

Table 3.4 Soil layers in LSFD (Seed et al., 1973)

\begin{tabular}{ccc}
\hline Layer number & Soil & Soil type for dynamic evaluation \\
\hline 1 & Lower alluvium & Cohesionless \\
2 & Upper alluvium & Cohesionless \\
3 & Clay core & Saturated clay \\
5 & Ground shale & Cohesionless \\
6 & Hydraulic sand fill & Cohesionless \\
7 & Hydraulic sand fill & Cohesionless \\
8 & Rolled fill berm & Rolled fill
\end{tabular}


Table 3.5 Parameters of the soil inside the upstream hydraulic fill (from the static and dynamic analyses) for evaluation of liquefaction triggering and determination of pore water pressure

\begin{tabular}{|c|c|c|c|c|}
\hline Parameter & Symbol & Unit & Analysis & Value \\
\hline Initial minimum effective stress & $\sigma_{3 \mathrm{c}}^{\prime}$ & $\mathrm{kPa}$ & Static & 85.80 \\
\hline Initial vertical effective stress & $\sigma_{\mathrm{v} 0}^{\prime}$ & $\mathrm{kPa}$ & Static & 138.70 \\
\hline Initial horizontal shear stress & $\tau_{\mathrm{hv}}$ & $\mathrm{kPa}$ & Static & 26.28 \\
\hline Maximum cyclic shear stress & $\sigma_{\mathrm{d}}$ & $\mathrm{kPa}$ & Dynamic & 155.16 \\
\hline Initial pore water pressure & $\mathrm{u}_{\mathrm{i}}$ & $\mathrm{kPa}$ & Static & 150.11 \\
\hline Atmospheric pressure & $\mathrm{P}_{a}$ or $\mathrm{P}_{0}$ & $\mathrm{kPa}$ & - & 101.3 \\
\hline
\end{tabular}

Table 3.6 Additional SPT blow-count $\left(\mathrm{N}_{\text {corr }}\right)$ corrected for fines content (Seed and Harder, 1990)

\begin{tabular}{c|c} 
Percent Fines & $\mathrm{N}_{\text {corr }}($ blows $/ 30 \mathrm{~cm})$ \\
\hline $10 \%$ & 1 \\
$25 \%$ & 2 \\
$50 \%$ & 4 \\
$75 \%$ & 5
\end{tabular}




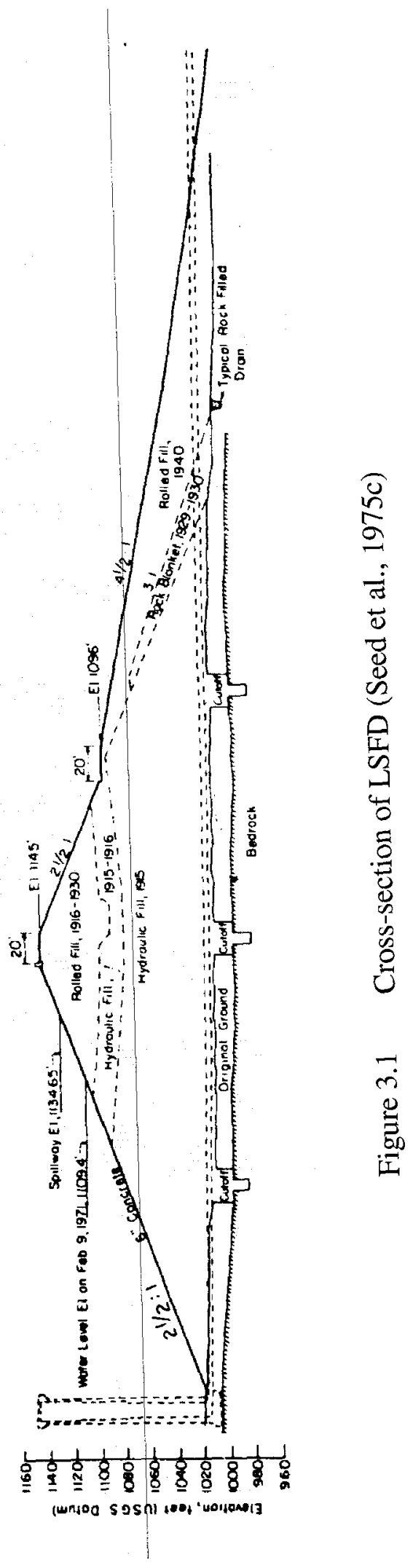

Reproduced with permission of the copyright owner. Further reproduction prohibited without permission. 


\section{Lower San Fernando Dam}

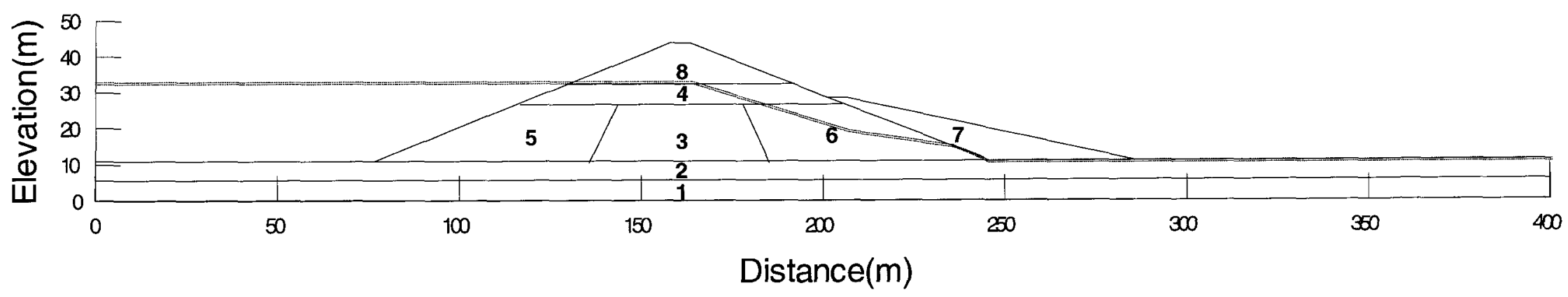

(a)

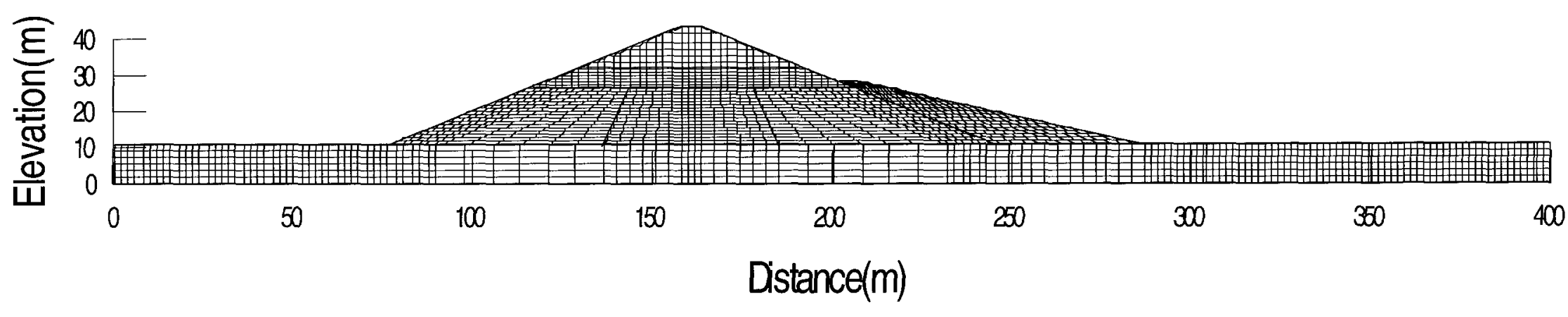

(b)

Figure 3.2 (a) Cross-section and water table and (b) Finite element mesh of LSFD for the present study 


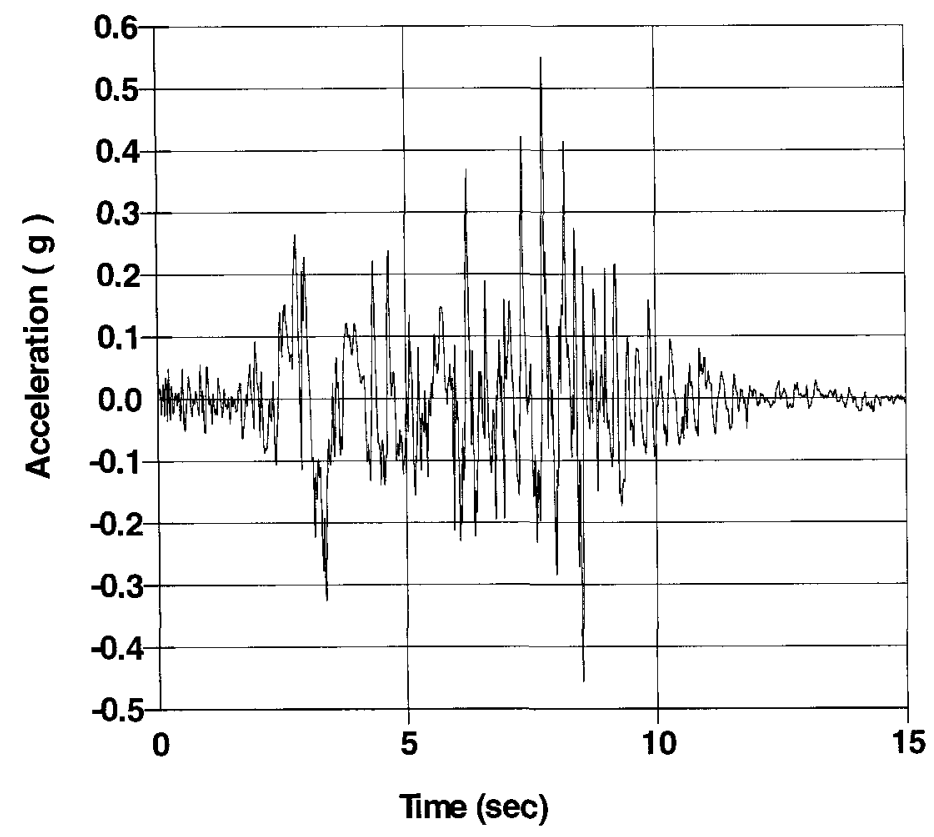

Figure 3.3 Pacoima Dam earthquake records for stability analysis of LSFD 


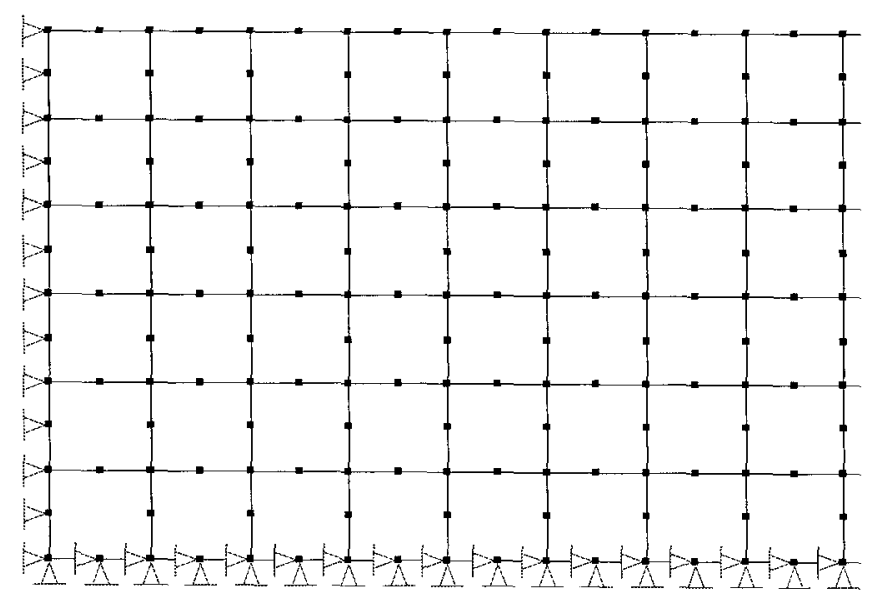

Figure 3.4 Boundary conditions for initial static analysis

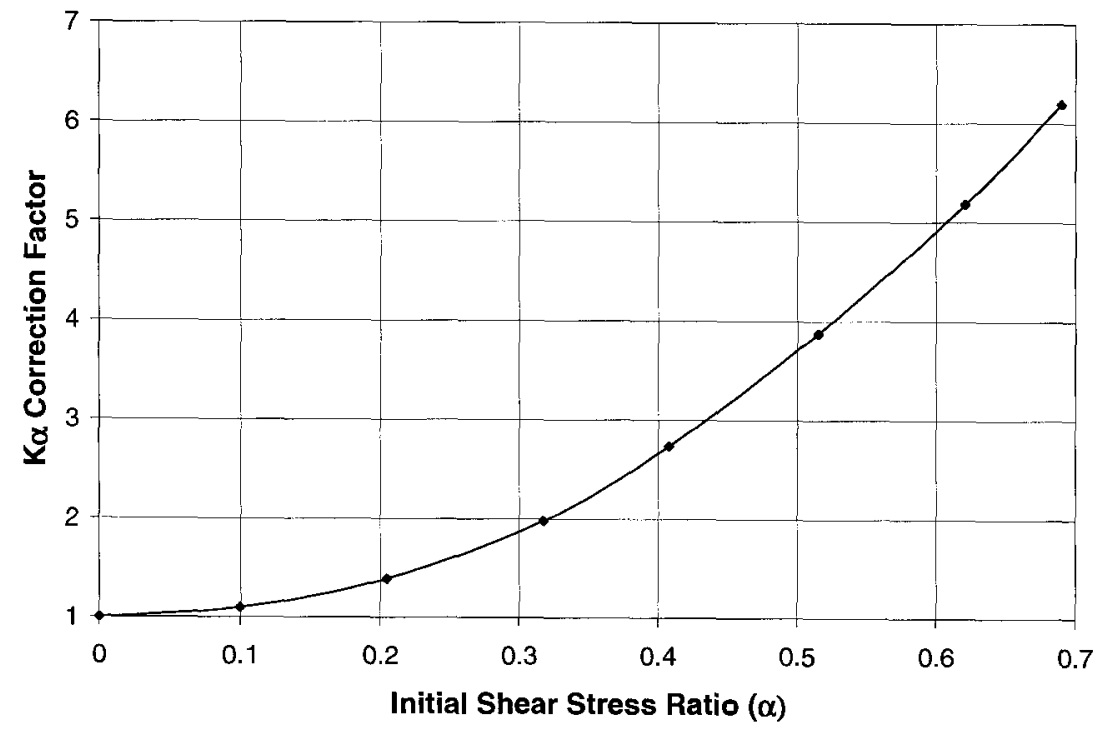

Figure 3.5 Relationship between initial shear stress ratio, $\alpha$, and $\mathrm{K}_{\alpha}$ correction factor 


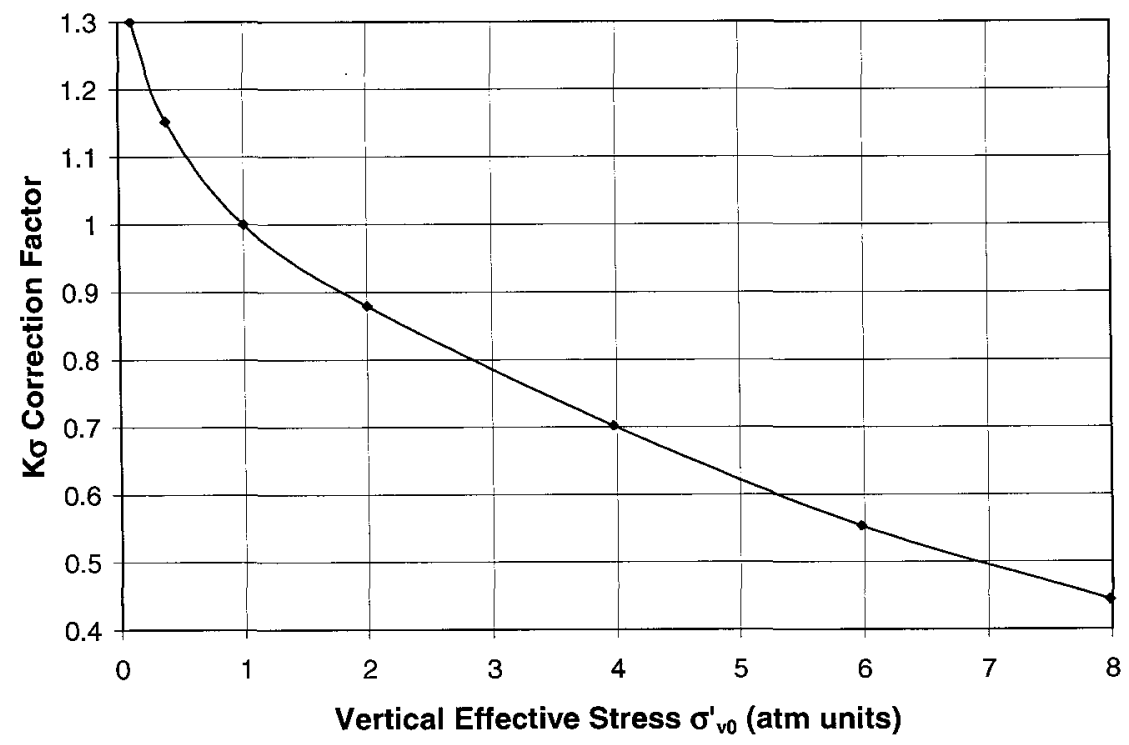

Figure $3.6 \quad \mathrm{~K}_{\sigma}$ correction function for the soil layers susceptible to liquefaction 


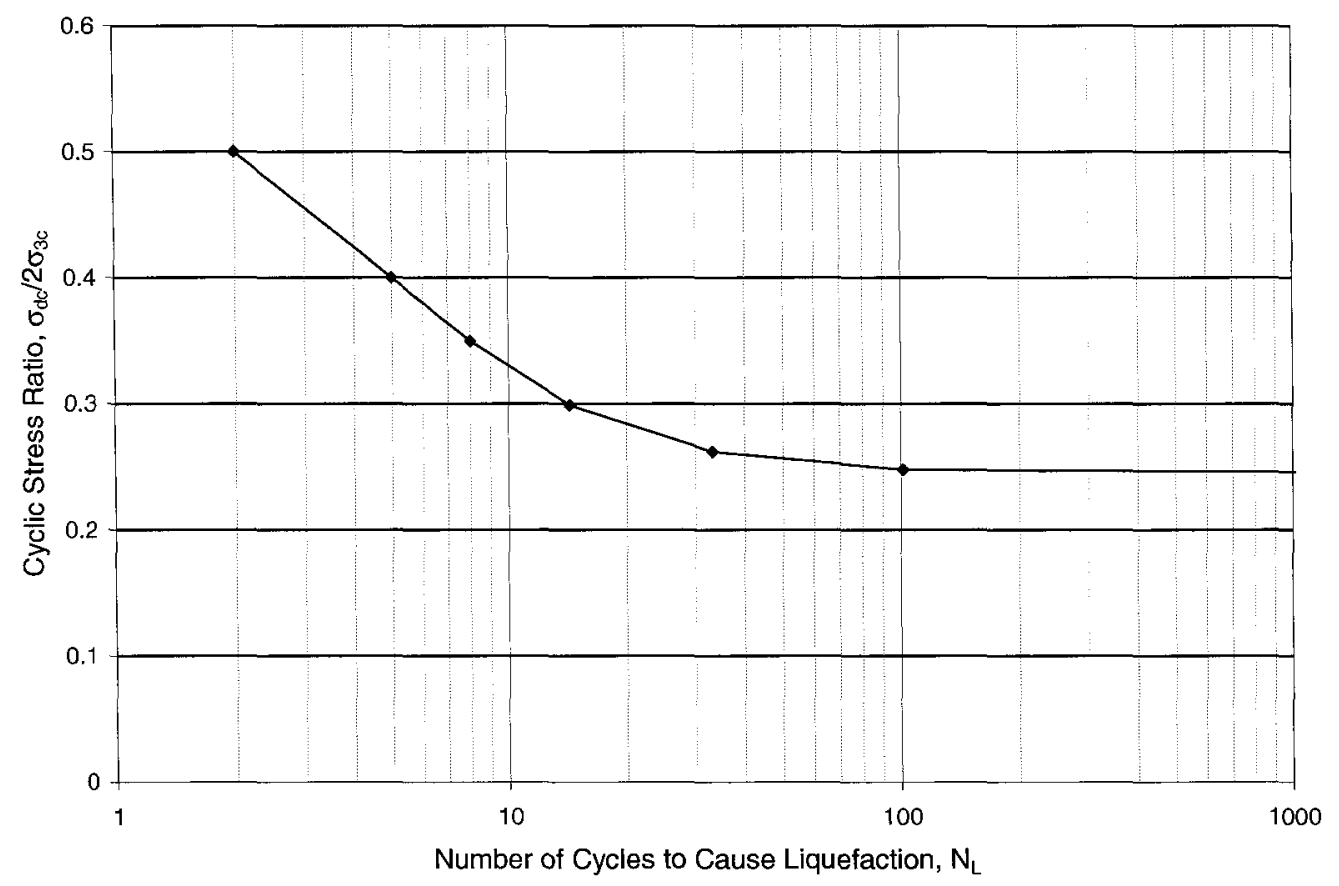

Figure 3.7 Cyclic number function for the hydraulic sand fill of LSFD (Seed et al., 1973)

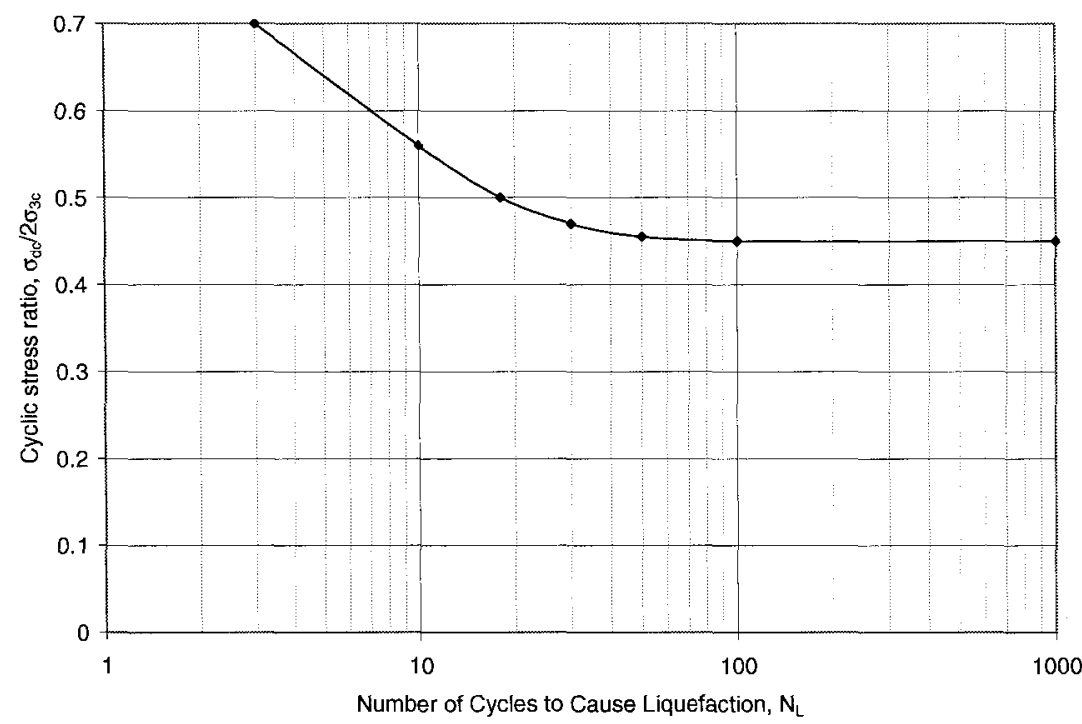

Figure 3.8 Cyclic number function for the alluvium foundation of LSFD (Seed et al., 1973) 


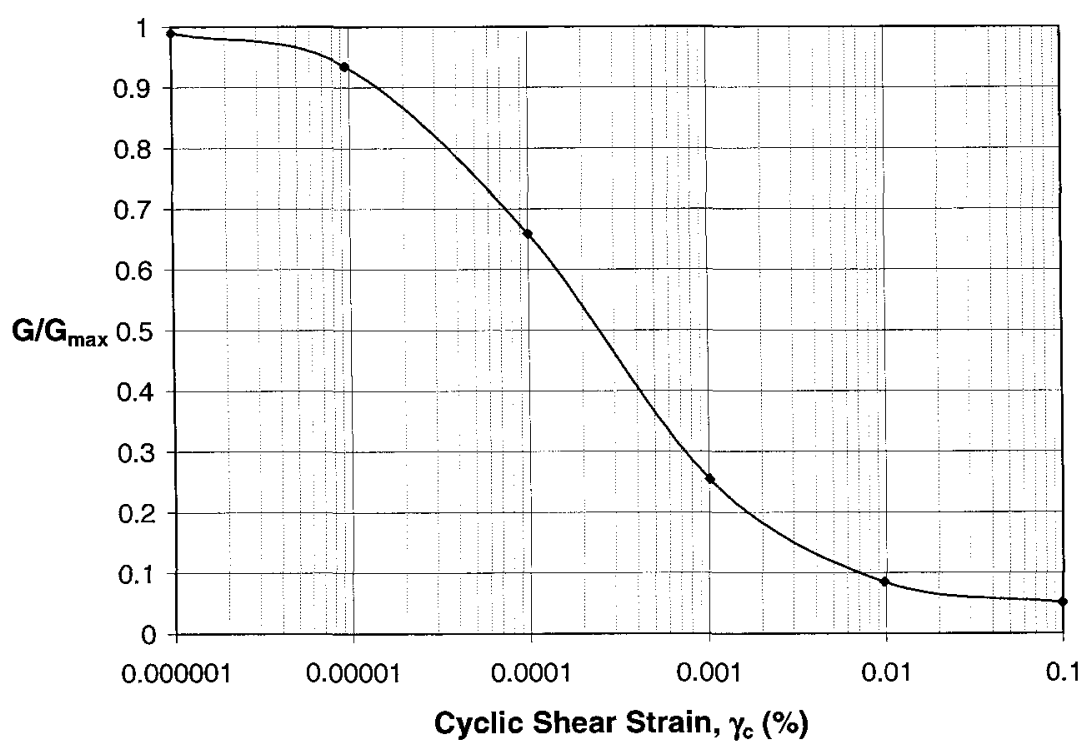

Figure 3.9 G-reduction function for cohesionless soils in LSFD (Seed et al., 1973)

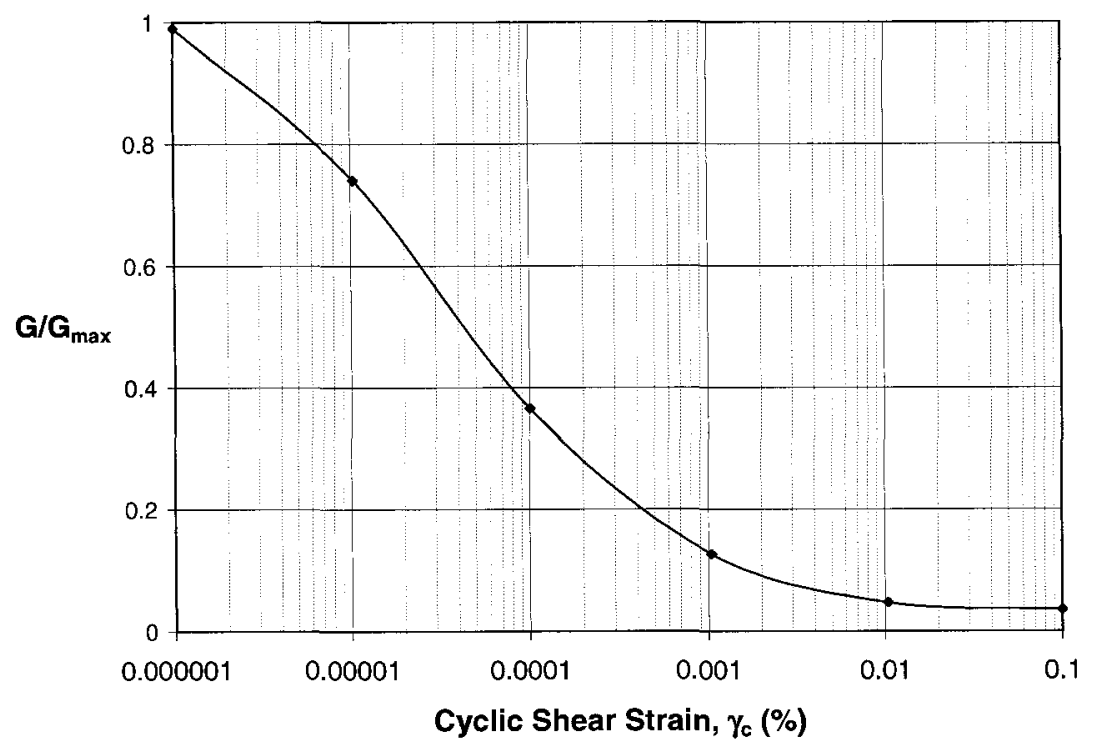

Figure 3.10 G-reduction function for cohesive soils in LSFD (Seed et al., 1973) 


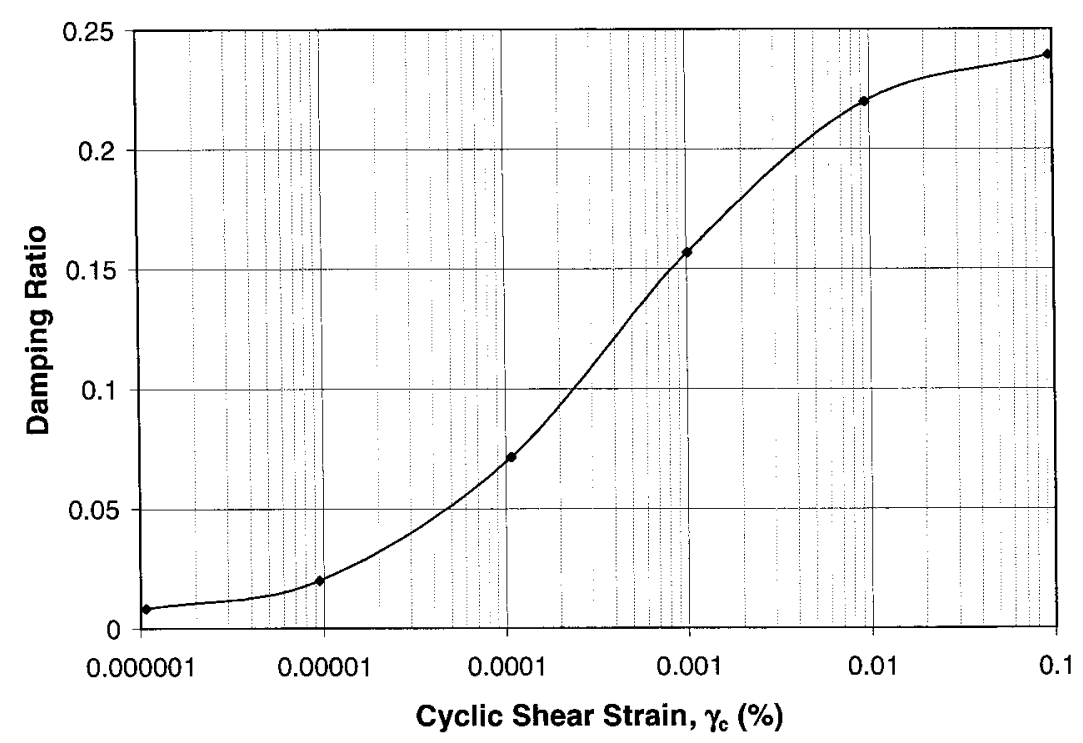

Figure 3.11 Damping ratio function of cohesionless soils in LSFD (Seed et al., 1973)

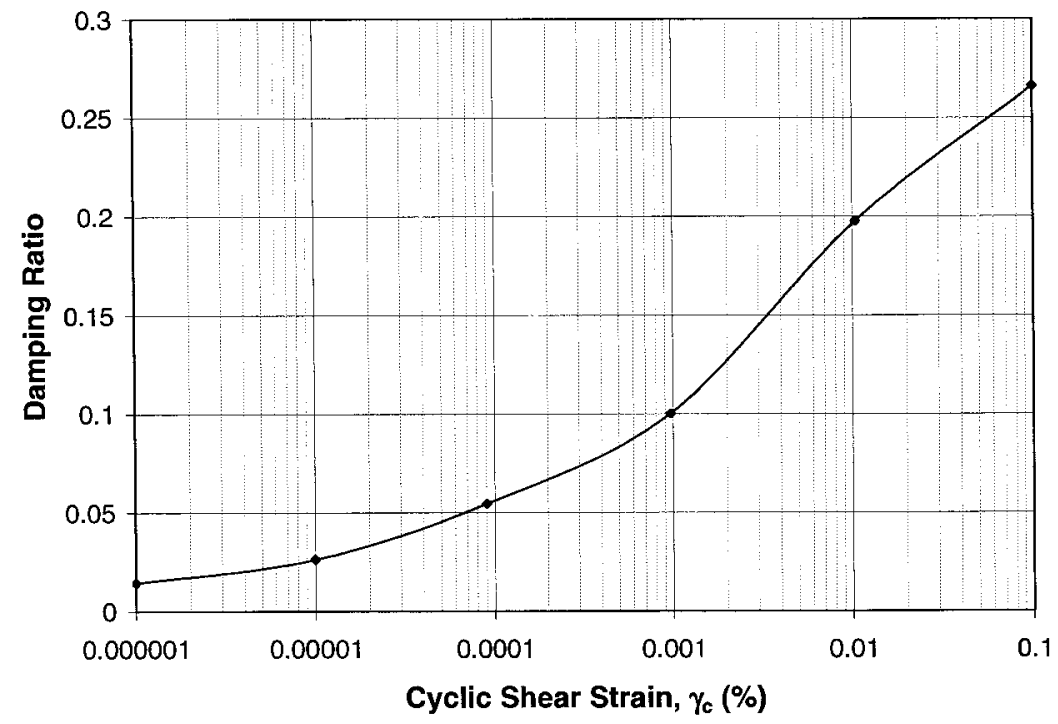

Figure 3.12 Damping ratio function of cohesive soils (Seed et al., 1973) 


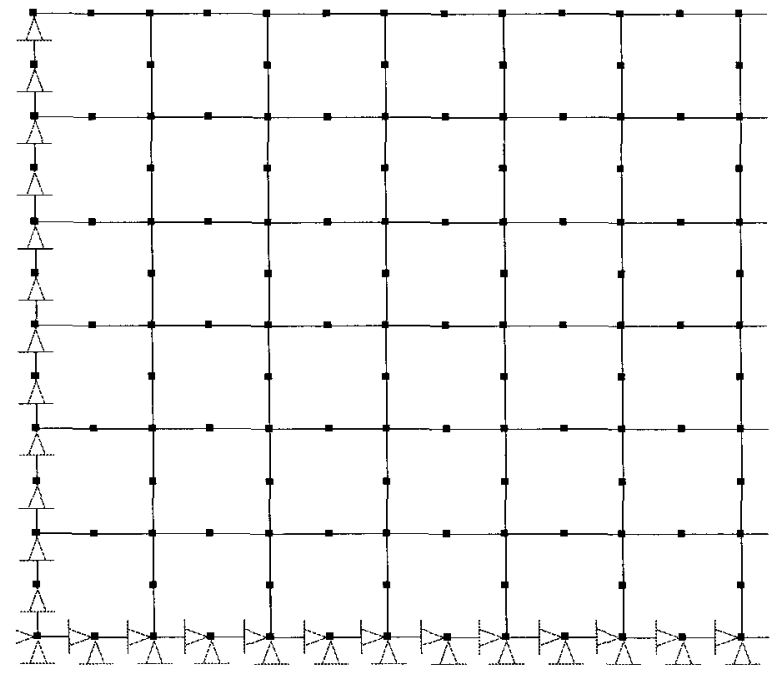

Figure 3.13 Boundary conditions for dynamic analysis 


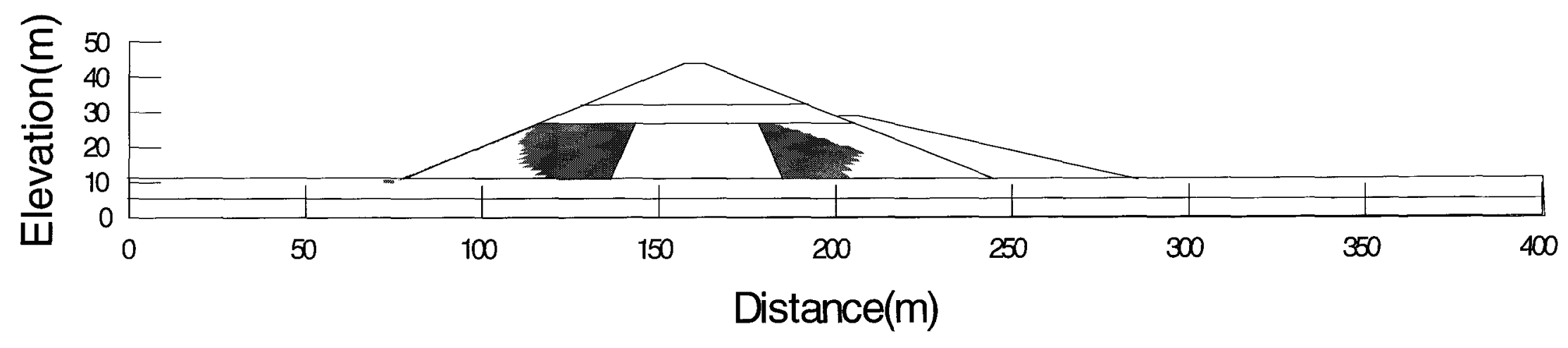

Figure 3.14 Result of the evaluation of liquefaction triggering; shadowy regions indicate liquefied zones. 

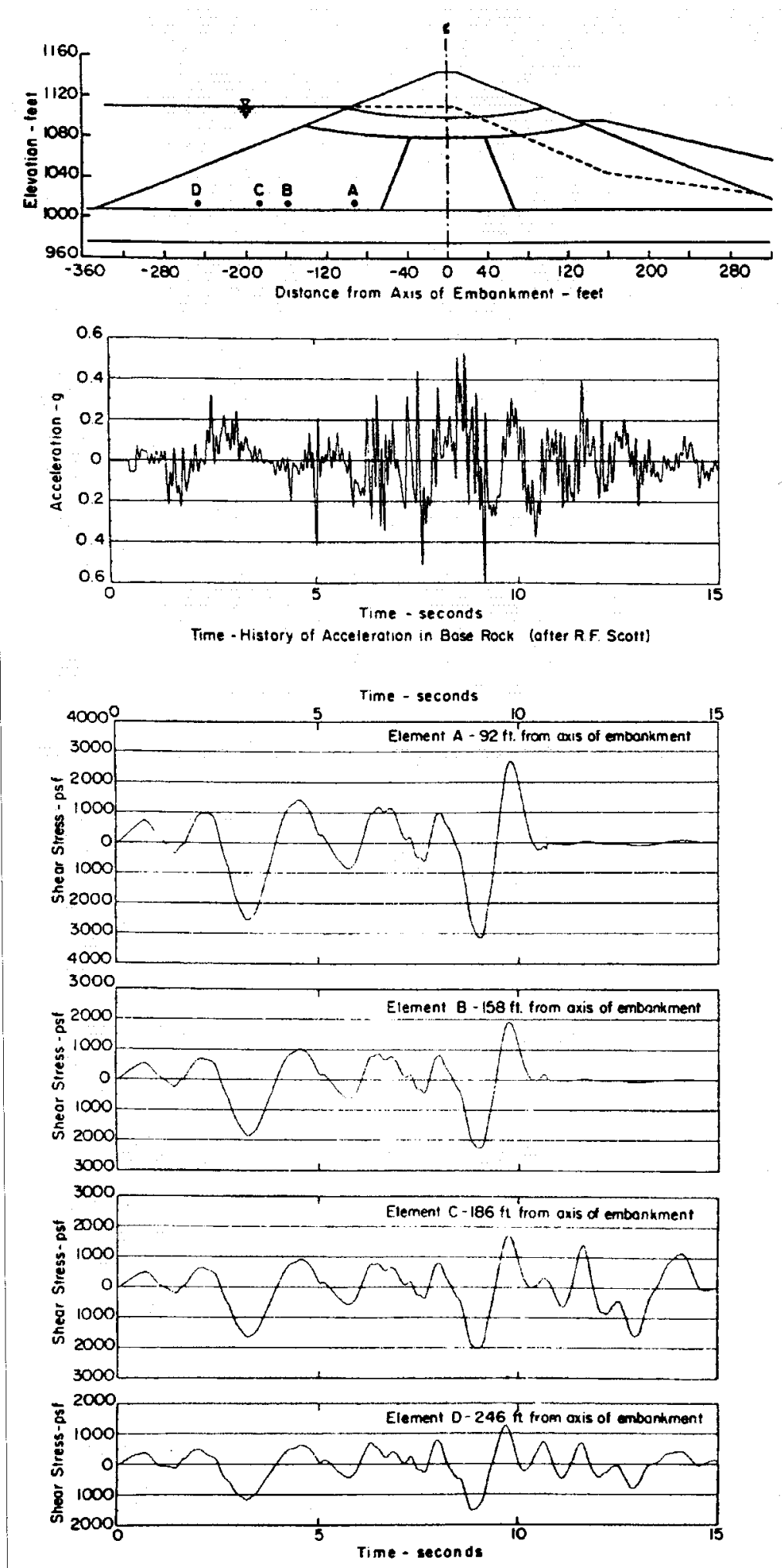

Figure 3.15 Shear stresses-time histories of representative locations (Seed et al., 1973) 


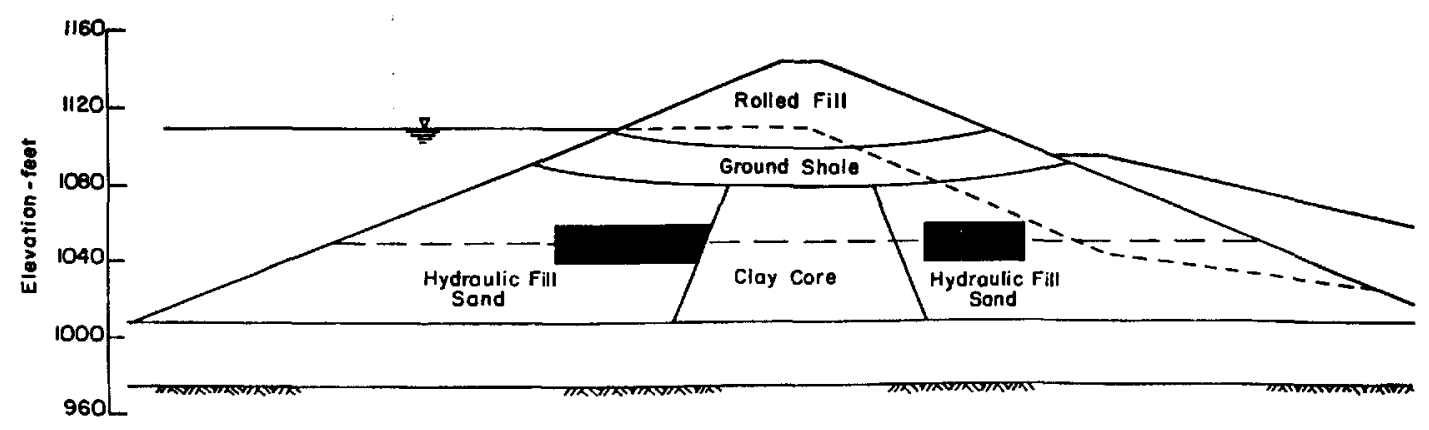

Zone of liquefaction ofter 8 seconds of shoking

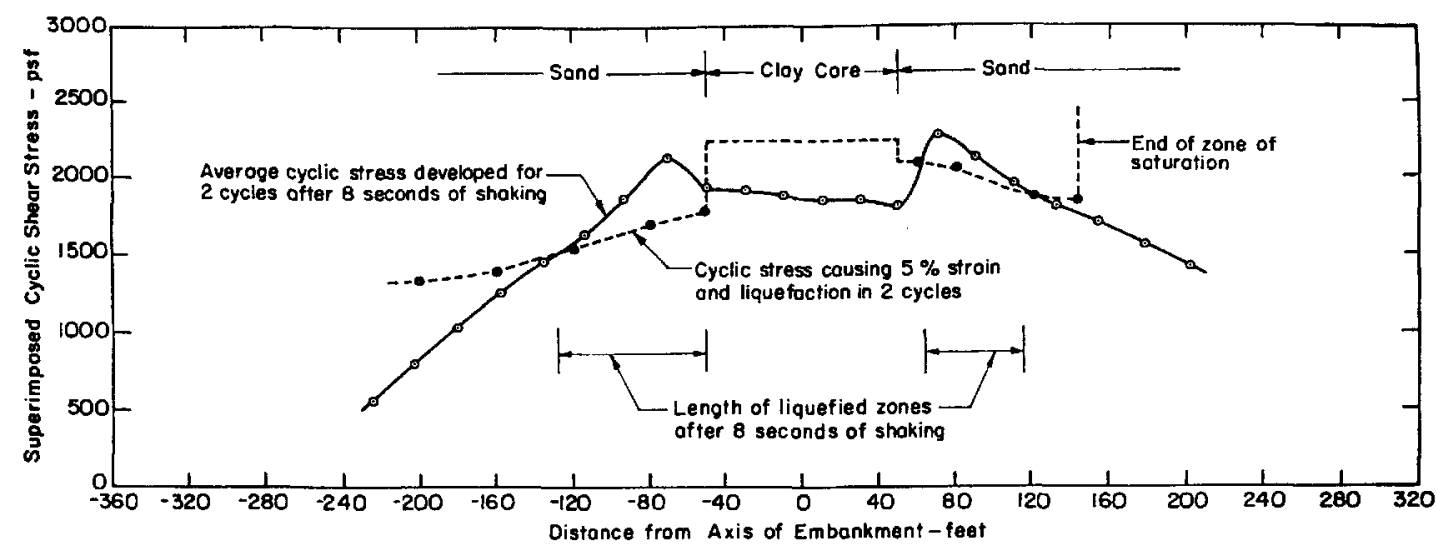

Figure 3.16 Analysis of soil liquefaction along one of the potential zones of LSFD after 8 seconds of shaking, using Pacoima ground motion records (Seed et al., 1973) 


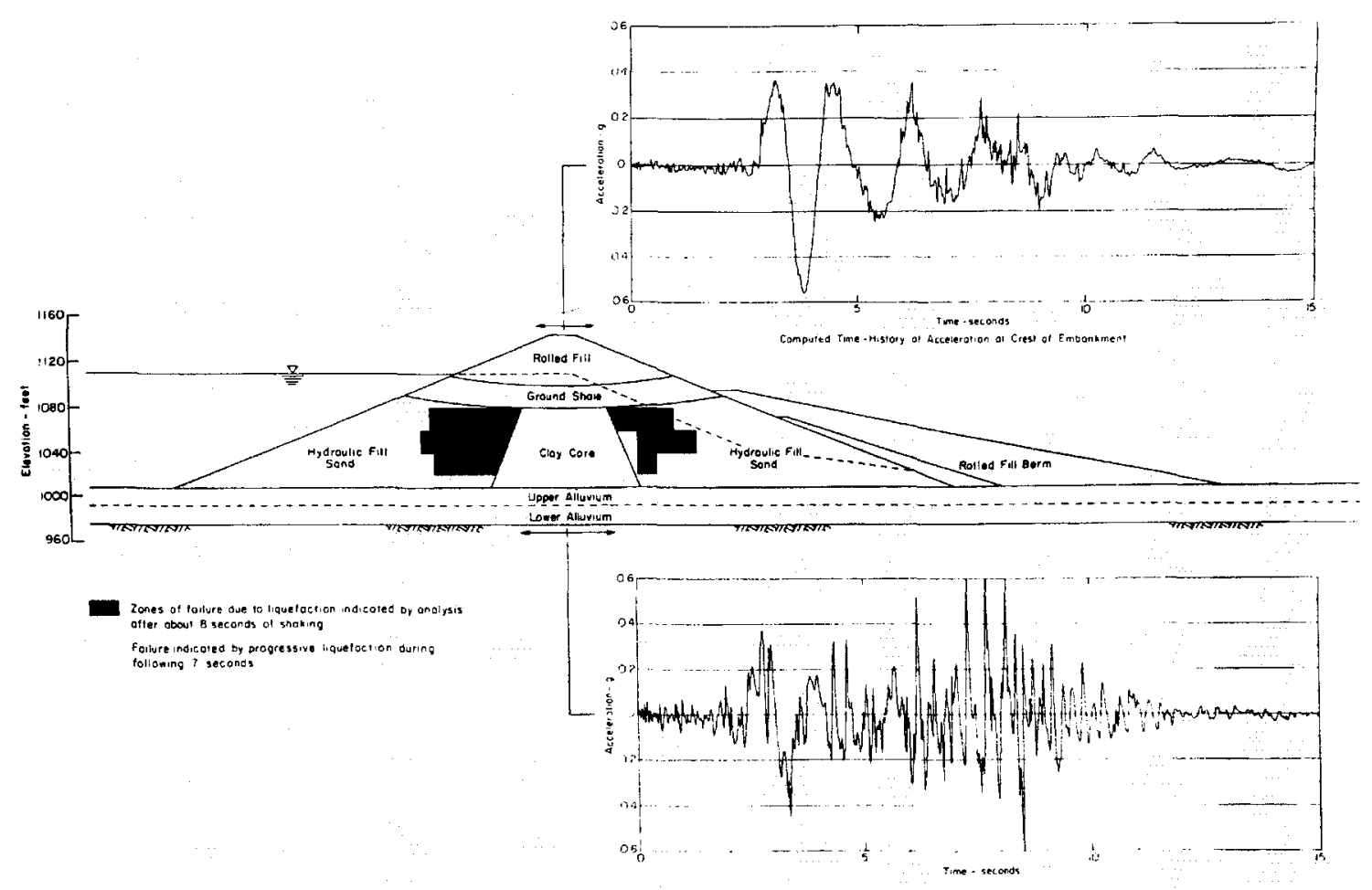

Figure 3.17 Computed liquefied zones in LSFD based on Pacoima ground motion records (Seed et al. 1973) 


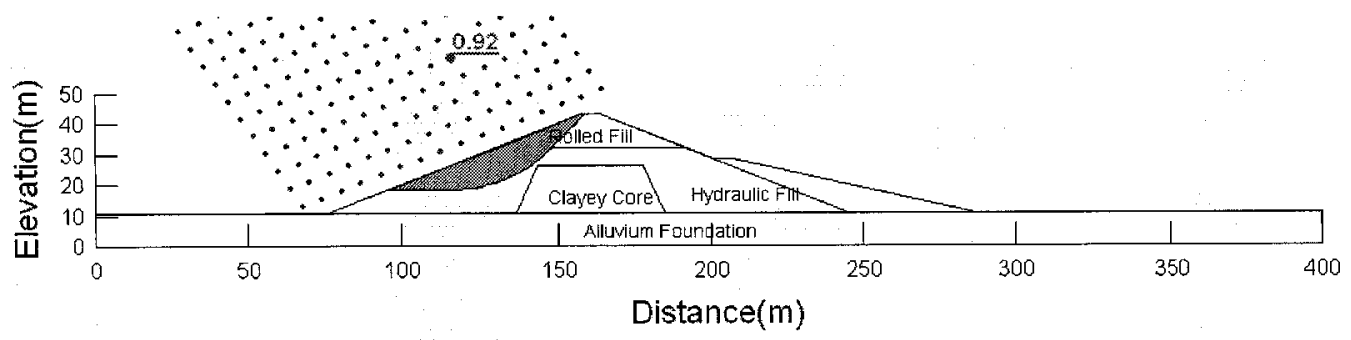

Figure 3.18 Result of slope stability analysis based on average residual strength from Seed and Harder (1990)

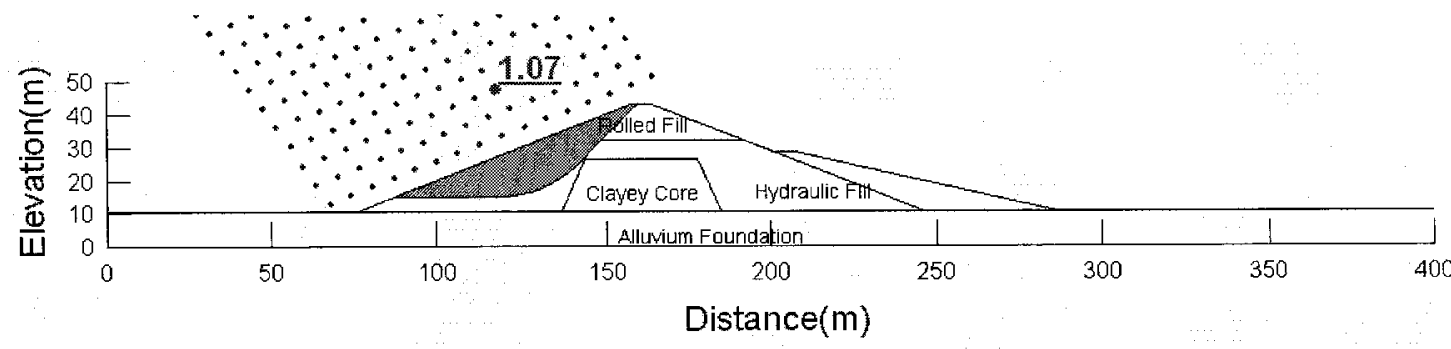

Figure 3.19 Result of slope stability analysis based on upper bound residual strength from Seed and Harder (1990)

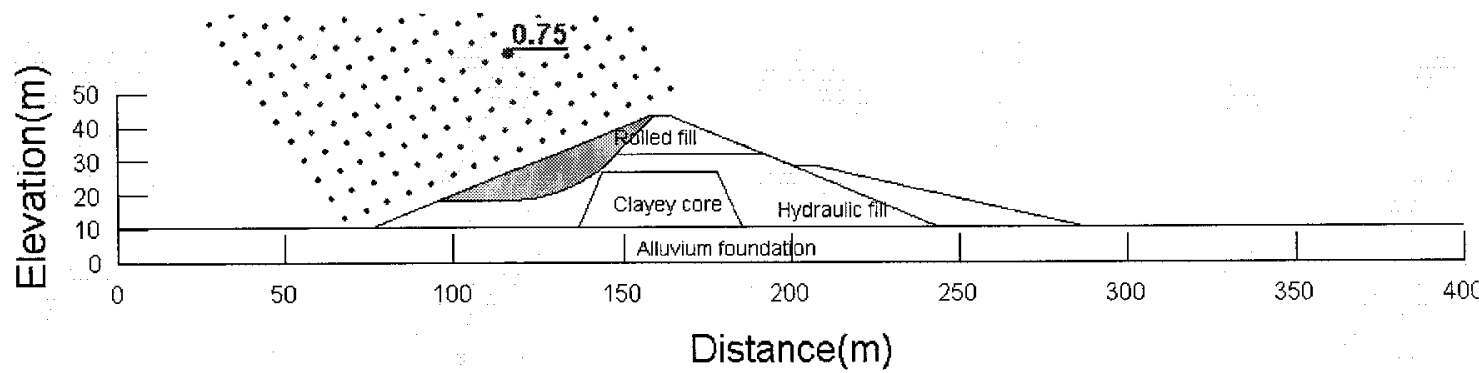

Figure 3.20 Result of slope stability analysis based on lower bound residual strength from Seed and Harder (1990) 


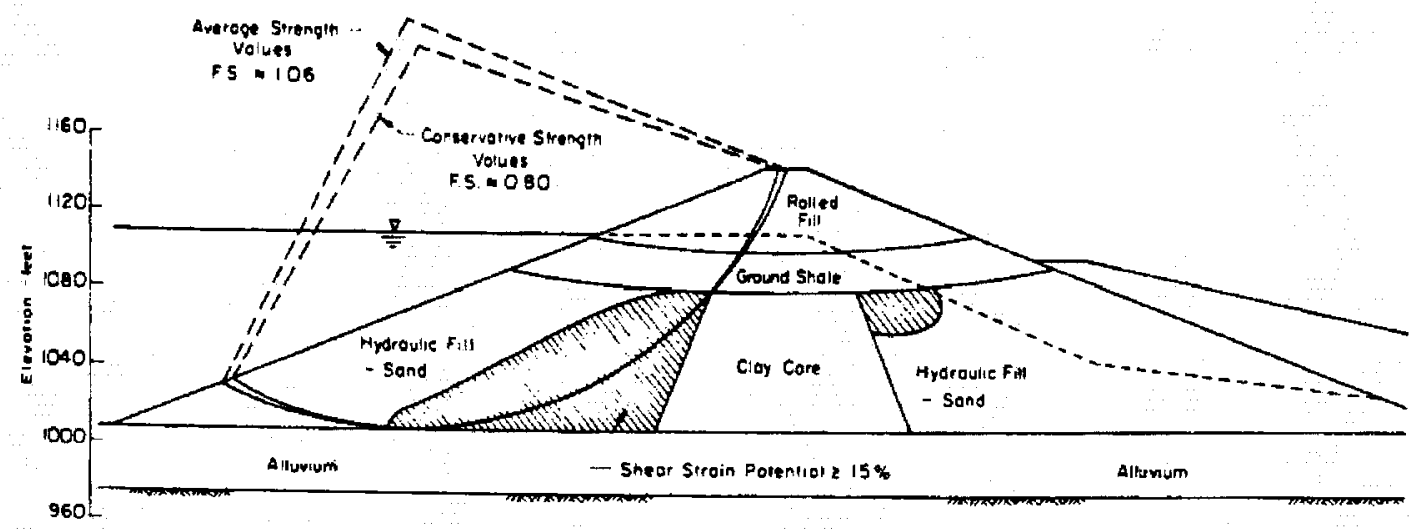

Figure 3.21 Factor of safety for upstream side of LSFD (Seed et al., 1973)

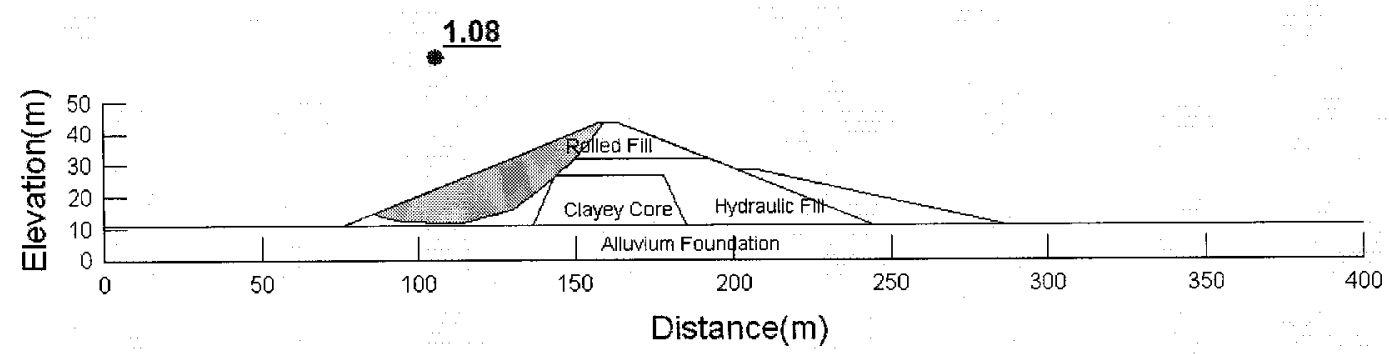

Figure 3.22 Factor of safety for the slip surface closely resembling what was considered by Seed et al. (1973) (from Seed and Harder (1990)) 


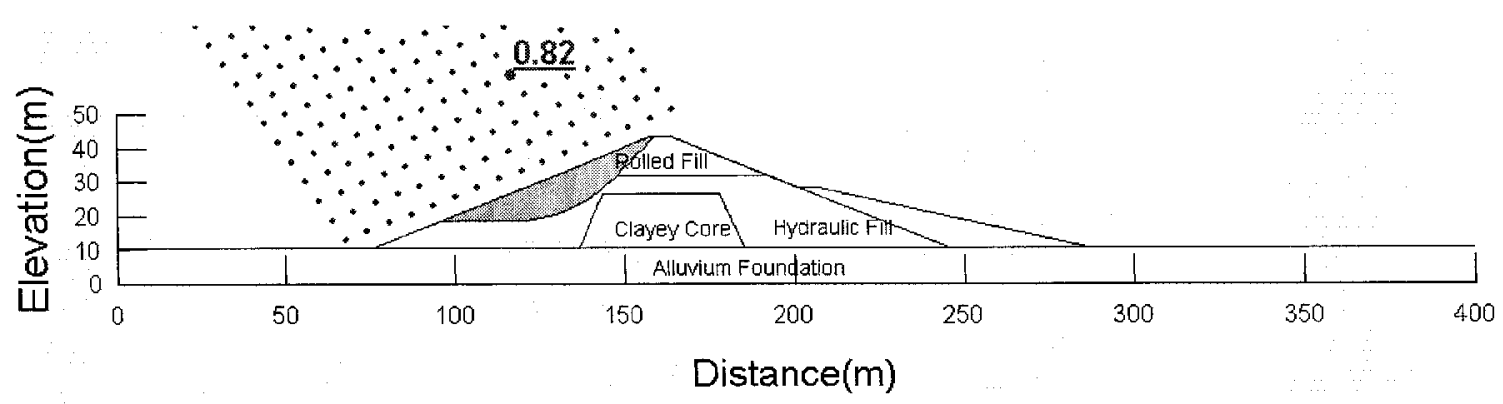

Figure 3.23 Result of slope stability analysis based on average liquefied shear strength from Olson and Stark (2002)

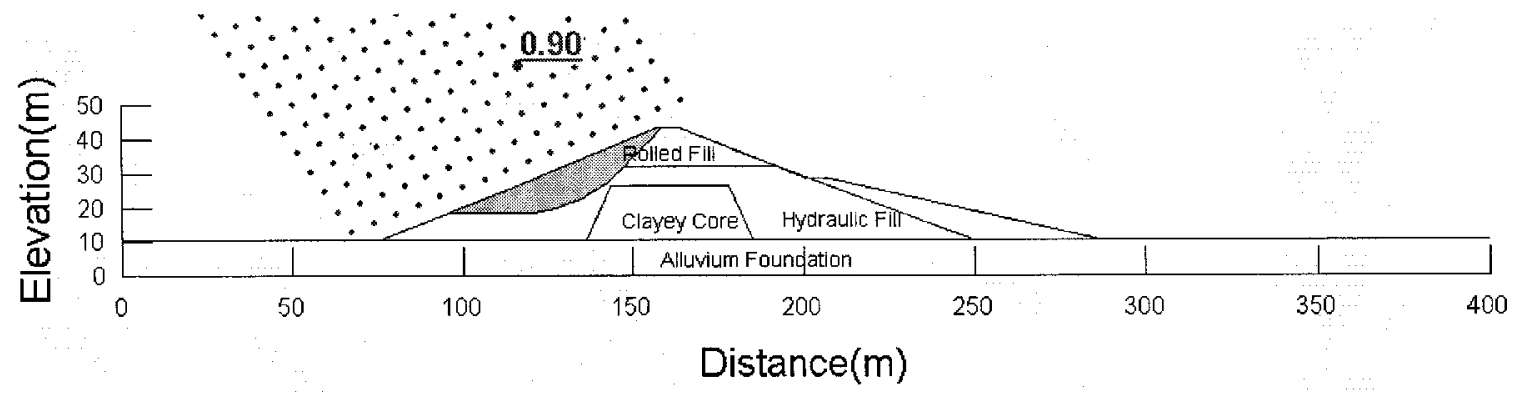

Figure 3.24 Result of slope stability analysis based on upper bound liquefied shear strength from Olson and Stark (2002)

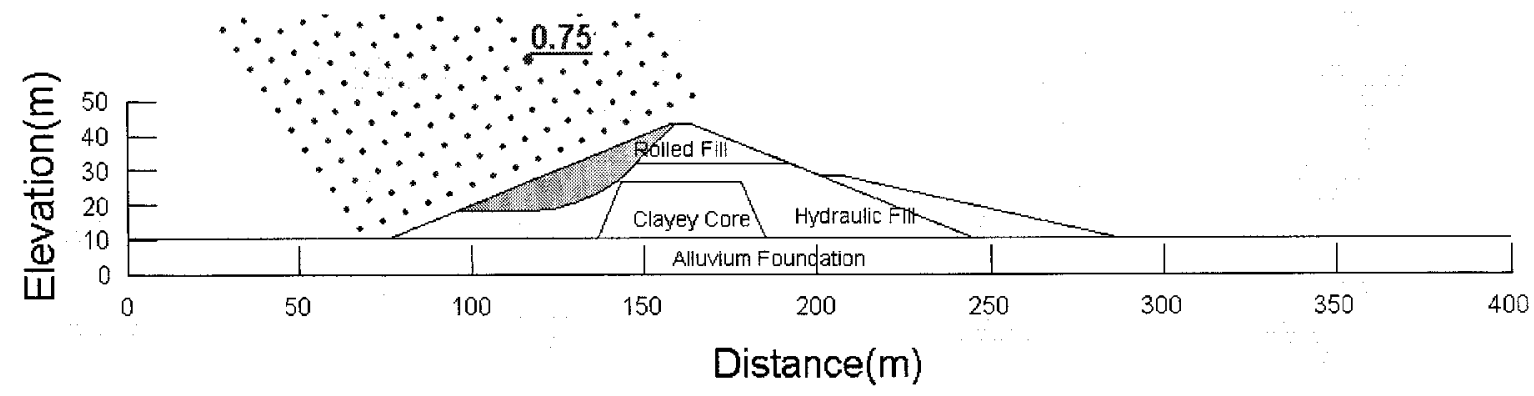

Figure 3.25 Result of slope stability analysis based on lower bound liquefied strength from Olson and Stark (2002) 


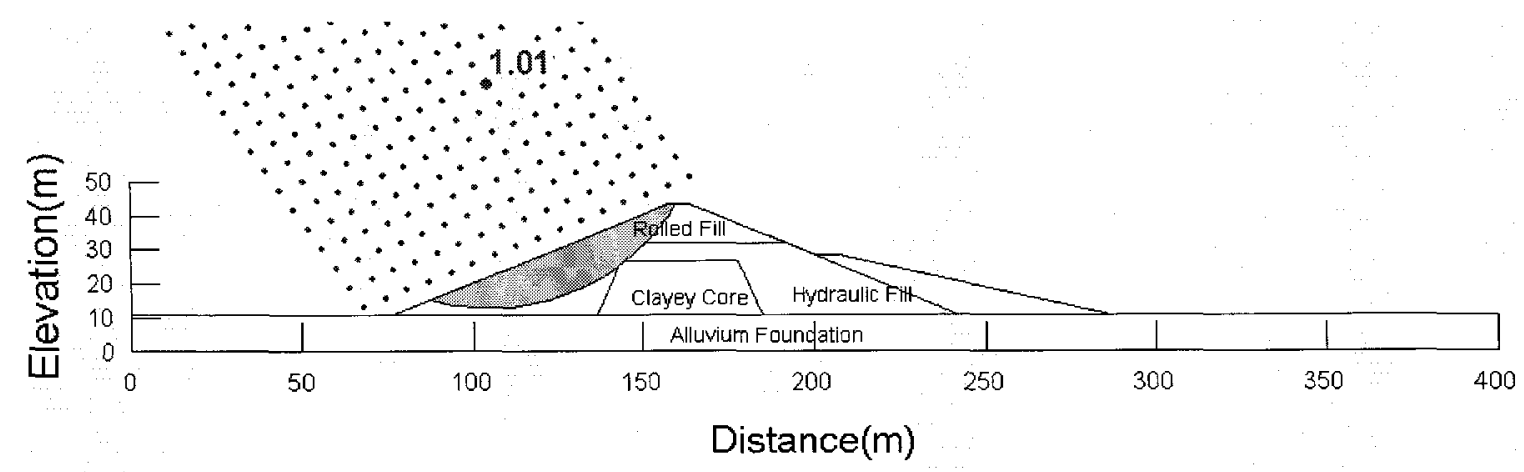

Figure 3.26 Factor of safety for the slip surface closely resembling what was considered by Seed et al. (1973) (from Olson and Stark (2002)) 


\section{CHAPTER 4}

\section{A TYPICAL LIQUEFIABLE DAM IN CANADA}

The analysis of this dam is based on the verified approach of the analysis on Lower San Fernando Dam (LSFD) in Chapter 3. The embankment is constructed from loose to compact fine to medium sand fill and located in a seismic area. Therefore, the fill may be susceptible to liquefaction followed by a flow slide failure under some earthquake conditions. To evaluate the liquefaction triggering, the static analysis with linear-elastic soil modeling and subsequently the dynamic analysis with equivalent-linear modelling have been performed. The results of the dynamic analysis with identified liquefied zones using Quake/W are exported to Slope/W to conduct the static slope stability analysis of the dam. 


\subsection{Geometry and general characteristics of the dam}

\section{Geometry of the dam}

Figure 4.1 and Figure 4.2 show the schematic geometry and the plan of the dam, respectively. The dam has a crest width of $6.00 \mathrm{~m}$ with the height of $6.00 \mathrm{~m}$ from the bottom of the embankment. The slopes of the upstream and downstream sides of the dam are $1: 2$ and $1: 2.5$, respectively.

\section{General aspect}

The embankment is constructed using fill of loose to compact fine to medium sand, with some silt. The Standard Penetration Test (SPT) data of the fill layer varies between 3 and 20 blows $/ 30 \mathrm{~cm}$. This fill overlies a natural layer of dense to very dense silty sand or sandy silt till. Bedrock is suspected below the till. Because of their granular nature, the fill and the underlying soil might be susceptible to liquefaction if subjected to earthquake shaking. Figure 4.3 and Figure 4.4 show the two bore-hole data of SPT results at this site. Comparison of the average $\mathrm{N}$ values from the two bore-holes for different depths in the fill layer is shown in Table 4.1.

Because the fill is built of sand, a considerable amount of seepage would be expected to occur. Field evidence showed no significant seepage on the downstream side or even at the toe after many years of dam operation. This implies that an impervious cutoff may exist in the centre part of the dam. However, existing records do not show the existence of such a cut-off. Therefore, to be conservative, no cut-off has been considered in this analysis. 


\subsection{Applied earthquake record and PGA}

According to the 2005 National Building Code of Canada, it is recommended for seismic analyses, ground motions corresponding to events of a return period of 2,500 years (2\% exceedance in 50 years) be used. As dams are critical structures, it is prudent to analyze them with earthquakes with even longer return period of 10,000 years.

In this research, two sets of earthquake records with a return period of 10,000 years are first applied. According to their epicentral distance, they are known as the farfield ground motion or the near-field ground motion. Each set of ground motions contains ten artificial trials based on the design uniform hazard spectrum at the site. Each of these twenty trials is analysed in order to find the critical (most severe) record for the far- and the near-field ground motions. The characteristics of these two critical records have been summarized in Table 4.2 and their acceleration time histories are shown in Figure 4.5 and Figure 4.6. The acceleration response spectra for these two ground motions, corresponding to five percent damping, have been shown in Figure 4.7.

In the second approach, the ground motions with a return period of 2,500 years are applied. The characteristics associated with two of these motions are given in Table 4.3. Record m6r50t3 is known as the short-period record and Record m7r50t2 is the longperiod record. The acceleration time histories of these two ground motions are shown in Figure 4.8 and Figure 4.9. Their acceleration response spectra, corresponding to five percent damping, have been shown in Figure 4.10.

\subsection{Soil parameters}

No in-situ and laboratory except the SPT test data are available for the layers of the dam. Therefore, all necessary parameters are obtained from the correlations and 
information in the existing literature. The determination of the parameters of each layer is discussed in the following.s

\section{- Upper layer:}

\section{Unit weight}

The unit weight of the loose to compact fine sandy fill with $\mathrm{N}=7$ blows $/ 30 \mathrm{~cm}$, according to Das (1998) and Budhu (2000), is considered equal to $17 \mathrm{kN} / \mathrm{m}^{3}$.

\section{$\left(\mathrm{N}_{1}\right)_{60}$ values and friction angle}

The standardized $\mathrm{N}$ values, $\left(\mathrm{N}_{1}\right)_{60}$, are determined using Equation 4.1 where $\mathrm{C}_{\mathrm{N}}$ is the correction factor for the effective overburden pressure (see Equation 2.3). $\mathrm{N}_{60}$ is determined from Equation 4.2.

$\left(N_{1}\right)_{60}=C_{N} N_{60}$

$N_{60}=\Psi N$

The values of $\Psi$, for the safety and the donut hammer, are approximately equal to 1.0 and 0.75 , respectively (Seed et al., 1985).

The drained friction angles of the layers of the dam are determined from the proposed equation by Wolff (1989), which associates friction angle with $\mathrm{N}_{1}$ (Equation 4.3).

$$
\phi(\operatorname{deg})=27.1+0.3 N_{1}-0.00054 N_{1}^{2}
$$

where $\mathrm{N}_{1}$ is determined from Equation 4.4.

$$
N_{1}=C_{N} N
$$

To determine $\left(\mathrm{N}_{1}\right)_{60}$ and the friction angle, both the fill and the till layers are divided into sixty centimetres thick sub-layers with their own specific $\mathrm{N}_{\text {ave }}$ values. Then, by knowing 
the unit weight of each sub-layer and the pore water pressure distribution, the vertical effective stress $\left(\sigma_{v o}^{\prime}\right)$ associated with that sub-layer is determined and used in calculating $C_{N}$. The value of $\Psi$ for this case is assumed to be equal to 1.0. The results of this exercise are shown in Table 4.4.

\section{Poisson's ratio}

According to Das (1998) for medium sand, the value of Poisson's ratio is between 0.25 and 0.40 and for loose sand or silty sand it is between 0.20 and 0.40 . For this study, the Poisson's ratio is considered to be 0.40 .

\section{Modulus of Elasticity}

Budhu (2000) suggested values between 20 and $40 \mathrm{MPa}$ for medium sands, while Das (1998) suggested values between 34.5 and $69 \mathrm{MPa}$ for dense sands and values between 10.35 and 27.6 MPa for loose sands. Therefore, for the fill layer which is between loose and dens sand, Young's modulus is considered equal to $30 \mathrm{MPa}$.

$\mathbf{K}_{2 \max }$

$\mathrm{K}_{2 \max }$ is required in the dynamic analysis. In order to determine this parameter, a correlation by Seed and Idriss 1970 and shown in Table 4.5 is used. In this table, $\mathrm{K}_{2 \max }$ is correlated with the relative density of the soil, which can be obtained from Table 4.6 taken from Tokimatsu and Seed (1987). Hence, the calculated $K_{2 \max }$ are shown in Table 4.7 with an average $\mathrm{K}_{2 \max }$ equal to 48 for the whole fill layer.

\section{Initial damping ratio $(\xi)$}

An initial damping ratio $(\xi)$ is first estimated to begin the iterative process. This initial damping ratio has been obtained via Equation 3.2 and 3.3 that use the plasticity index (PI), cyclic shear strain $\left(\gamma_{c}\right)$, and effective confining pressure $\left(\sigma_{m}^{\prime}\right)$. The PI for this 
layer is assumed equal to zero, as this layer is a mixture of sand and gravel. The cyclic shear strain is assumed to be $0.01 \%$ for obtaining the initial damping ratio. The effective confining pressure can be determined for each sub-layer and, consequently, for the whole layer. The summary of determining the initial damping ratio is shown in Table 4.8. From these data the average initial damping ratio has been found to be $7 \%$.

An attempt to estimate the initial damping ratio has been made using the method by Vucetic and Dobry (1991). This method correlates the damping ratio with the OCR, PI and the cyclic shear strain $\left(\gamma_{c}\right)$. This method also yields an initial damping ratio equal to $7 \%$ is correct.

The estimated damping ratio is applied in the iterative procedure during the equivalent-linear analysis. In the first iteration, the cyclic shear strain is obtained based on the initial shear modulus and damping ratio. Then, the new shear modulus and damping ratio are computed from the obtained cyclic shear strain. A new dynamic loading analysis starts with the new shear modulus and the damping ratio. This iterative process is repeated until the changes in displacements within two successive iterations are negligible.

\section{$K_{\sigma}$ correction function}

To define the $K_{\sigma}$ correction function, Equation 2.17 by Youd and Idriss (2001) is used. They recommended that the following "f" values for applying the equation:
for
$40 \%<\mathrm{D}_{\mathrm{r}}<60 \%, 0.7<\mathrm{f}<0.8 ;$ and
for
$60 \%<\mathrm{D}_{\mathrm{r}}<80 \%, 0.6<\mathrm{f}<0.7$. 
For the fill having a relative density of $54 \%$ (Table 4.7 ), the value of " $\mathrm{f}$ " is found to be 0.73 based on interpolation. Then, the values of $K_{\sigma}$ have been determined for different effective overburden pressures and are shown in Figure 4.11.

\section{$\mathbf{K}_{\alpha}$ correction function}

According to Figure 2.6 and based on the fill relative density being equal to $54 \%$, the appropriate $\mathrm{K}_{\alpha}$ function has been determined as shown in Figure 4.12. It should be noted that the function presented in Figure 2.6 is based on the data for conditions where $\sigma_{0}^{\prime}<300 \mathrm{kPa}$ and are appropriate only for these conditions (Seed and Harder, 1990). For this layer the maximum value of static overburden pressure is $60 \mathrm{kPa}$ which fulfills the condition.

\section{Cyclic number function}

The cyclic number function of this layer is taken from the work by Seed and his colleagues in 1975. They presented different cyclic number functions with respect to different relative densities. The appropriate function for the fill layer is shown in Figure 4.13.

\section{Pore pressure function}

The pore pressure function is determined from Equation 2.22. The function is common for both the fill layer and the till layer. The cyclic number ratio to be applied to Equation 2.22, however, is different to reflect the differences in the characteristics of the soils. The relationship between the pore pressure ratio and the cyclic number ratio is shown in Figure 4.14 . 


\section{$G$ reduction function}

The $G$ reduction function is obtained based on the work of Vucetic and Dobry (1991), in which the function is dependent on the PI and the confining stress on the soil. The appropriate function is shown in Figure 4.15.

\section{Damping ratio function}

The damping ratio function is obtained in the same way as the $\mathrm{G}$ reduction function based on the work of Vucetic and Dobry (1991). Figure 4.16 shows the selected function for the fill layer.

\section{- Lower layer (till):}

\section{Unit weight}

The lower layer of soil is a dense to very dense till with an average $\mathrm{N}$ value of 50 blows $/ 30 \mathrm{~cm}$. Based on Budhu's (2000) suggestion, the unit weight of this layer is assumed equal to $21 \mathrm{kN} / \mathrm{m}^{3}$.

\section{$\left(\mathbf{N}_{1}\right)_{60}$ values and friction angle}

From Equation 4.1 to Equation 4.4, the standardized $\mathrm{N}$ value and drained friction angle of the soil are determined and have been summarized in Table 4.9 (the rows with bold numbers describe this layer).

\section{Poisson's ratio}

For dense sands, Das (1998) suggested that Poisson's ratio ranges from 0.3-0.45. Therefore, the value of 0.41 is selected for the lower layer. 


\section{Modulus of elasticity}

Budhu (2000) suggested values between 40 and $80 \mathrm{MPa}$ for the modulus of dense sand while Das (1998) recommended values between 34.5 and $69 \mathrm{MPa}$. Therefore, for this layer, Young's modulus is taken at $50 \mathrm{MPa}$.

$\mathbf{K}_{2 \max }$

From Table 4.9 , it appears that the minimum $\left(\mathrm{N}_{1}\right)_{60}$ is 40 blows $/ 30 \mathrm{~cm}$ for this layer. According to Table 4.6 (Tokimatsu and Seed, 1987), this $\left(\mathrm{N}_{1}\right)_{60}$ value already corresponds to the densest state, which in turn related to the highest value of $K_{2 \max }$ of 70 . Therefore, $\mathrm{K}_{2 \max }$ is set to 70 for this whole layer.

\section{Initial damping ratio $(\xi)$}

By considering PI equal to 5, the damping ratio of this layer is estimated in a way similar to what has been employed for the fill layer. The estimated damping ratio is listed in Table 4.10 (the rows with bold numbers describe this layer).

\section{$\mathbf{K}_{\sigma}$ correction function}

Like what has been developed for the upper layer, this function is determined with "f" equal to 0.55 , which corresponds to a relative density of $90 \%$. The function is shown in Figure 4.17.

\section{$\mathbf{K}_{\alpha}$ correction function}

This function is not applicable because this layer is largely horizontal.

\section{Cyclic number function}

By using the suggested correlation by Seed et al. in 1975, the cyclic number function of the soil with the relative density of $90 \%$ has been determined and is shown in Figure 4.18. 


\section{Pore pressure function}

The pore pressure function is assumed the same as that for the fill layer as presented in Figure 4.14.

\section{G reduction function}

The process for defining the $\mathrm{G}$ reduction function for this layer is the same as what has been used for the upper layer, except that the PI of 5 has been considered. The relevant function of the soil is shown in Figure 4.19.

\section{Damping ratio function}

By assuming PI equal to 5, the damping ratio function of the till layer is derived in a way similar to what has been determined for the fill layer. The resulted function is shown in Figure 4.20.

\subsection{Initial static analysis}

The main points of the initial static analysis have been described in section 3.3. Similar to analysing Lower San Fernando Dam, a linear-elastic soil model is selected for this analysis. The phreatic surface in the dam is shown in Figure 4.1. The data were taken in October and can be considered to represent the maximum water level. The equivalent numbers of cycles of the ground motions are shown in Table 4.2 and Table 4.3. The boundary conditions for the static analysis are the same as those employed for the LSFD analysis. The appropriate soil parameters for this static analysis are presented in Table 4.11. The defined finite element mesh for the static and dynamic analyses is shown in Figure 4.21 and the vertical effective stresses are shown in Figure 4.22. 


\subsection{Dynamic analysis}

The considerations and theories for this analysis have been described and illustrated in Chapter 3. The equivalent-linear soil model is used in this analysis. The dynamic parameters of each layer of soils are summarized in Table 4.12. The boundary conditions for the analysis are similar to those for analysing LSFD. To reduce the effect of wave reflection in dynamic analysis, these boundaries are applied at a distance of around 75 metres from the toe of the dam.

The results of the dynamic analysis of this dam for the liquefaction initiation based on the near- and the far-field ground motions with return period of 10,000 years are shown in Figure 4.23 and Figure 4.24, respectively. The results show that both the nearand the far-field ground motions will give rise to liquefaction failure in a large part of the dam. The results also show that the far-field ground motion gives even larger liquefaction failure than the near-field ground motion.

For the ground motions with a return period of 2,500 years, the results are shown in Figure 4.25 and Figure 4.26 for the short- and the long-period ground motions, respectively. As shown in these two figures, the long-period earthquake causes much larger liquefaction failure than the short-period earthquake.

\subsection{Slope stability of the dam}

After the evaluation of liquefaction initiation, the stability analysis of the dam is performed. The main assumptions and techniques are similar to what have been applied for LSFD. As the liquefied area due to some of the earthquakes extends near the downstream side of the dam, the factor of safety against flow failure has been assessed 
for both the upstream and the downstream sides of the dam and using both the approaches of Seed and Harder (1990) and Olson and Stark (2002).

\subsubsection{Input file for the stability analysis}

\section{Analysis setting}

Like the stability analysis of LSFD, the static finite element stress option is chosen in Slope/W for this stability analysis. The pore pressures and stresses of the last time sequence of the dynamic analysis are imported to the slope stability file.

\section{Soil parameters}

Based on the reasons given for analysing LSFD, drained soil parameters are applied to the non-liquefied soils and are listed in Table 4.11.

\section{Liquefied shear strength}

The liquefied strength is applied to the liquefied regions. As described in Chapter 3 , there are two approaches to determine the liquefied shear strength. Both approaches have been applied in this stability analysis. The analyses based on these two approaches are described in the following.

\section{Method of Seed and Harder (1990)}

By knowing the representative $\left(\mathrm{N}_{1}\right)_{60}$ of the liquefied layer and correcting for the effect of fines contents, the liquefied shear strength is determined from Figure 2.9. From Table 4.4 , the representative $\left(\mathrm{N}_{1}\right)_{60}$ of the fill layer is 12 . For a conservative assumption, the fine contents of this layer are assumed to be zero. Therefore, from Figure 2.9 the average value of the undrained liquefied shear strength of this layer will be $19.5 \mathrm{kPa}$ and is applied in the stability analysis of the dam. The factors of safety for the upstream side of the dam based on this average value and corresponding to the near- and the far-field 
ground motions are 1.50 and 1.47, respectively and shown in Figure 4.27 and Figure 4.28. The factors of safety for the downstream side of the dam based on the undrained shear strength of $19.5 \mathrm{kPa}$ and corresponding to the near- and far-field ground motions are 1.40 and 1.42, respectively and shown in Figure 4.29 and Figure 4.30.

The lower and upper bounds of the liquefied strength are $9.8 \mathrm{kPa}$ and $31.7 \mathrm{kPa}$, respectively. Since the factors of safety with the average residual strength are quite large, no stability analysis with the upper bound is performed. The results of the analysis related to the lower bound are shown from Figure 4.31 to Figure 4.34 for both sides of the dam and for the near- and the far-field ground motions.

The analyses show no failure occurrence in either the upstream or the downstream side of the dam for the ground motions with return period of 10,000 years. Therefore, no analysis using the ground motions with return period of 2,500 years has been carried out.

\section{Method of Olson and Stark (2002)}

This approach gives the liquefied shear strength ratio based on SPT data. From Equation 2.21, the average liquefied strength ratio of the fill layer with $\left(\mathrm{N}_{1}\right)_{60}$ of 12 is 0.12. From Figure 4.35, the pre-earthquake vertical effective stress, $\sigma_{v 0}^{\prime}$, in the mid-depth of the liquefied area is $49 \mathrm{kPa}$. This amount is associated with the far- and near-field earthquakes with a return period of 10,000 years and the long-period ground motion with a return period of 2,500 years. Therefore, the liquefied strength is obtained to be $5.9 \mathrm{kPa}$. The short-period ground motion with a $2 \%$ exceedance in 50 years causes a limited area of the dam to be liquefied, Figure 4.25 . The representative effective overburden pressure of the liquefied regions due to this earthquake is $34 \mathrm{kPa}$ and the liquefied shear strength of this zone will be $4.08 \mathrm{kPa}$. 
Figure 4.36 to Figure 4.39 show the results of slope stability analysis for the upstream and the downstream sides of the dam based on the near- and the far-field ground motions. Also, the results of stability analysis for the upstream and the downstream sides of the dam for the short- and the long-periods have been shown in Figure 4.40 to Figure 4.43 . Based on this approach, the critical factor of safety for the upstream side of the dam is 0.71 which corresponds to the far-field ground motion with return period of 10,000 years and long-period ground motion with return period of 2,500 years. The critical factor of safety for the downstream side is 0.96 which corresponds to the far-field ground motion with return period of 10,000 years.

\section{Analysis with different soil parameters}

More analyses have been conducted with different shear modulus, Poisson's ratio, and Plasticity Index (PI) to cover possible variation of the parameters to evaluate their effects on the stability of the dam. The factors of safety are determined for the upstream side of the dam based on the far-field ground motion with the return period of 10,000 years. To change the reference shear modulus of the soil, the power of the term $\sigma_{m}^{\prime}$ in Equation 3.1 is changed from 0.5 to 0.32 and 0.60 . This produces modulus values $50 \%$ lower and 50\% higher than the reference value, respectively. The results are summarized in Table 4.15 and show no significant change in the factor of safety computed based on the Seed and Harder's (1990) approach and Olson and Stark's (2002) approach. The results of analysis using the ranges of Poisson's ratio and PI are shown in Tables 4.16 and 4.17. A comparison of the results shows that the safety factor is not sensitive to variations of these two parameters within the expected range. 


\subsection{Discussion}

To compare the stability analysis results, the factors of safety based on the preearthquake condition and the near- and the far-field ground motions are summarized in Table 4.13. Also the factors of safety based on the short- and the long-period ground motions are shown in Table 4.14.

Seed and Harder (1990) and Olson and Stark (2002) approaches give nearly the same results for LSFD. For this case, however, they give different safety factors against flow failure. Hence, it is necessary to investigate the strong and weak points of these two methods to make a final judgment about the stability of the dam.

Some weak and strong points of these two approaches have been presented in section 2.2.3. Olson and Stark (2002) mentioned some of the uncertainties in the Seed and Harder (1990) approach. First, all the selected case histories by Seed and Harder (1990) are not liquefaction flow failure and 6 of them involve liquefaction-induced lateral spreading. Stark and his colleagues (1998) believe that the calculated liquefied shear strength from lateral spreading cases may not correspond to the shear strength of liquefaction flow failure. Second, the proposed correlation by Seed and Harder (1990) is based on the Seed's (1987) approach. Back-calculating the case histories, Seed (1987) used pre-failure geometry of some cases while post-failure geometry for the most of them. The study of these inconsistent geometries can cause some uncertainties in the presented correlation for determination of liquefied shear strength. Third, for selecting the representative $\left(\mathrm{N}_{1}\right)_{60}$ of 7 out of 17 cases, Seed and Harder (1990) were obliged to select the representative $\left(\mathrm{N}_{1}\right)_{60}$ value based on the relative density and for many of the other cases use a limited number of SPT data. This limitation in available SPT data causes 
some uncertainties in the correlation for the liquefied shear strength. They admitted that the proposed correlation may give higher liquefied strength than the actual value. Therefore, they recommended that "the lower-bound, or near lower-bound relationship between $\mathrm{S}_{\mathrm{r}}$ [liquefied shear strength] and $\left(\mathrm{N}_{1}\right)_{60-\mathrm{cs}}$ be used..." (Seed and Harder, 1990).

Olson and Stark (2002), on the other hand, developed back-analysis of thirty-three case histories of the liquefaction flow failures involving loose clean sands, silty sands, sandy silts, and tailing sands. In their analysis, they excluded the lateral spreading case histories. They applied three levels of stability analysis during the back-calculation: the simplified stability analysis, the rigorous stability analysis, and the stability analysis incorporating the kinetics of the failure mass movements. Depending on the available details and information, the appropriate method of analysis was selected for each case history. For 10 out of 33 cases, sufficient penetration test data were available and for these 10 cases they incorporated the kinetics analysis. For 21 out of 33 cases, they used the rigorous stability analysis proposed by Olson (2001). For the rest of the cases they applied the simplified method to assess the mobilized shear strength during liquefaction flow failure.

The tenet of determining the liquefied shear strength is different in Seed and Harder (1990) and Olson and Stark (2002) approaches. With a certain $\left(\mathrm{N}_{1}\right)_{60}$, Seed and Harder's (1990) approach gives the absolute value of the liquefied (residual) shear strength, while Olson and Stark's (2002) approach gives the ratio of liquefied shear strength over the initial vertical effective stress. Conceptually, the liquefied shear strength of many contractive cohesionless soils is linearly proportional to the major principal effective stress after consolidation (Ishihara, 1993; Baziar and Dobry, 1995; Vaid and 
Sivathayalan, 1996) and therefore, is proportional to the pre-failure vertical effective stress (Olson and Stark, 2002).

A comparison of liquefied shear strengths with respect to $\left(\mathrm{N}_{1}\right)_{60}$ based on the approaches of Seed and Harder (1990) and of Olson and Stark (2002) are shown in Figure 4.44. Five vertical effective stresses of $50,100,150,160$, and $200 \mathrm{kPa}$ are considered to determine the liquefied strength with Olson and Stark's (2002) approach. The results clearly show that the Seed and Harder's (1990) approach underestimates the average liquefied shear strength at high confining pressures, which are associated with large structures, as indicated by Olson and Stark (2002). This is particularly true if the lower bound of their approach is used. On the other hand, this comparison shows that at lower confining pressures that are associated with small structures, the Seed and Harder's approach may produce overestimated strengths.

For the fill layer of the Canadian dam under study, $\left(\mathrm{N}_{1}\right)_{60}$ is 12 blows $/ 30 \mathrm{~cm}$ and $\sigma^{\prime}{ }_{v 0}$ is $49 \mathrm{kPa}$, for these values, the comparison shows that two significantly different liquefied shear strengths are obtained from the two approaches. The Seed and Harder's (1990) approach yields an average and lower bound liquefied strengths of $19.5 \mathrm{kPa}$ and $9.8 \mathrm{kPa}$, respectively. On the other hand, the Olson and Stark's (2002) approach gives an average liquefied strength of $5.9 \mathrm{kPa}$. Hence as noted before for small structures, the Seed and Harder (1990) approach gives an overestimated liquefied strength. Because of this reason, the results based on the Olson and Stark's (2002) approach is considered more credible. As the critical factors of safety based on this approach for the upstream and downstream sides of the dam at the end of the far-field earthquake are 0.71 and 0.96 , respectively, this dam will likely fail when it is subjected to the design earthquakes. 
Because of the likelihood of liquefaction flow failure under the design earthquakes, some remedial measures should be considered. The use of stabilizing berms and recompaction of the original loose fill of the dam are the two common applicable techniques. Some exercises in applying these remedial methods will be described in the next chapter. 
Table 4.1 Average $\mathrm{N}$ value from two the bore-hole data for different depths of the fill of the dam

\begin{tabular}{|c|c|c|}
\hline depth(ft) & depth(m) & $\mathrm{N}_{\text {ave }}$ \\
\hline 2 & 0.6 & 9 \\
\hline 4 & 1.2 & 9 \\
\hline 6 & 1.8 & 13 \\
\hline 8 & 2.4 & 13 \\
\hline 10 & 3.0 & 6 \\
\hline 12 & 3.7 & 6 \\
\hline 14 & 4.3 & 4 \\
\hline 16 & 4.9 & 4 \\
\hline 18 & 5.5 & 5 \\
\hline 20 & 6.1 & 5 \\
\hline Average for the whole fill & & 7 \\
\hline
\end{tabular}


Table 4.2 Characteristics of the critical records for both near- and far-field ground motions with $0.5 \%$ exceedance in 50 years

\begin{tabular}{|l|c|c|}
\hline Characteristics & Near-field & Far-field \\
M5.5R13\#9 & M7R40\#9 \\
\hline Magnitude & 5.5 & 7.0 \\
\hline Epicentre Distance (km) & 13 & 40 \\
\hline Peak Horizontal Acceleration (g) & 0.524 & 0.326 \\
\hline Duration (sec) & 6.34 & 20.75 \\
\hline Equivalent number of cycles & 3.3 & 10 \\
\hline
\end{tabular}

Table 4.3 Characteristics of the critical records for both Short- and long-period ground motions with $2 \%$ exceedance in 50 years

\begin{tabular}{|l|c|c|}
\hline \multicolumn{1}{|c|}{ Characteristics } & $\begin{array}{c}\text { Short-period } \\
\text { M6R50\#3 }\end{array}$ & $\begin{array}{c}\text { Long-period } \\
\text { M7R50\#2 }\end{array}$ \\
\hline Magnitude & 6.0 & 7.0 \\
\hline Epicentre Distance (km) & 50 & 50 \\
\hline Peak Horizontal Acceleration (g) & 0.283 & 0.379 \\
\hline Duration (sec) & 12.39 & 20.54 \\
\hline Equivalent number of cycles & 3.9 & 10 \\
\hline
\end{tabular}


Table 4.4 Determination of $\left(\mathrm{N}_{1}\right)_{60}$ and the friction angle

\begin{tabular}{|c|c|c|c|c|c|c|c|c|}
\hline Depth(m) & $\mathrm{N}_{\text {ave }}$ & $\gamma\left(\mathrm{kN} / \mathrm{m}^{3}\right)$ & $\sigma_{\mathrm{v} 0}^{\prime}(\mathrm{kPa})$ & $\mathrm{C}_{\mathrm{N}}$ & $\Psi$ & $\mathrm{N}_{1}$ & $\left(\mathrm{~N}_{1}\right)_{60}$ & $\phi(\mathrm{deg})$ \\
\hline 0.6 & 9 & 17 & 5.18 & 1.70 & 1 & 15 & 15 & 32 \\
\hline 1.2 & 9 & 17 & 15.54 & 1.70 & 1 & 15 & 15 & 32 \\
\hline 1.8 & 13 & 17 & 25.91 & 1.70 & 1 & 22 & 22 & 33 \\
\hline 2.4 & 13 & 17 & 32.95 & 1.70 & 1 & 22 & 22 & 33 \\
\hline 3.0 & 6 & 17 & 37.33 & 1.64 & 1 & 10 & 10 & 30 \\
\hline 3.7 & 6 & 17 & 41.72 & 1.55 & 1 & 9 & 9 & 30 \\
\hline 4.3 & 4 & 17 & 46.10 & 1.47 & 1 & 6 & 6 & 29 \\
\hline 4.9 & 4 & 17 & 50.48 & 1.41 & 1 & 6 & 6 & 29 \\
\hline 5.5 & 5 & 17 & 54.87 & 1.35 & 1 & 7 & 7 & 29 \\
\hline 6.1 & 5 & 17 & 59.25 & 1.30 & 1 & 6 & 6 & 29 \\
\hline Average & 7 & 17 & 37 & & & 12 & 12 & 31 \\
\hline
\end{tabular}

Table 4.5 Variation of $\mathrm{K}_{2 \max }$ with respect to relative density (Seed and Idriss, 1970)

\begin{tabular}{|c|c|c|c|c|c|c|}
\hline $\mathrm{Dr} \%$ & 30 & 40 & 45 & 60 & 75 & 90 \\
\hline $\mathrm{K}_{2 \max }$ & 34 & 40 & 43 & 52 & 59 & 70 \\
\hline
\end{tabular}


Table 4.6 Correlation between $\left(\mathrm{N}_{1}\right)_{60}$ and relative density (Tokimatsu and Seed, 1987)

\begin{tabular}{|c|c|c|}
\hline$\left(\mathrm{N}_{1}\right)_{60}$ (blows/30cm) & Sand density & Relative density, $\mathrm{D}_{\mathrm{r}} \%$ \\
\hline $0-2$ & Very loose condition & $0-15$ \\
\hline $2-5$ & Loose condition & $15-35$ \\
\hline $5-20$ & Medium condition & $35-65$ \\
\hline $20-35$ & Dense condition & $65-85$ \\
\hline Over 35 & Very dense condition & $85-100$ \\
\hline
\end{tabular}


Table 4.7 Determined relative densities and $\mathrm{K}_{2 \max }$ in each depth interval of the fill layer

\begin{tabular}{|c|c|c|c|}
\hline depth(m) & $\left(\mathrm{N}_{1}\right)_{60}$ & $\mathrm{D}_{\mathrm{r}} \%$ & $\mathrm{~K}_{2 \max }$ \\
\hline 0.6 & 15 & 55 & 49 \\
\hline 1.2 & 15 & 55 & 49 \\
\hline 1.8 & 22 & 69 & 56 \\
\hline 2.4 & 22 & 69 & 56 \\
\hline 3.0 & 10 & 45 & 43 \\
\hline 3.7 & 10 & 45 & 43 \\
\hline 4.3 & 6 & 37 & 38 \\
\hline 4.9 & 6 & 37 & 38 \\
\hline 5.5 & 7 & 39 & 39 \\
\hline 6.1 & 6 & 39 & 39 \\
\hline Average & 12 & 54 & 48 \\
\hline
\end{tabular}




\begin{tabular}{|c|c|c|c|c|c|c|c|c|c|c|c|}
\hline wr & $\frac{O}{0}$ & 足 & Oे & $\overbrace{0}^{\circ}$ & $\stackrel{\circ}{\circ}$ & 8 & $\begin{array}{l}8 \\
0 \\
0\end{array}$ & $\underset{0}{8}$ & : & $\begin{array}{l}0 \\
0 \\
0\end{array}$ & io \\
\hline$\underbrace{\stackrel{.}{J}}_{\circlearrowleft}$ & $\frac{F}{N}$ & $\begin{array}{l}\frac{n}{n} \\
0 \\
0 \\
0\end{array}$ & $\mid \begin{array}{l}\hat{b} \\
\infty \\
0 \\
0\end{array}$ & $\frac{\overrightarrow{2}}{\frac{2}{0}}$ & $\frac{\partial}{\tilde{\sigma}}$ & $\begin{array}{l}\infty \\
\infty \\
\stackrel{N}{0} \\
\dot{0}\end{array}$ & $\frac{m}{\frac{n}{2}}$ & $\frac{\frac{\infty}{+}}{\frac{D}{0}}$ & $\begin{array}{l}\frac{m}{n} \\
\frac{n}{0} \\
\dot{0}\end{array}$ & $\frac{n}{n}$ & \\
\hline $\begin{array}{l}\widehat{a} \\
\frac{\vec{a}}{\Delta}\end{array}$ & 尚 & $\begin{array}{l}n \\
0 \\
n \\
0\end{array}$ & 苢 & 旡 & 象 & 旾 & $\begin{array}{l}n \\
8 \\
n \\
0\end{array}$ & $\begin{array}{l}n \\
0 \\
n \\
0\end{array}$ & $\begin{array}{l}n \\
\delta \\
n \\
0\end{array}$ & $\begin{array}{l}n \\
\tilde{8} \\
\tilde{n} \\
0\end{array}$ & \\
\hline 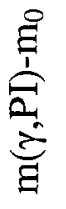 & $\underset{0}{0}$ & $\bar{z}$ & $\vec{z}$ & $\overrightarrow{\ddot{0}}$ & 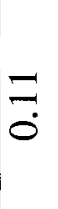 & $=$ & $\vec{\Xi}$ & $\overrightarrow{\overrightarrow{0}}$ & $\overline{0}$ & $\overrightarrow{7}$ & \\
\hline$\underset{\Xi}{\stackrel{\Xi}{\Xi}}$ & 0 & 10 & 0 & 10 & 0 & 10 & 0 & 10 & 10 & 10 & \\
\hline 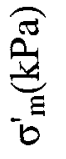 & $\tilde{m}$ & $\stackrel{2}{\stackrel{0}{0}}$ & $\mid \begin{array}{l}\infty \\
\\
ٍ\end{array}$ & 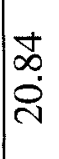 & $\mid \begin{array}{l}\partial \\
\stackrel{\sim}{\sim}\end{array}$ & $\mid \begin{array}{l}\infty \\
\infty \\
\\
\end{array}$ & 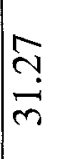 & 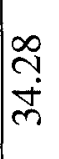 & $\begin{array}{l}\infty \\
0 \\
\infty \\
\text { m. }\end{array}$ & $\mid \begin{array}{l}\infty \\
0 \\
0 \\
\\
\end{array}$ & $\mid \begin{array}{l}\text { ర్ } \\
\stackrel{J}{d}\end{array}$ \\
\hline $\begin{array}{l}\frac{\pi}{\pi} \\
0 \\
0 \\
0 \\
0\end{array}$ & $\underset{\sim}{\tilde{\gamma}}$ & 导 & 尚 & $\mid \begin{array}{l}\infty \\
\pm \\
\Xi\end{array}$ & $\begin{array}{l}\mathbf{\sigma} \\
\infty \\
\infty\end{array}$ & 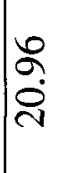 & $\begin{array}{l}\infty \\
\infty \\
\infty \\
\end{array}$ & $\frac{\infty}{\stackrel{\infty}{\sim}}$ & $\mid \begin{array}{c}\infty \\
\stackrel{\infty}{\sim} \\
\stackrel{\infty}{\sim}\end{array}$ & 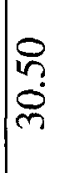 & \\
\hline i & $\mid \begin{array}{l}\infty \\
+ \\
0\end{array}$ & $\stackrel{\infty}{\stackrel{\infty}{0}}$ & $\stackrel{n}{\mathscr{0}}$ & $\stackrel{n}{+}$ & in & non & ח & ñ & $\tilde{n}$ & $\tilde{n}$ & 守 \\
\hline$\underbrace{\stackrel{\overbrace{}}{\Xi}}_{\theta}$ & ñ & 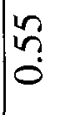 & 文 & $\mid$\begin{tabular}{l}
$\infty$ \\
$n$ \\
\hdashline
\end{tabular} & ñ & ñ & గin & ஜ̊ & $\tilde{n}$ & $\tilde{n}$ & 苞 \\
\hline$\frac{800}{\frac{d}{\sigma}}$ & N & लै & $m$ & $m$ & প্ & p & İ & શิ & જે & શิ & $\bar{m}$ \\
\hline$\frac{8}{2}$ & n & $\stackrel{n}{2}$ & N & ヘิ & $\stackrel{ }{=}$ & $a$ & 0 & 0 & $r$ & 0 & 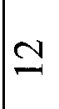 \\
\hline 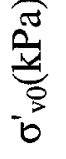 & $\frac{\infty}{\dot{v}}$ & $\begin{array}{l}\dot{v} \\
\stackrel{n}{2}\end{array}$ & $\begin{array}{l}\vec{a} \\
\ddot{n} \\
\tilde{1}\end{array}$ & $\begin{array}{l}n \\
\tilde{c} \\
\tilde{n}\end{array}$ & $\frac{m}{m}$ & $\frac{N}{\dot{\gamma}}$ & $\frac{0}{0}$ & $\underset{\stackrel{\infty}{+}}{\stackrel{\infty}{\circ}}$ & $\begin{array}{l}\infty \\
\dot{1} \\
\dot{1}\end{array}$ & $\begin{array}{l}n \\
n \\
0 \\
n \\
n\end{array}$ & $\hat{m}$ \\
\hline 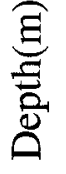 & $\begin{array}{l}0 \\
0\end{array}$ & $\stackrel{\text { I }}{\sim}$ & $\stackrel{\infty}{-}$ & $\stackrel{\Delta}{\sim}$ & ri & $\vec{r}$ & $\stackrel{m}{7}$ & $\dot{\gamma}$ & $n$ & $\mid \begin{array}{l}0 \\
8 \\
0 \\
0\end{array}$ & 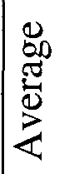 \\
\hline
\end{tabular}


Table $4.9 \quad\left(\mathrm{~N}_{1}\right)_{60}$ value and friction angle determination of lower layer

\begin{tabular}{|c|c|c|c|c|c|c|c|c|}
\hline $\operatorname{Depth}(\mathrm{m})$ & $\mathrm{N}_{\mathrm{ave}}$ & $\gamma\left(\mathrm{kN} / \mathrm{m}^{3}\right)$ & $\sigma_{\mathrm{v} 0}^{\prime}(\mathrm{kPa})$ & $\mathrm{C}_{\mathrm{N}}$ & $\Psi$ & $N_{1}$ & $\left(\mathrm{~N}_{1}\right)_{60}$ & $\phi(\mathrm{deg})$ \\
\hline 0.6 & 9 & 17 & 5.18 & 1.70 & 1 & 15 & 15 & 32 \\
\hline 1.2 & 9 & 17 & 15.54 & 1.70 & 1 & 15 & 15 & 32 \\
\hline 1.8 & 13 & 17 & 25.91 & 1.70 & 1 & 22 & 22 & 33 \\
\hline 2.4 & 13 & 17 & 32.95 & 1.70 & 1 & 22 & 22 & 33 \\
\hline 3.0 & 6 & 17 & 37.33 & 1.64 & 1 & 10 & 10 & 30 \\
\hline 3.7 & 6 & 17 & 41.72 & 1.55 & 1 & 9 & 9 & 30 \\
\hline 4.3 & 4 & 17 & 46.10 & 1.47 & 1 & 6 & 6 & 29 \\
\hline 4.9 & 4 & 17 & 50.48 & 1.41 & 1 & 6 & 6 & 29 \\
\hline 5.5 & 5 & 17 & 54.87 & 1.35 & 1 & 7 & 7 & 29 \\
\hline 6.1 & 5 & 17 & 59.25 & 1.30 & 1 & 6 & 6 & 29 \\
\hline 6.71 & 35 & 21 & 64.85 & 1.24 & 1 & 43 & $\overline{43}$ & 39 \\
\hline 7.32 & 35 & 21 & 71.67 & 1.18 & 1 & 41 & 41 & 39 \\
\hline 7.92 & 35 & 21 & 78.49 & 1.13 & 1 & 40 & 40 & 38 \\
\hline 8.53 & 64 & 21 & 85.32 & 1.08 & 1 & 69 & 69 & 45 \\
\hline 9.14 & 64 & 21 & 92.14 & 1.04 & 1 & 67 & 67 & 45 \\
\hline 9.75 & 64 & 21 & 98.96 & 1.01 & 1 & 64 & 64 & 44 \\
\hline $\begin{array}{l}\text { Average for till } \\
\text { layer }\end{array}$ & 50 & 21 & & & & 54 & 54 & 42 \\
\hline
\end{tabular}




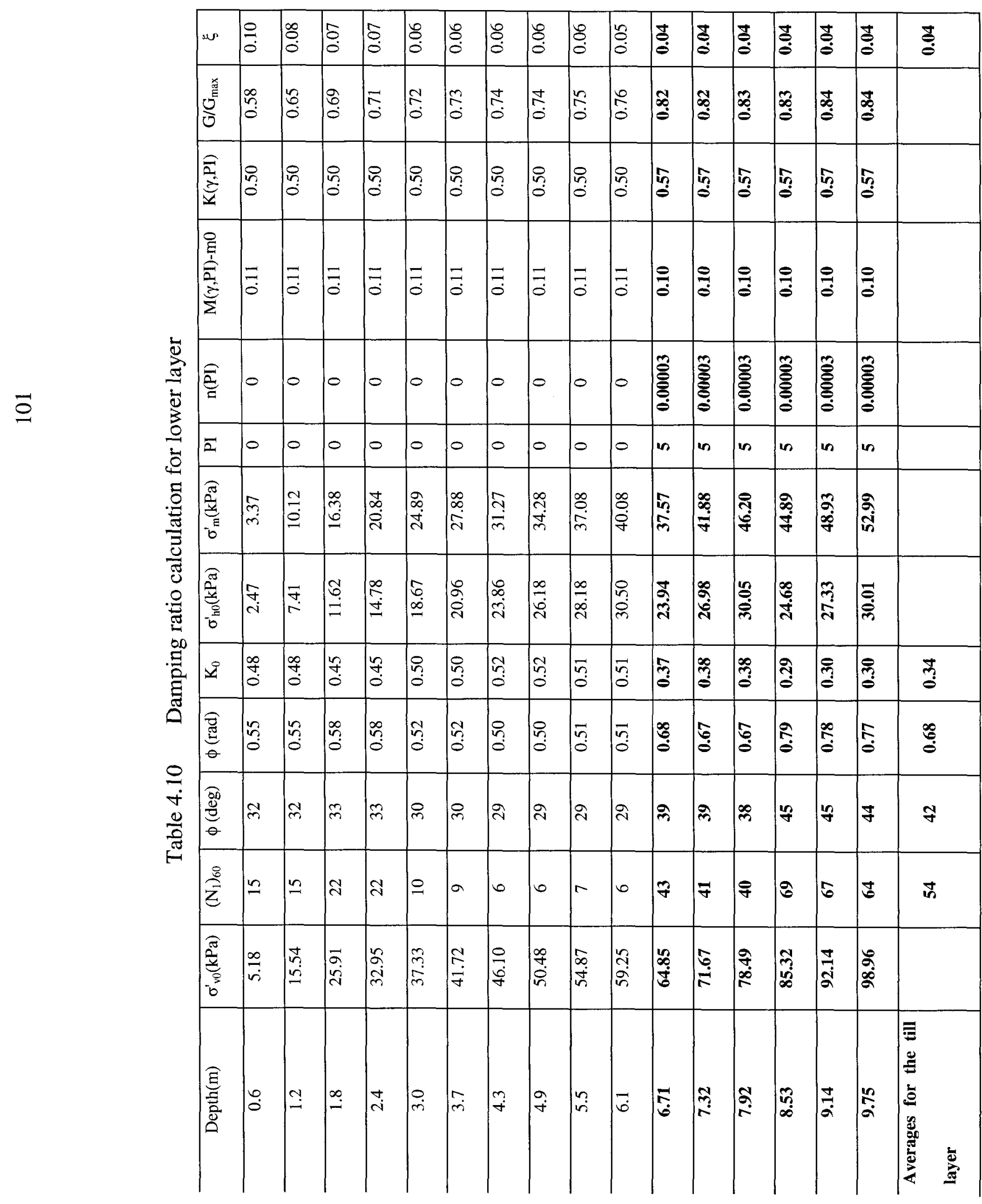


Table 4.11 Required soil parameters for static and slope stability analysis

\begin{tabular}{|c|c|c|c|c|}
\hline Soil parameters & Symbol & Unit & Fill layer & Till layer \\
\hline Unit weight & $\gamma$ & $\mathrm{kN} / \mathrm{m}^{3}$ & 17 & 21 \\
\hline Young's modulus & $\mathrm{E}$ & $\mathrm{MPa}$ & 30.00 & 50.00 \\
\hline Poisson's ratio & $v$ & - & 0.40 & 0.41 \\
\hline Cohesion & $\mathrm{c}$ & $\mathrm{kPa}$ & 0 & 0 \\
\hline Friction angle & $\phi$ & $\mathrm{Deg}$ & 31 & 42 \\
\hline
\end{tabular}

Table 4.12 Dynamic parameters of soils in Canadian dam

\begin{tabular}{|c|c|c|c|c|}
\hline Material number & Description & $\mathrm{K}_{2 \max }$ & Damping ratio & $\mathrm{n}$ \\
\hline 1 & Fill layer & 10500 & 0.07 & 0.5 \\
\hline 2 & Till layer & 15310 & 0.04 & 0.5 \\
\hline
\end{tabular}


Table 4.13 Results of the stability analysis of the Canadian dam for the ground motions with 10,000 years return period

\begin{tabular}{|c|c|c|c|c|}
\hline \multirow{2}{*}{} & \multicolumn{3}{|c|}{ FS for slope stability } \\
\cline { 2 - 5 } & \multicolumn{2}{|c|}{ Upstream } & \multicolumn{2}{c|}{ Downstream } \\
\hline Pre-earthquake & \multicolumn{2}{|c|}{1.12} & \multicolumn{2}{c|}{1.54} \\
\hline Method & near-field & far-field & near-field & far-field \\
\hline Seed \& Harder (1990) & 1.50 & 1.47 & 1.40 & 1.42 \\
\hline Seed \& Harder (1990)- Lower bound & 1.10 & 1.12 & 1.36 & 1.29 \\
\hline Olson \& Stark (2002) & 0.81 & 0.71 & 1.17 & 0.96 \\
\hline
\end{tabular}

Table 4.14 Results of the stability analysis of the Canadian dam for ground motions with 2500 years return period

\begin{tabular}{|c|c|c|c|c|}
\hline \multirow{2}{*}{} & \multicolumn{3}{|c|}{ FS for slope stability } \\
\cline { 2 - 5 } & \multicolumn{2}{|c|}{ Upstream } & \multicolumn{2}{c|}{ Downstream } \\
\hline Method & Short-period & Long-period & Short-period & Long-period \\
\hline Olson \& Stark (2002) & 0.96 & 0.71 & 1.48 & 1.00 \\
\hline
\end{tabular}


Table 4.15 Factors of safety of the upstream side of the dam with different shear modulus based on the far-field ground motion (the bolded column represents the values of the overall stability analysis of the dam.)

\begin{tabular}{|l|c|c|c|}
\hline & \multicolumn{3}{|c|}{$\mathrm{n}$} \\
\hline Factor of Safety & 0.32 & $\mathbf{0 . 5 0}$ & 0.60 \\
\hline Seed and Harder (1990) & 1.45 & $\mathbf{1 . 4 7}$ & 1.51 \\
\hline Olson and Stark (2002) & 0.71 & $\mathbf{0 . 7 1}$ & 0.71 \\
\hline
\end{tabular}

Table 4.16 Comparison of the factor of safety based on the new Poisson's Ratio of 0.25 with the factor of safety based on the applied Poisson's Ratio of 0.40

\begin{tabular}{|l|c|c|}
\hline & Poisson's Ratio=0.25 & Poisson's Ratio $=0.40$ \\
\hline Seed and Harder (1990) & 1.56 & 1.51 \\
\hline Olson and Stark (2002) & 0.73 & 0.71 \\
\hline
\end{tabular}

Table 4.17 Comparison of the factor of safety based on the new Plasticity Index of 5 with the factor of safety based on the applied Plasticity Index of zero

\begin{tabular}{|l|c|c|}
\hline & PI=5 & PI=0 \\
\hline Seed and Harder (1990) & 1.51 & 1.51 \\
\hline Olson and Stark (2002) & 0.71 & 0.71 \\
\hline
\end{tabular}




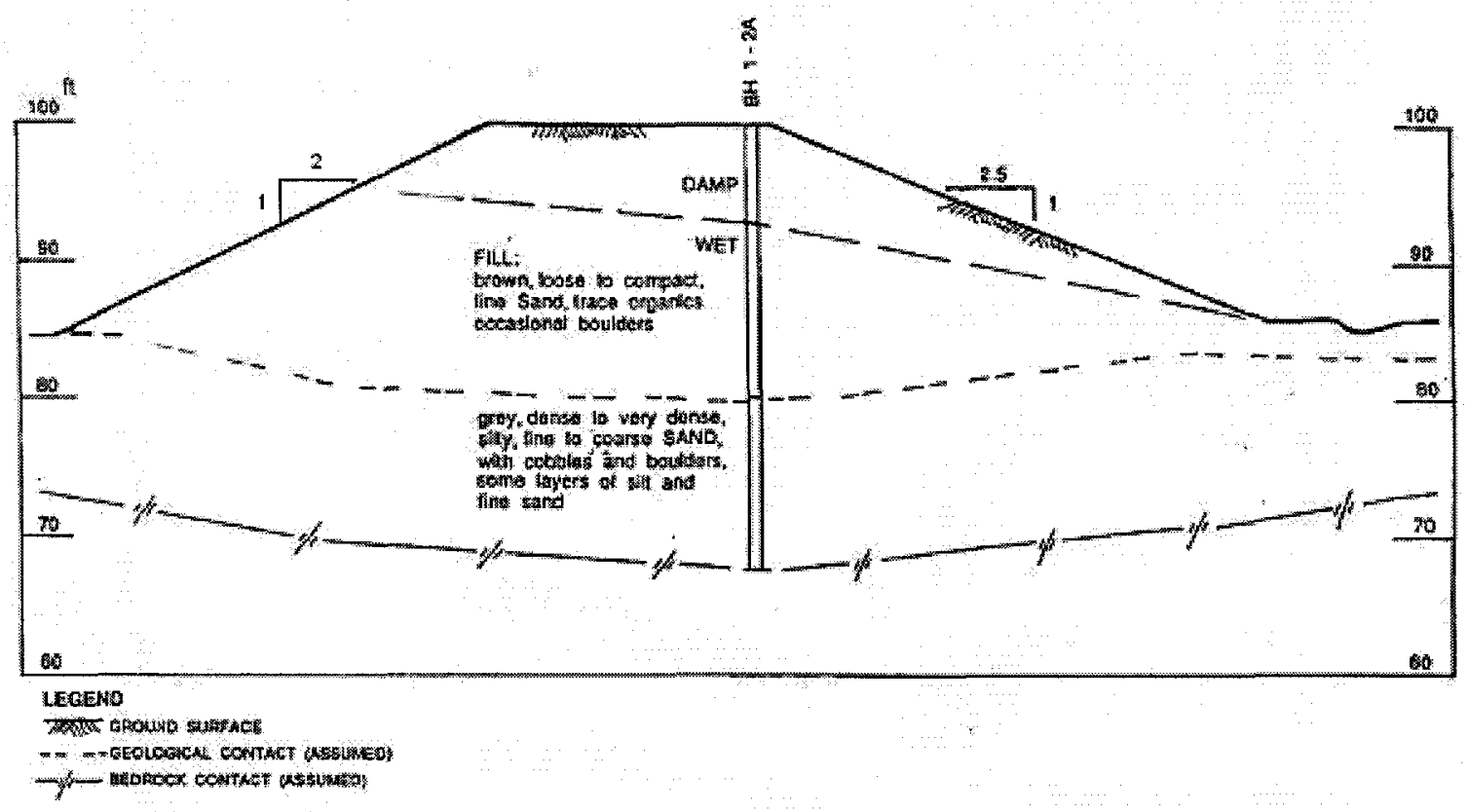

Figure 4.1 The geometry of the dam

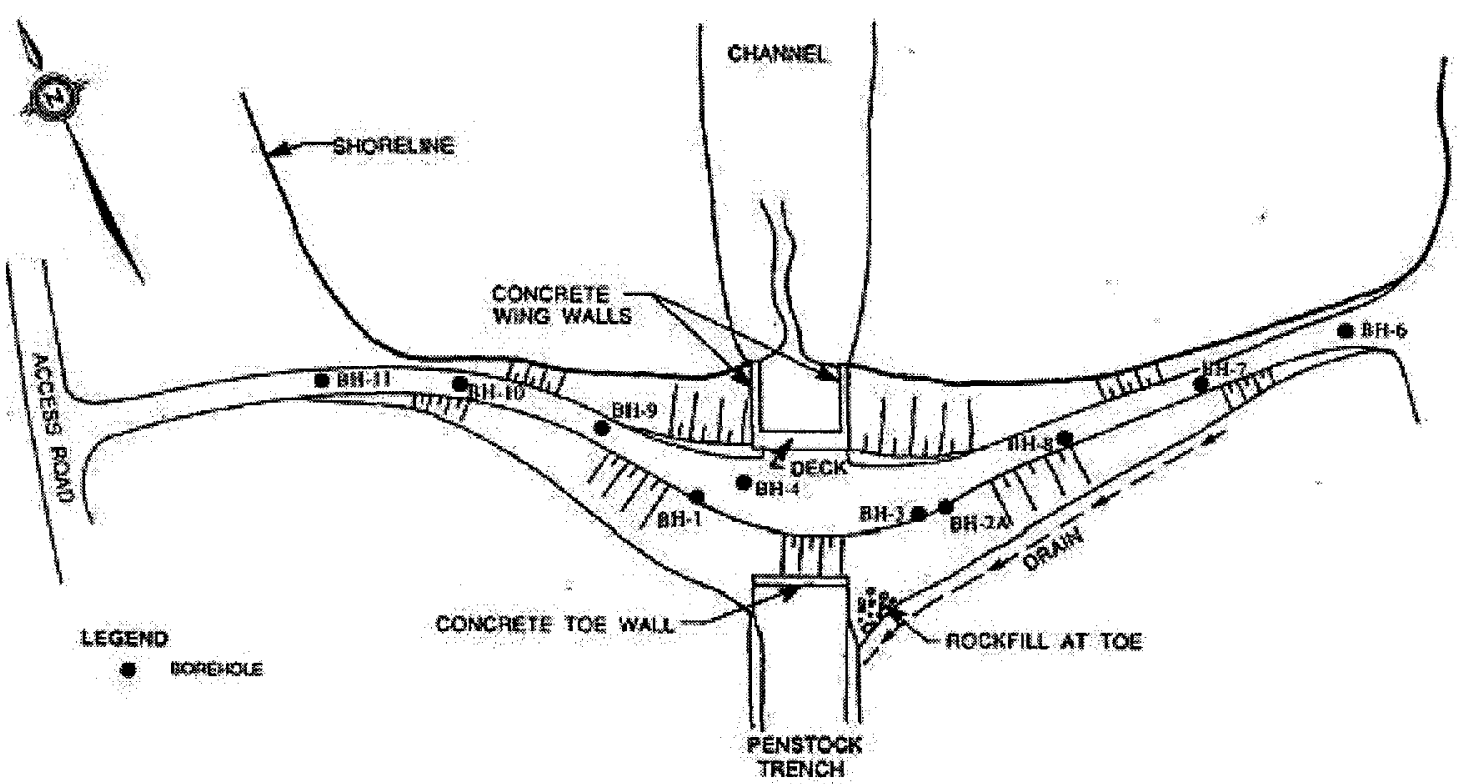

Figure 4.2 Plan of the dam 


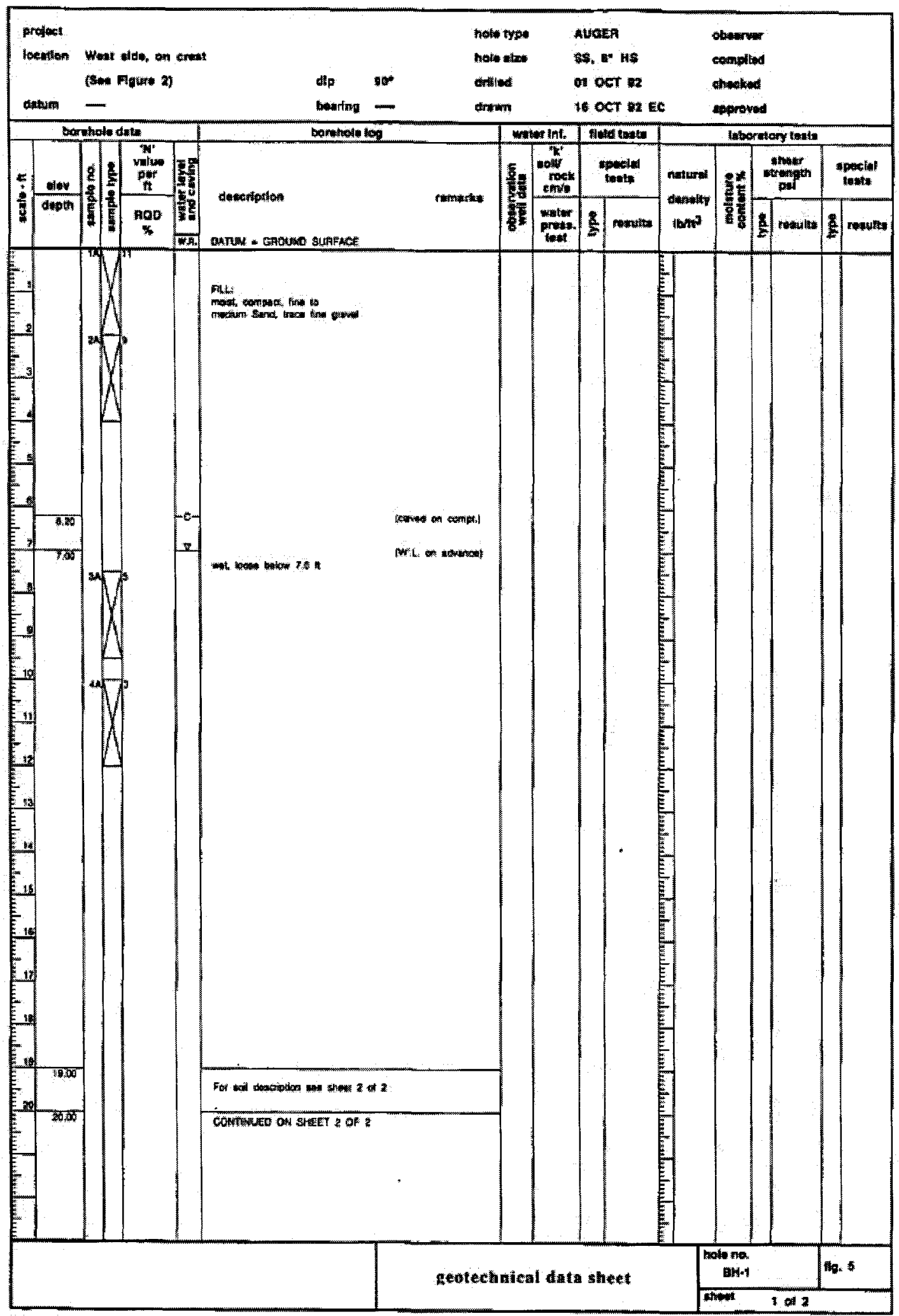




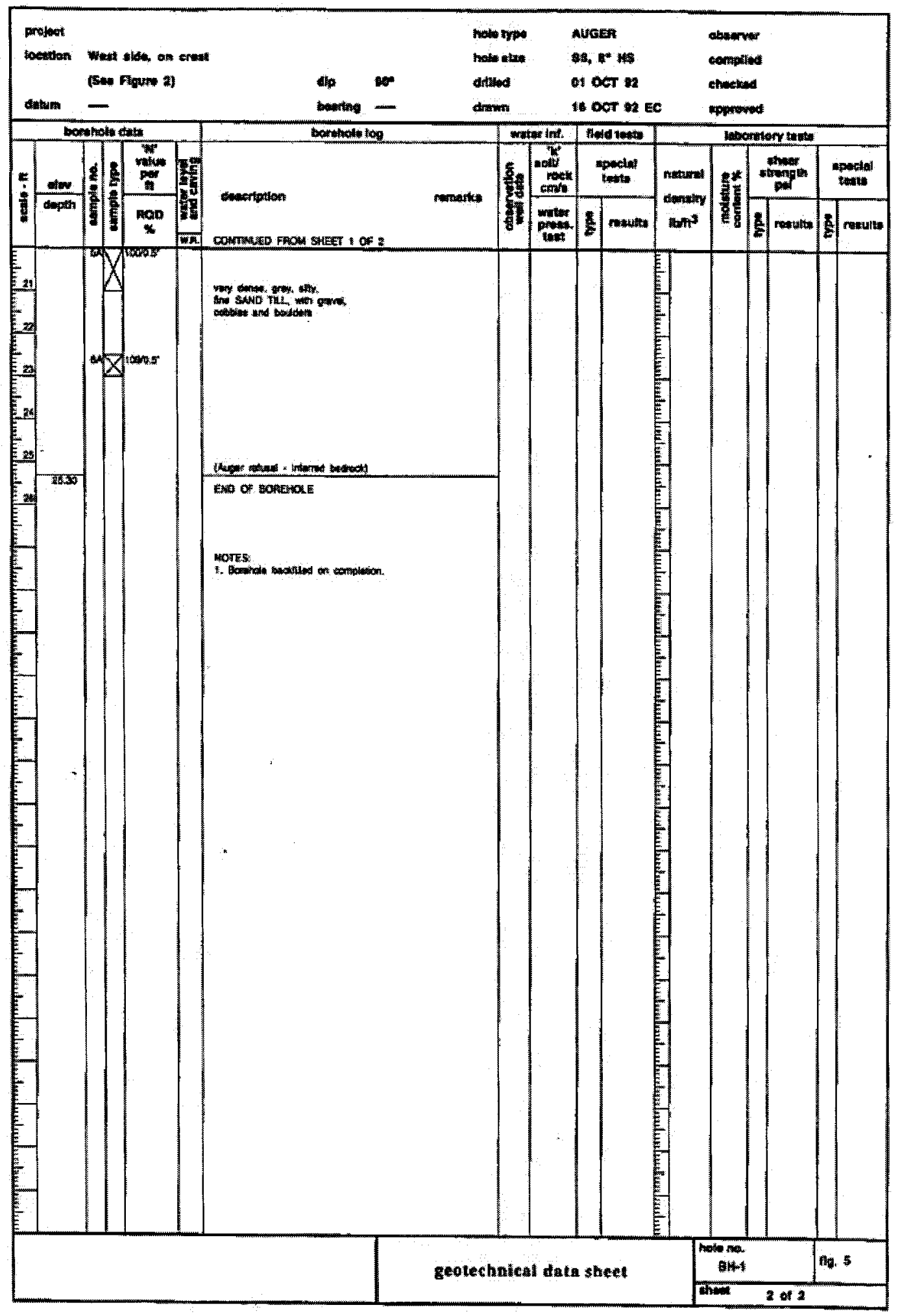

Figure 4.3 SPT data of bore-hole number one in referenced cross section from Figure 4.1 


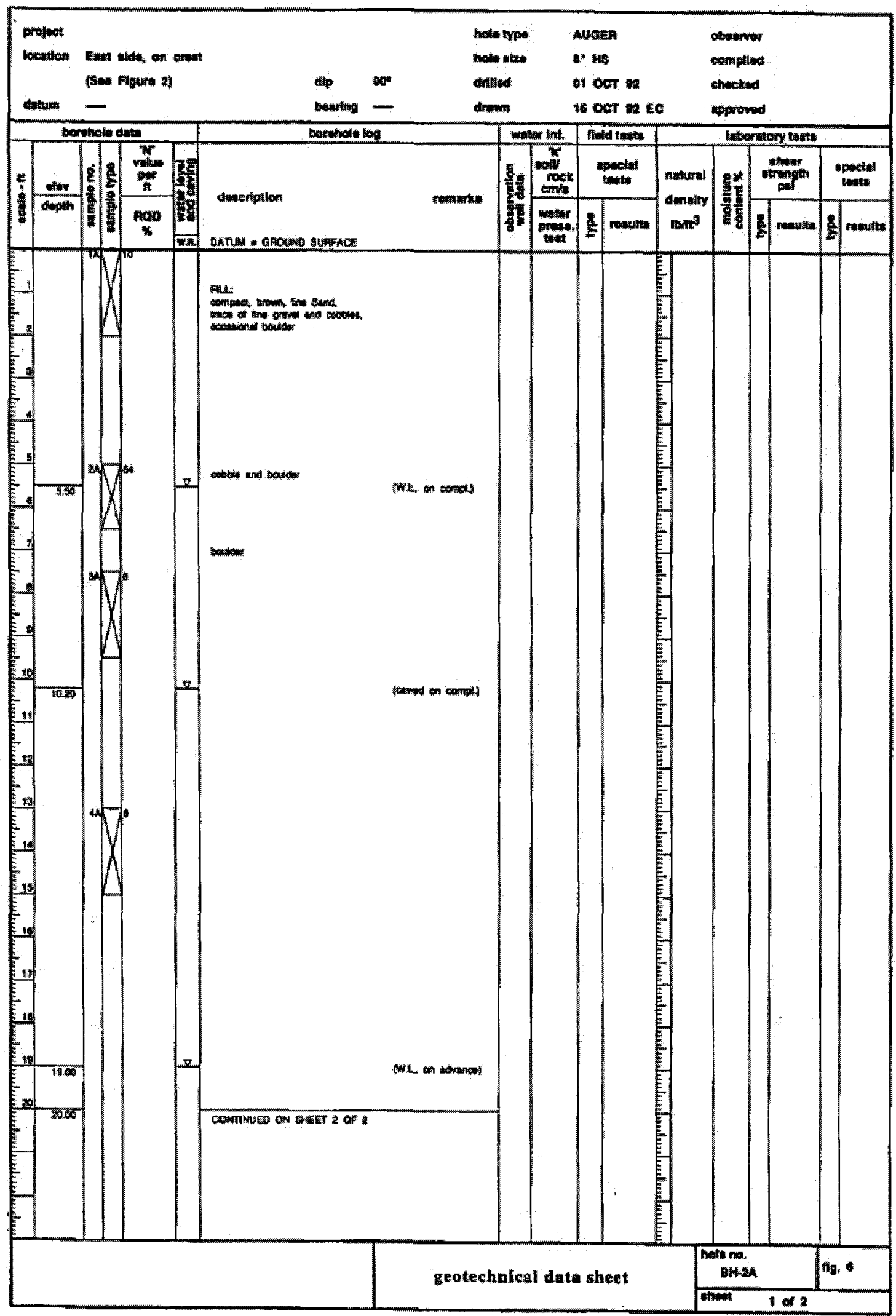




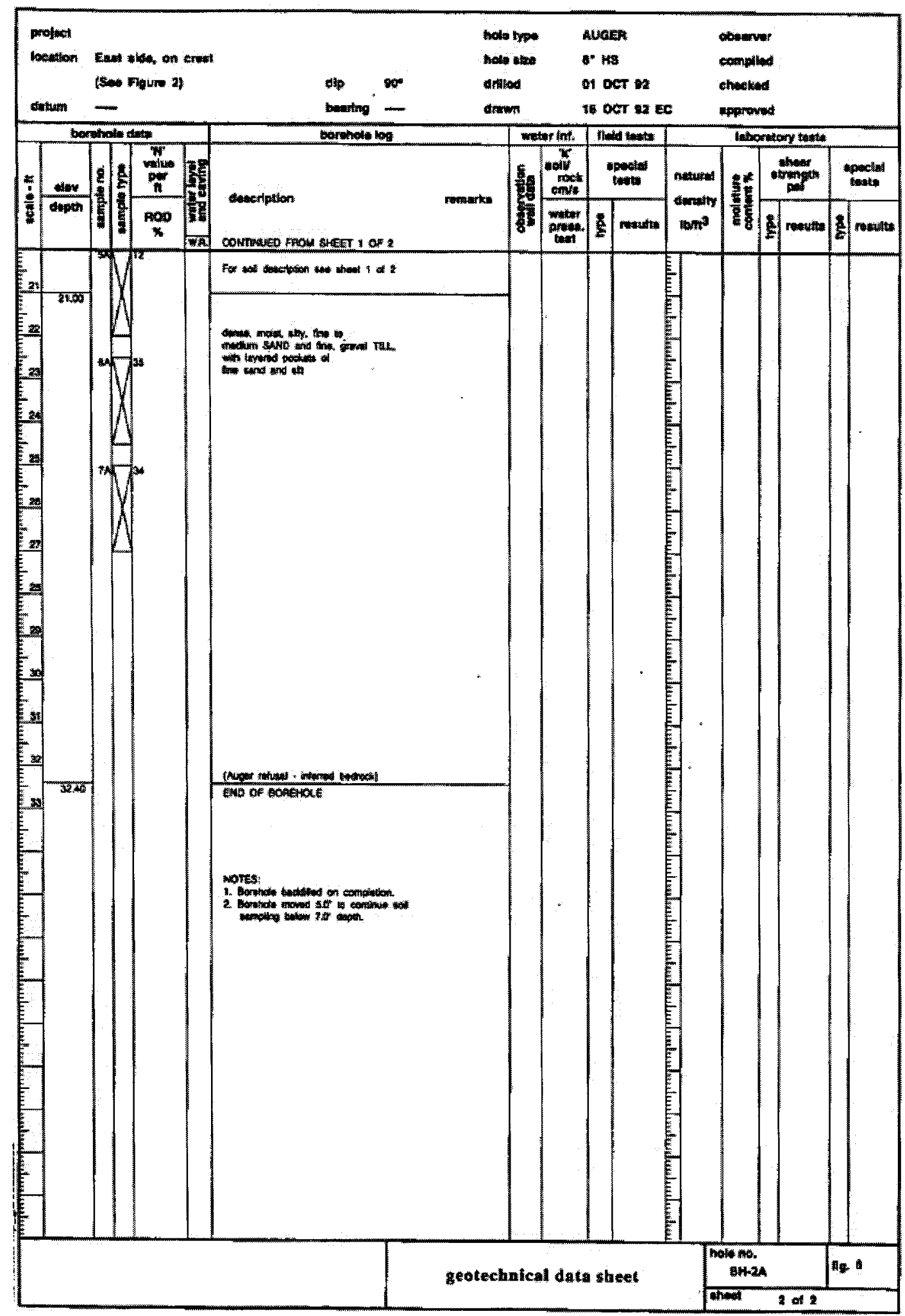

Figure 4.4 SPT data of bore-hole number two in referenced cross section from Figure 4.1 


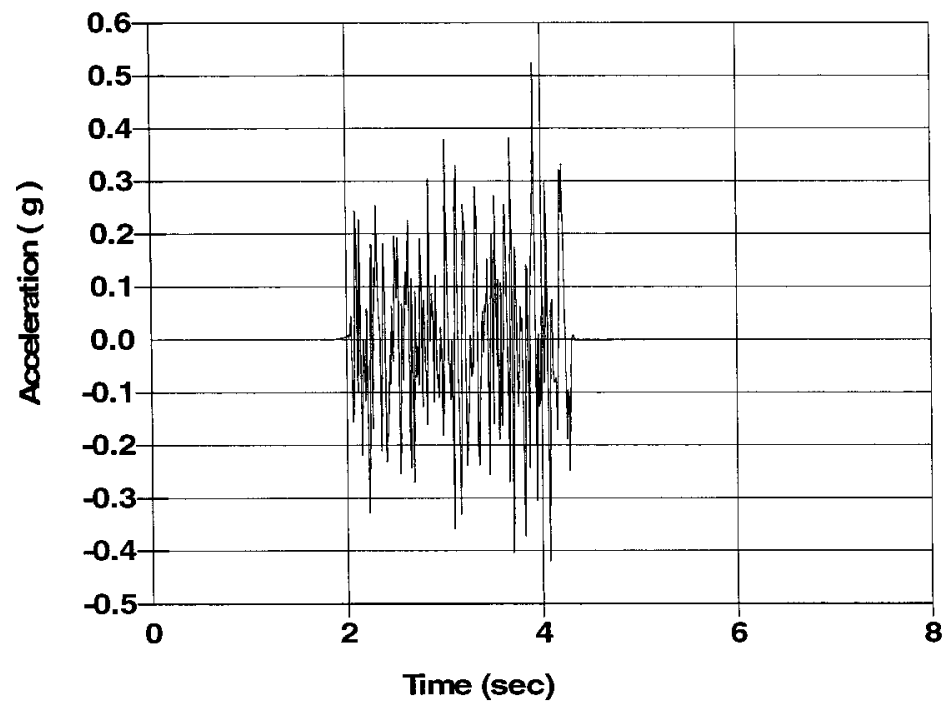

Figure 4.5 Acceleration time history of near-field ground motion with $0.5 \%$ exceedance in 50 years

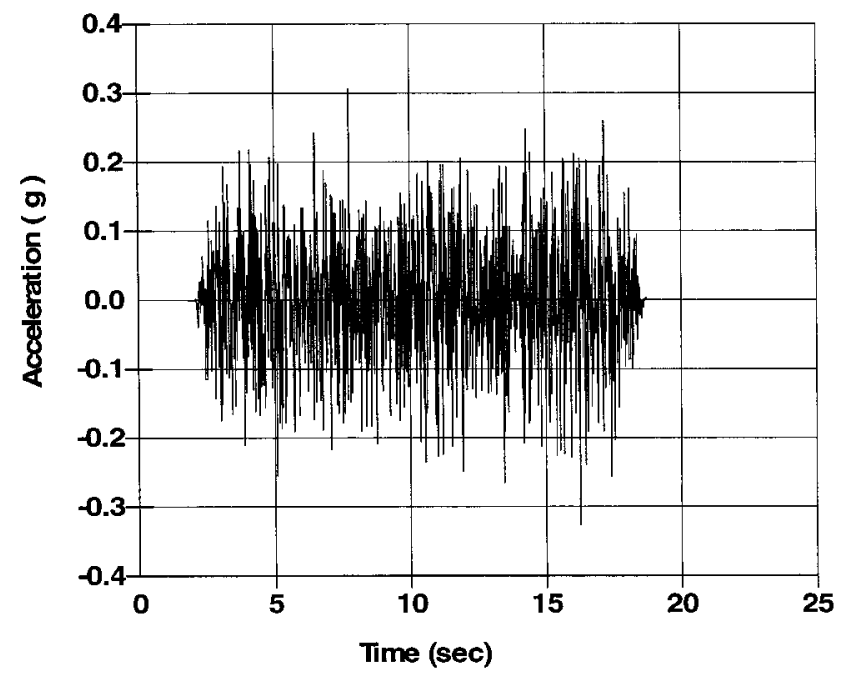

Figure 4.6 Acceleration time history of far-field ground motion with $0.5 \%$ exceedance in 50 years 


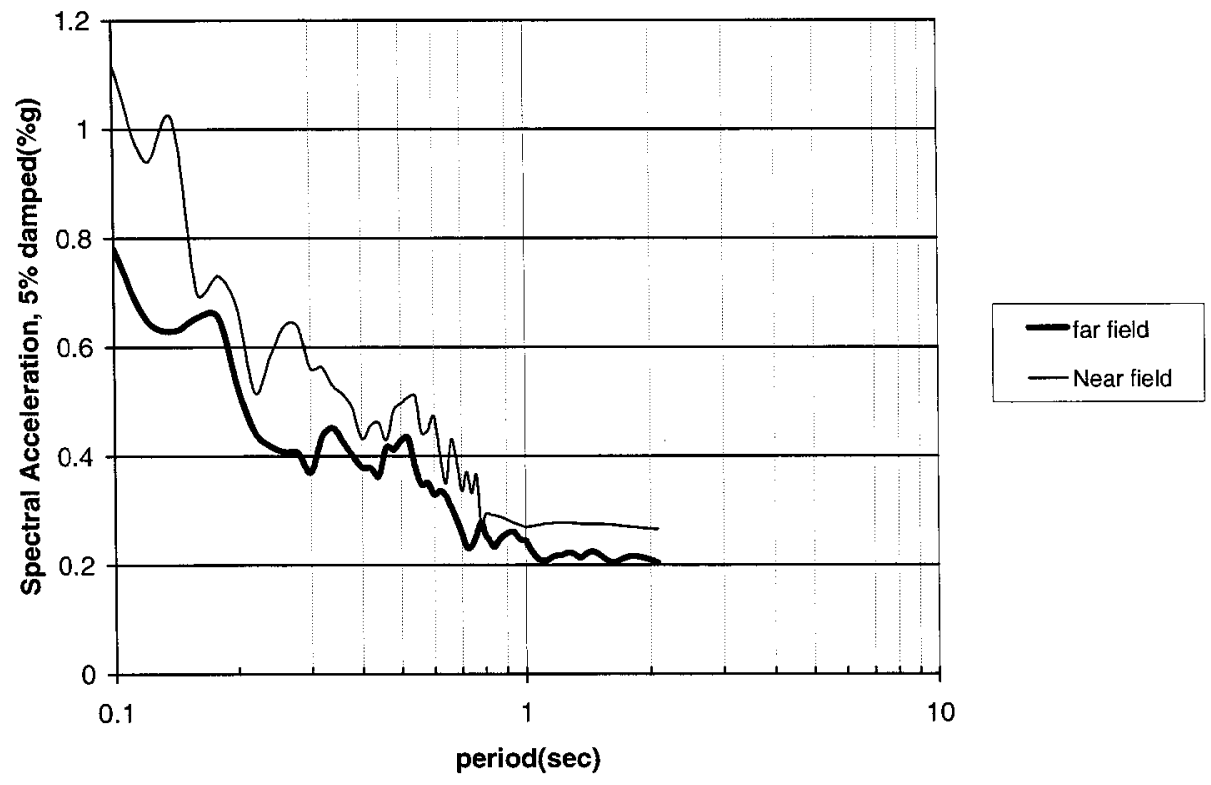

Figure 4.7 Acceleration spectra (5\% damping) for both near- and far-field ground motions with $0.5 \%$ exceedance in 50 years

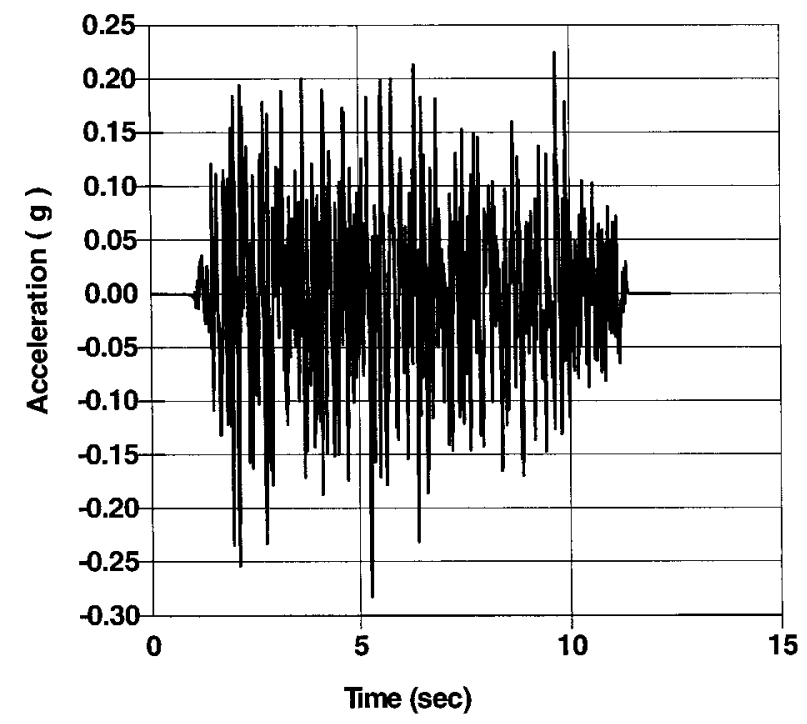

Figure 4.8 Acceleration time history of short-period ground motion (M6) with $2 \%$ exceedance in 50 years 


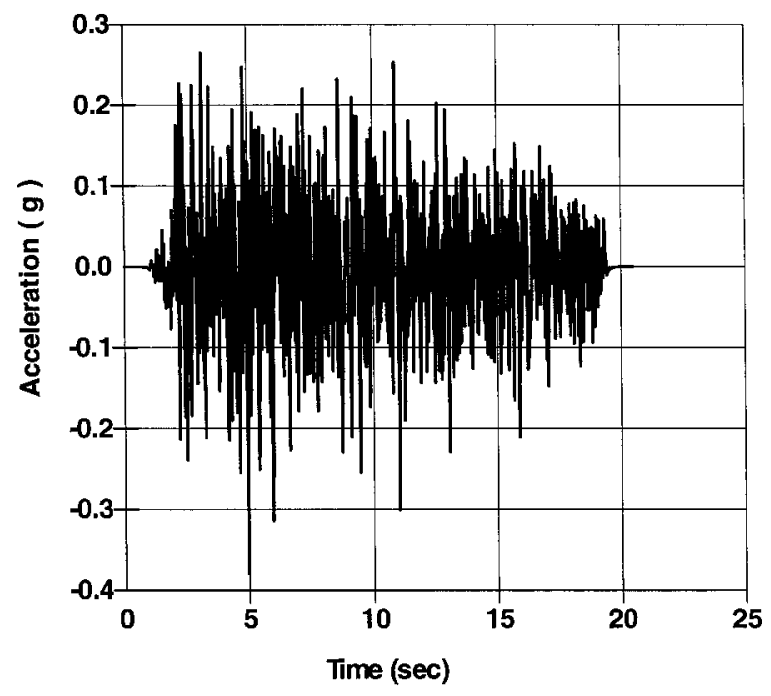

Figure 4.9 Acceleration time history of long-period ground motion (M7) with 2\% exceedance in 50 years

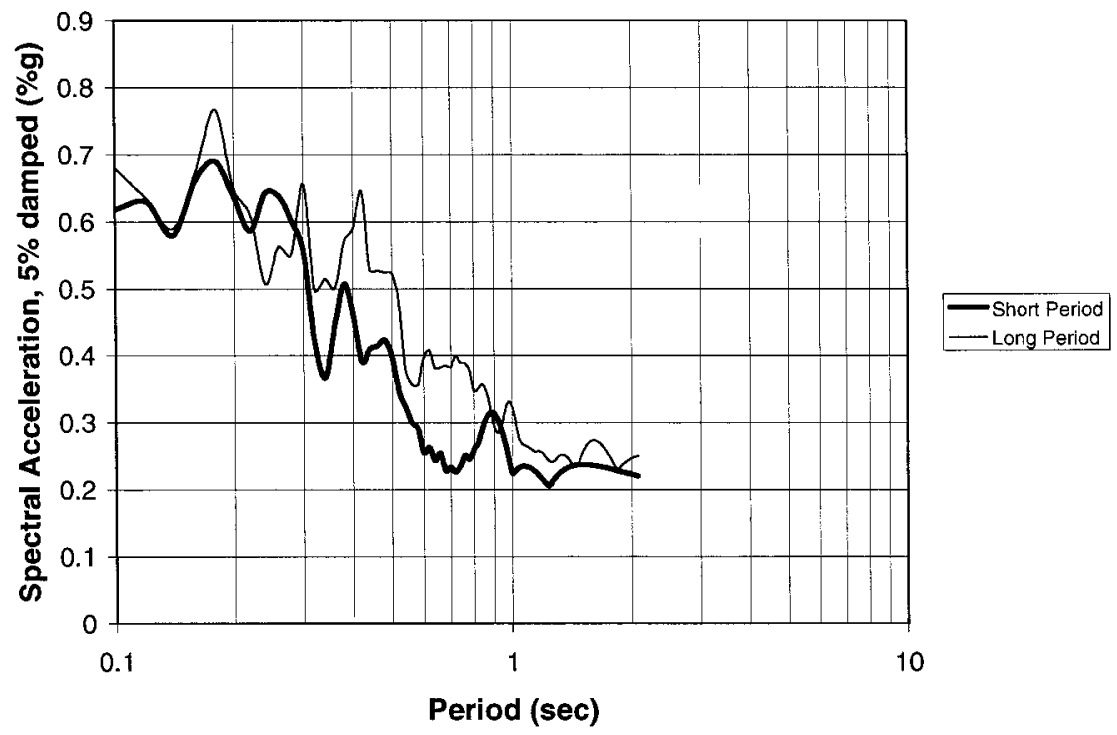

Figure 4.10 Acceleration spectra (5\% damping) for both short-period (M6) and longperiod (M7) ground motions with $2 \%$ exceedance in 50 years 


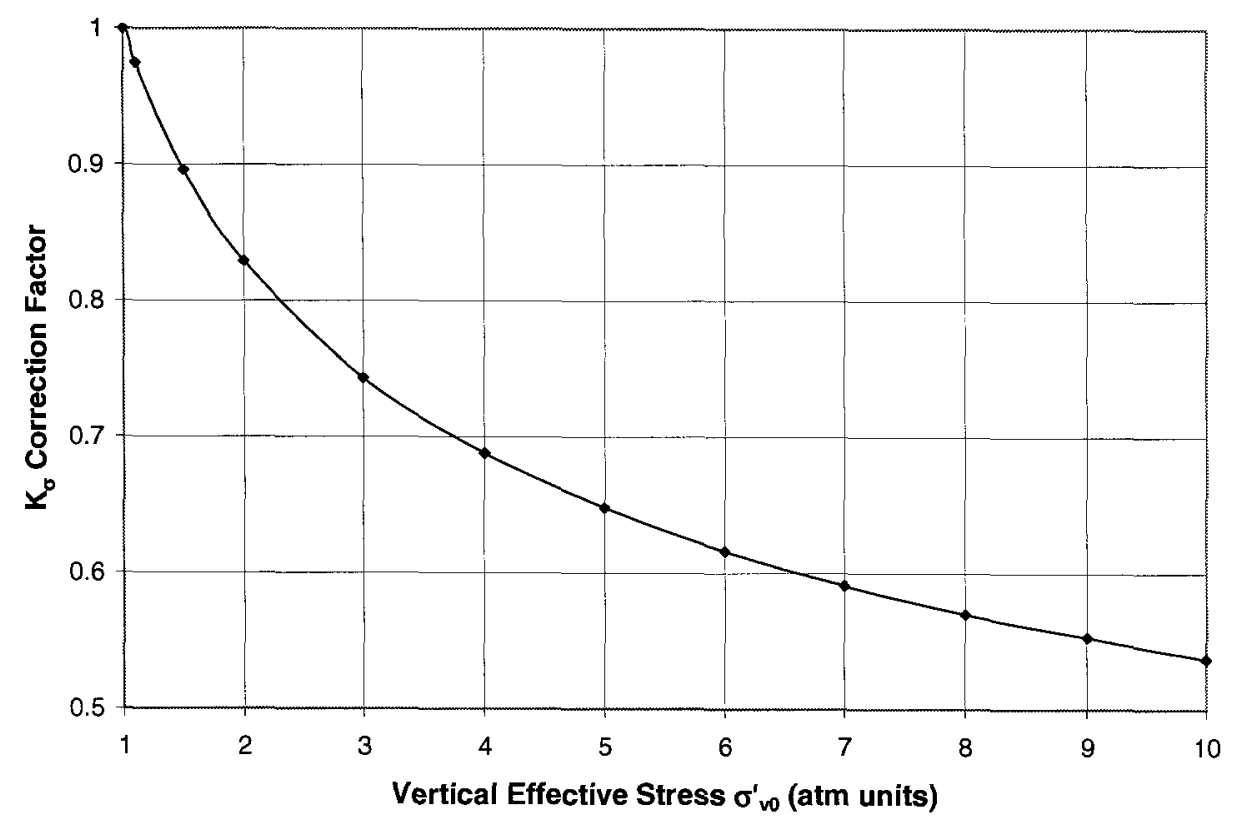

Figure 4.11 $\mathrm{K}_{\sigma}$ correction function for the fill layer

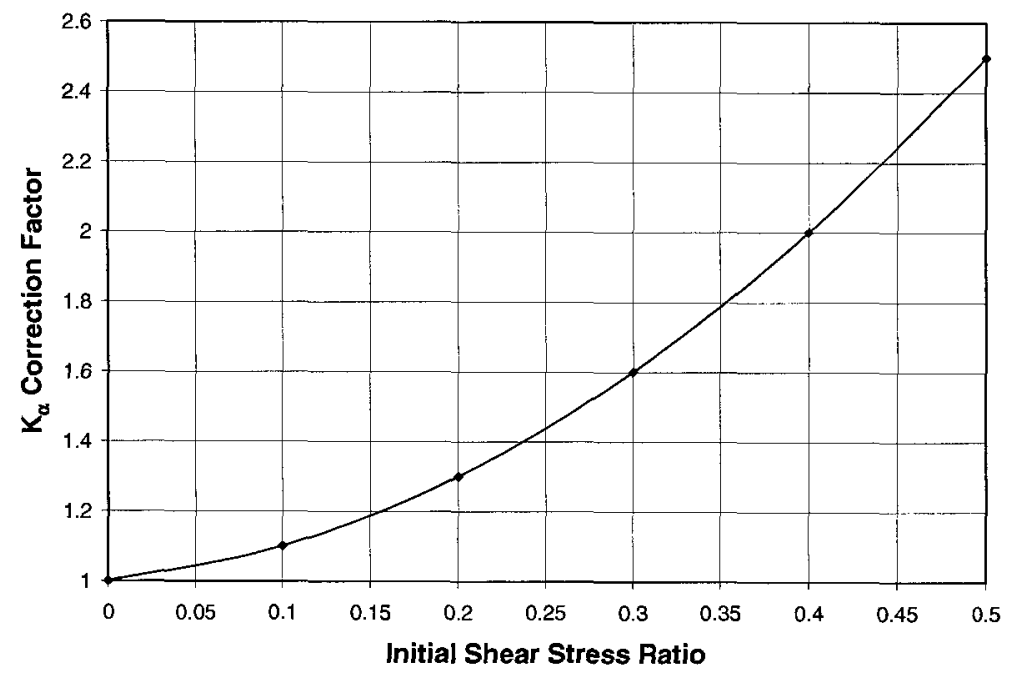

Figure 4.12 $\mathrm{K}_{\alpha}$ correction function versus the initial shear stress ratio, $\alpha$ for the fill layer 


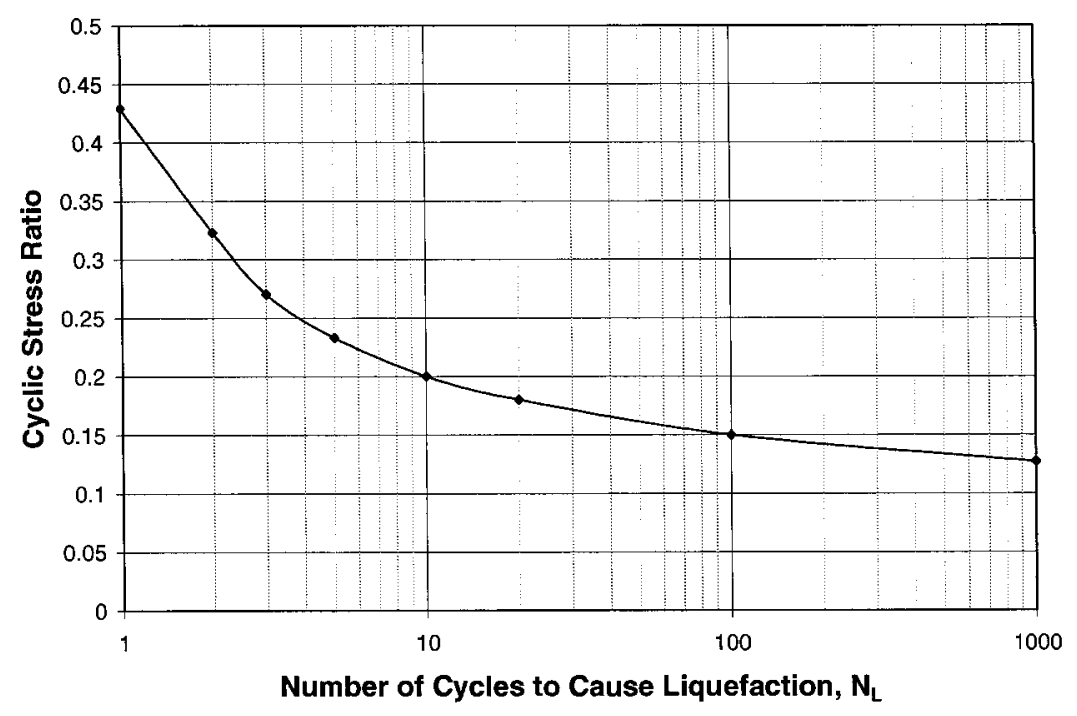

Figure 4.13 Cyclic number function for the fill layer

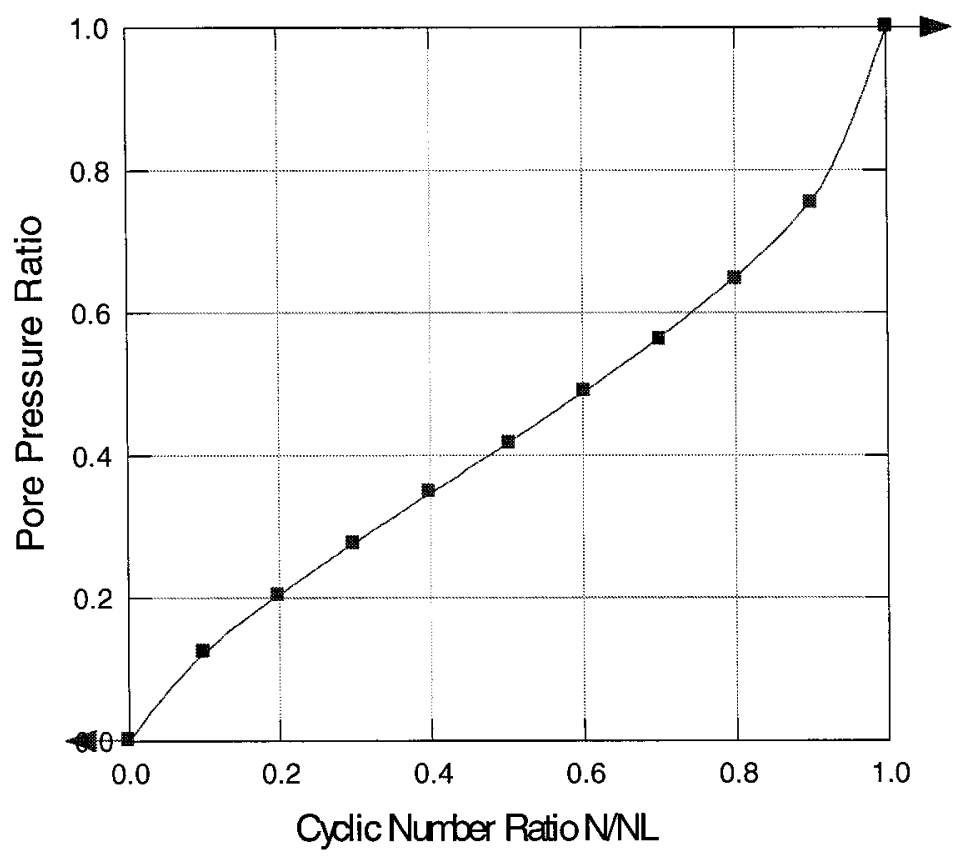

Figure 4.14 Pore pressure function for both the fill and the till layers 


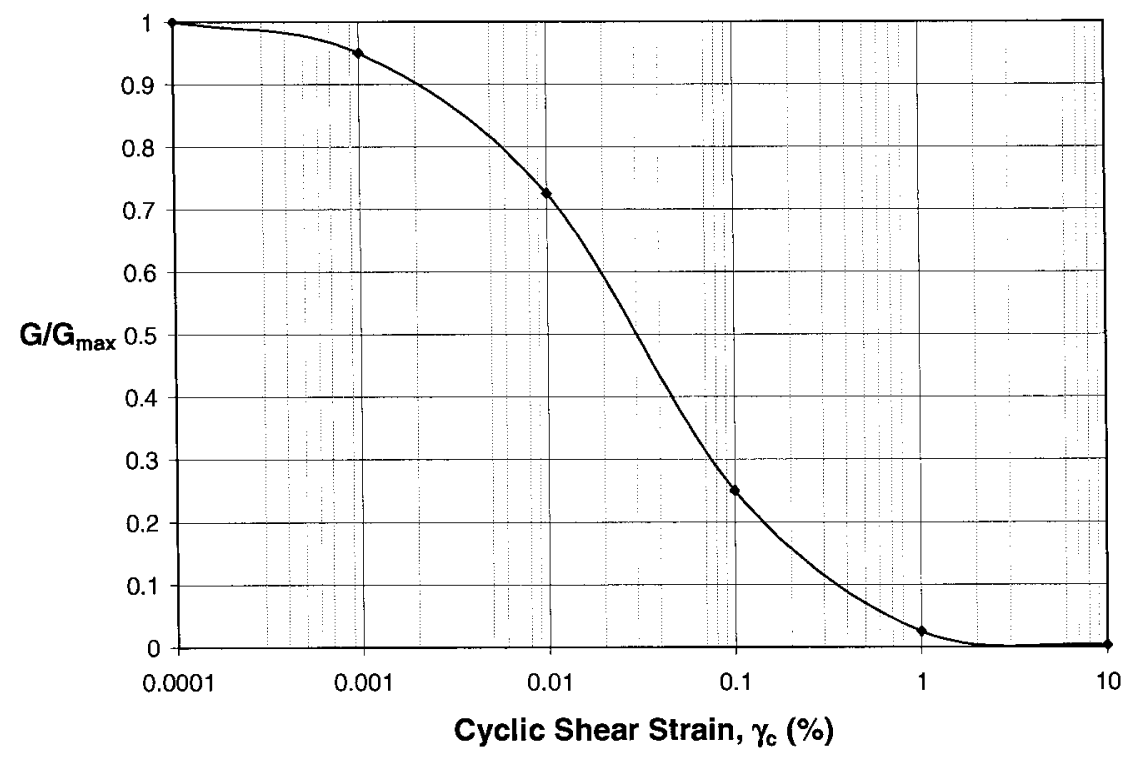

Figure 4.15 G reduction function for the fill layer

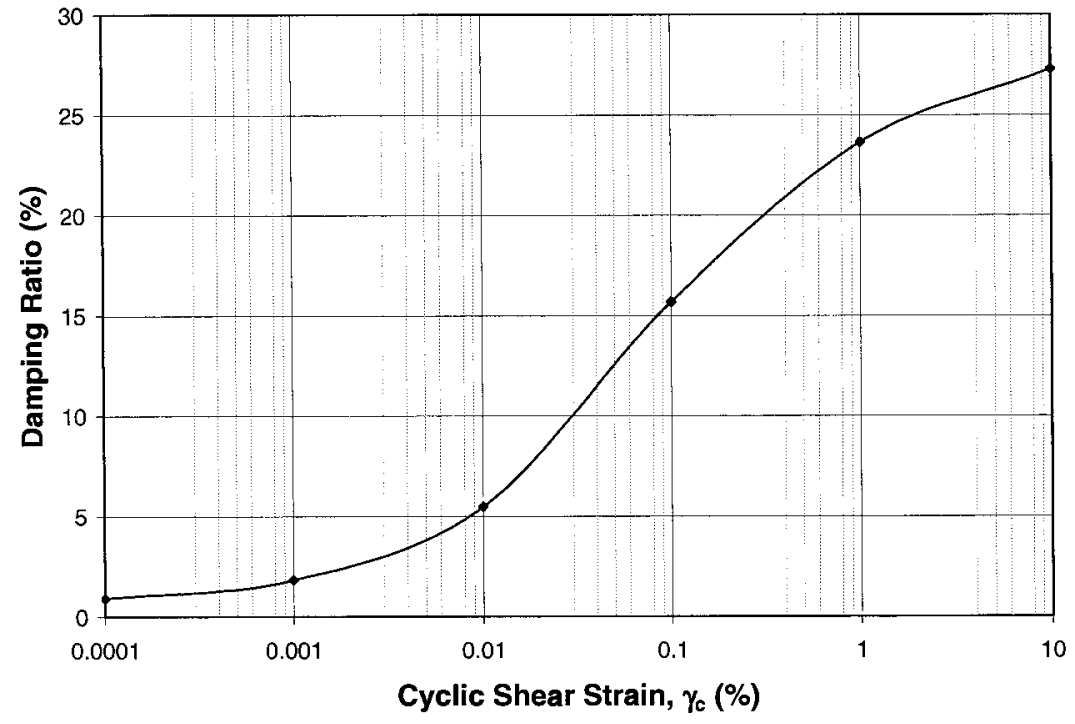

Figure 4.16 Damping ratio function for the fill layer 


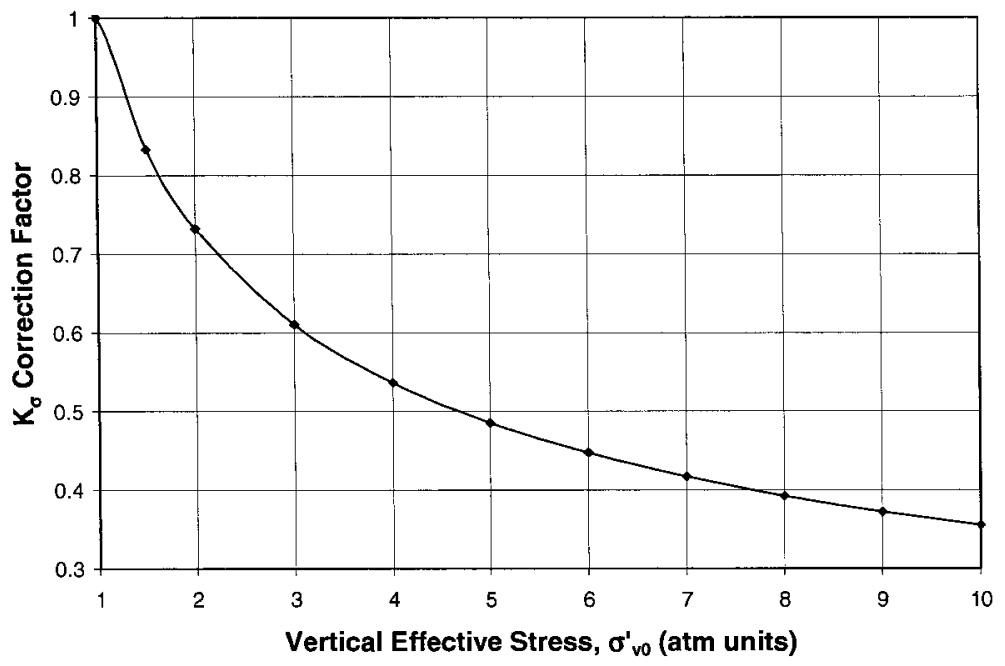

Figure 4.17 $\mathrm{K}_{\sigma}$ correction function for the till layer

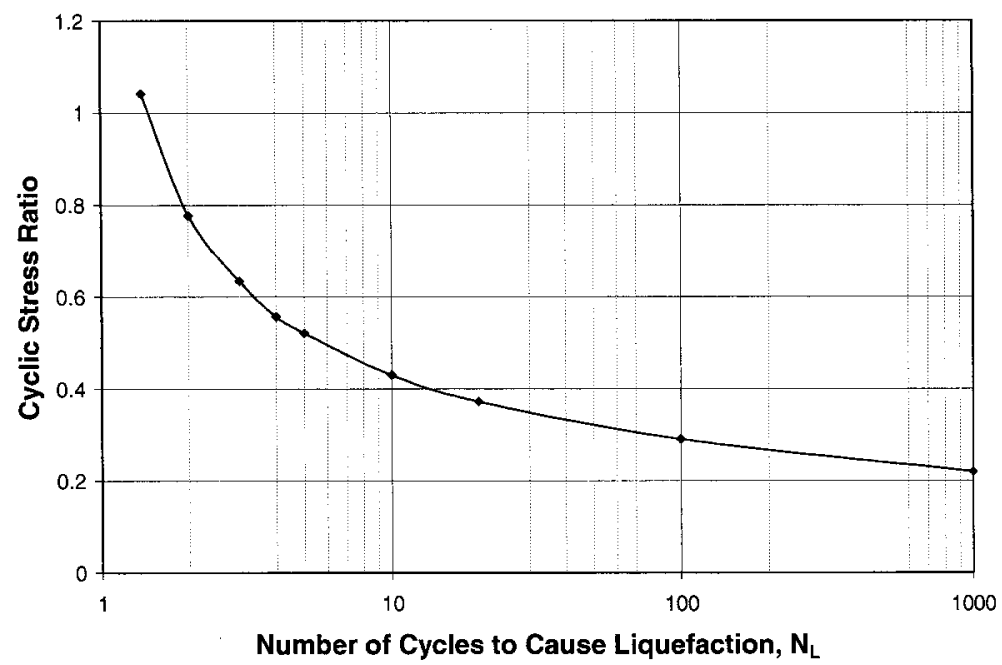

Figure 4.18 Cyclic number function for the till layer 


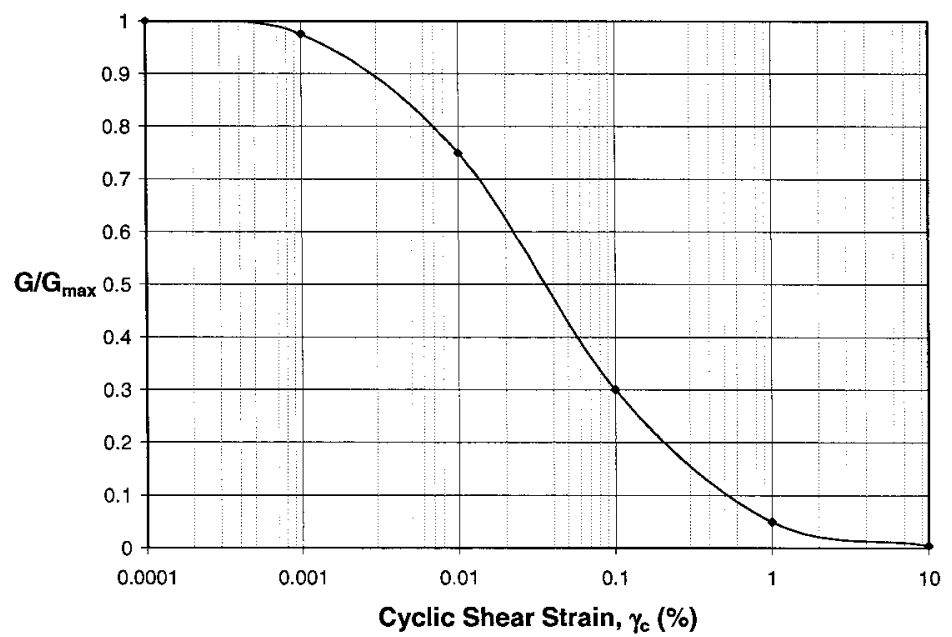

Figure 4.19 G reduction function for the till layer

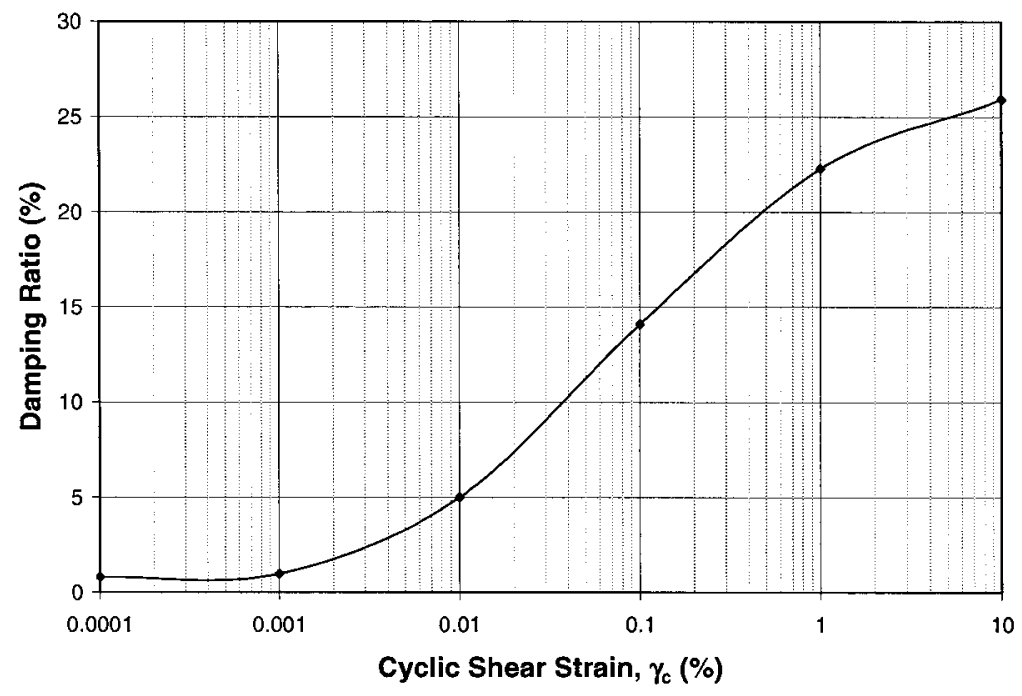

Figure 4.20 Damping ratio function for the till layer 


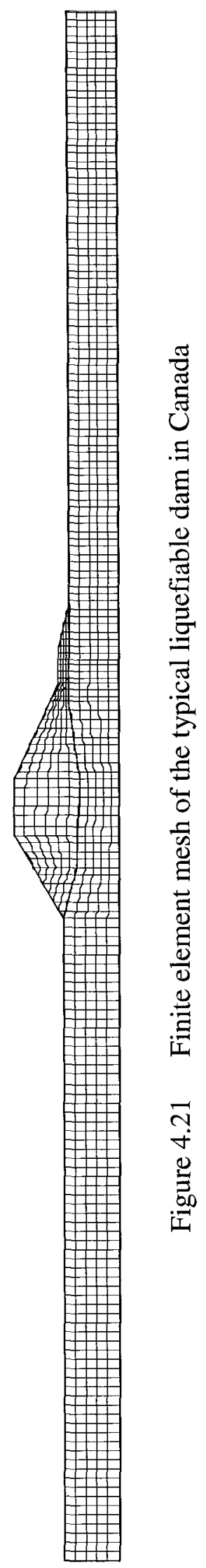

Reproduced with permission of the copyright owner. Further reproduction prohibited without permission. 

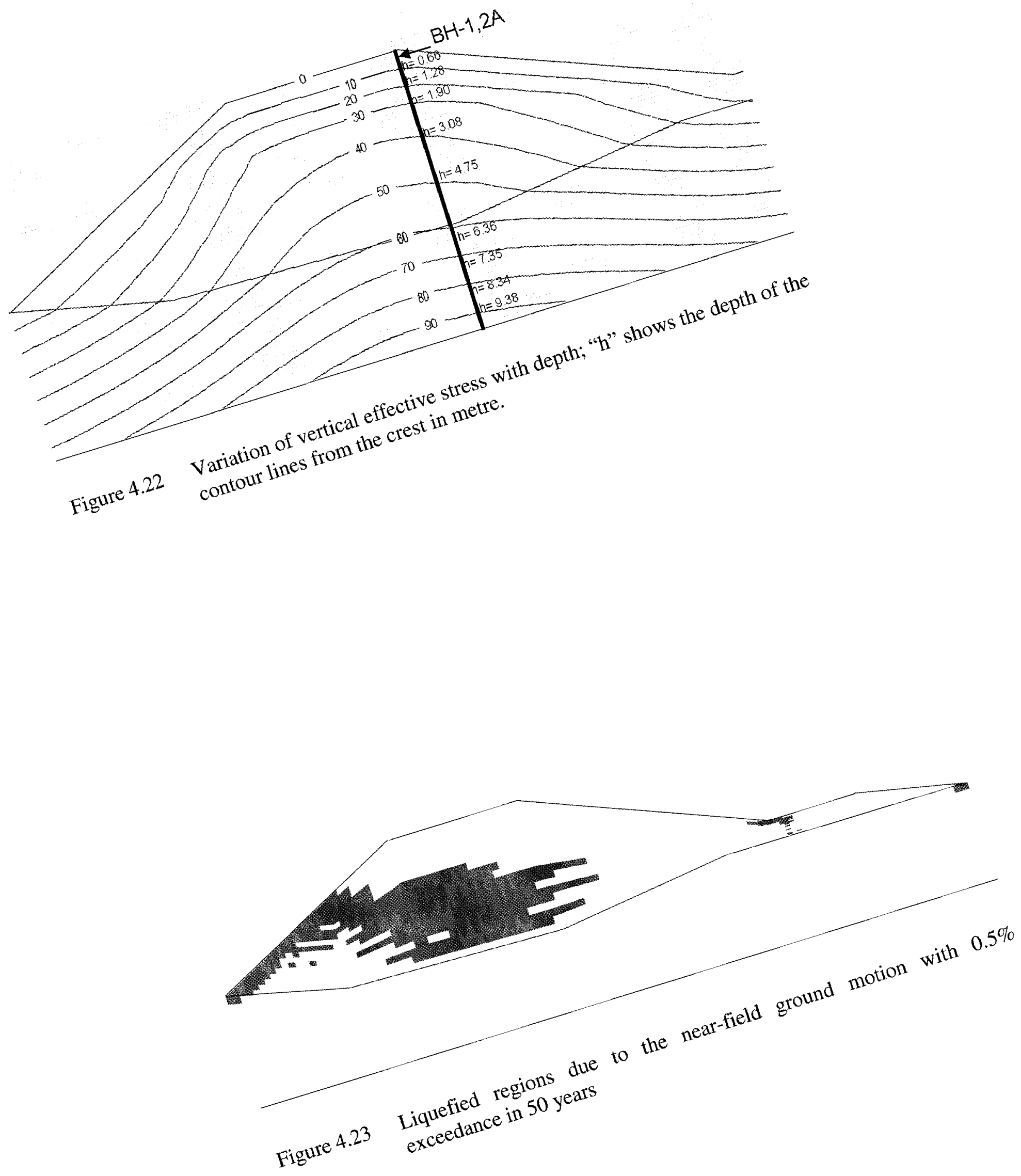

Reproduced with permission of the copyright owner. Further reproduction prohibited without permission.

2 


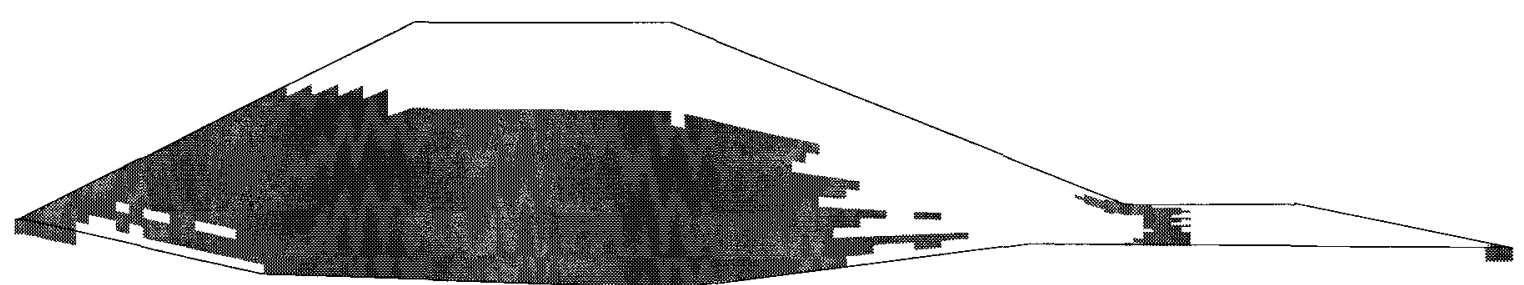

Figure 4.24 Liquefied regions due to the far-field ground motion with $0.5 \%$ exceedance in 50 years

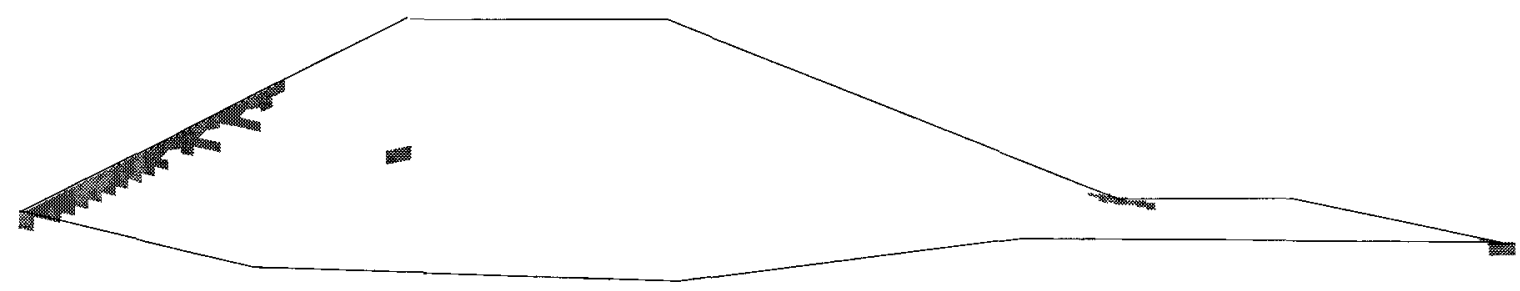

Figure 4.25 Liquefied regions due to the short-period (M6) ground motion with 2\% exceedance in 50 years

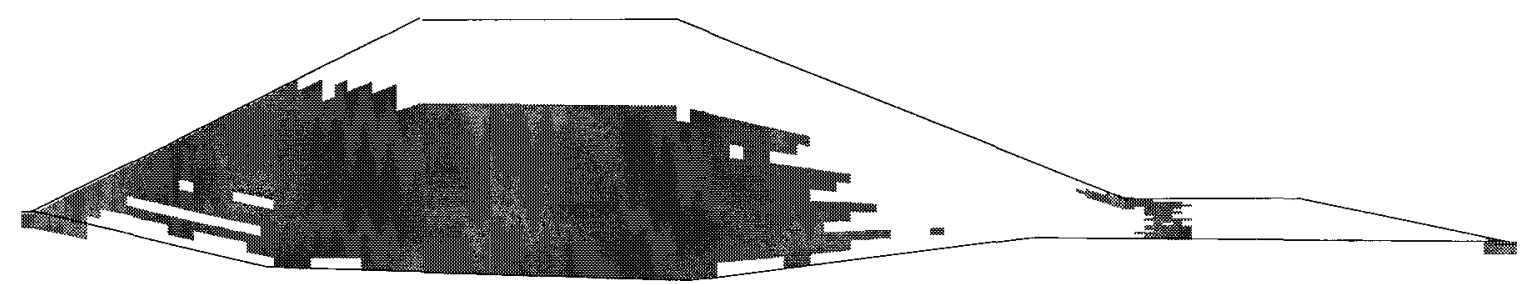

Figure 4.26 Liquefied regions due to the long-period (M7) ground motion with $2 \%$ exceedance in 50 years 


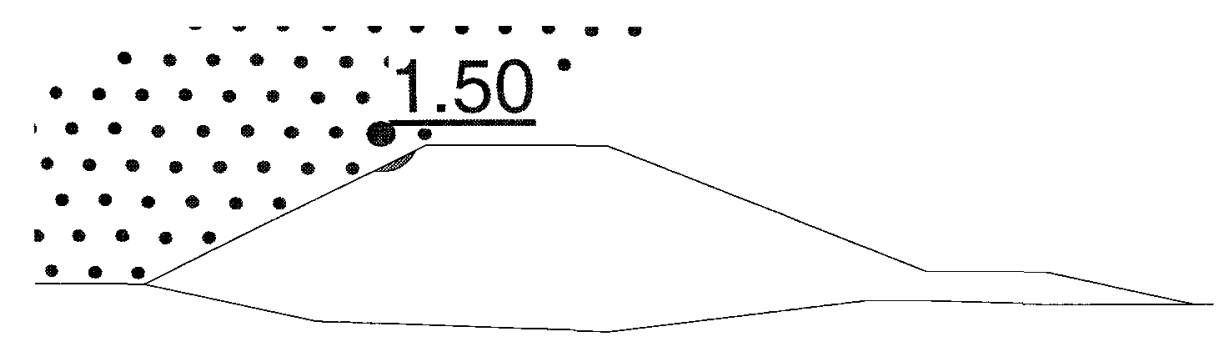

Figure 4.27 Factor of safety of the upstream side of the dam with the average liquefied strength from the Seed and Harder (1990) approach and based on the nearfield ground motion

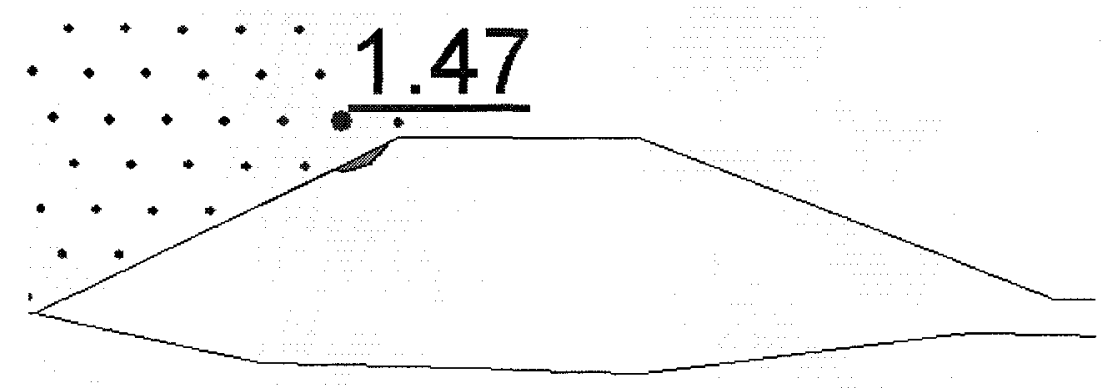

Figure 4.28 Factor of safety of the upstream side of the dam with the average liquefied strength from the Seed and Harder (1990) approach and based on the farfield ground motion 


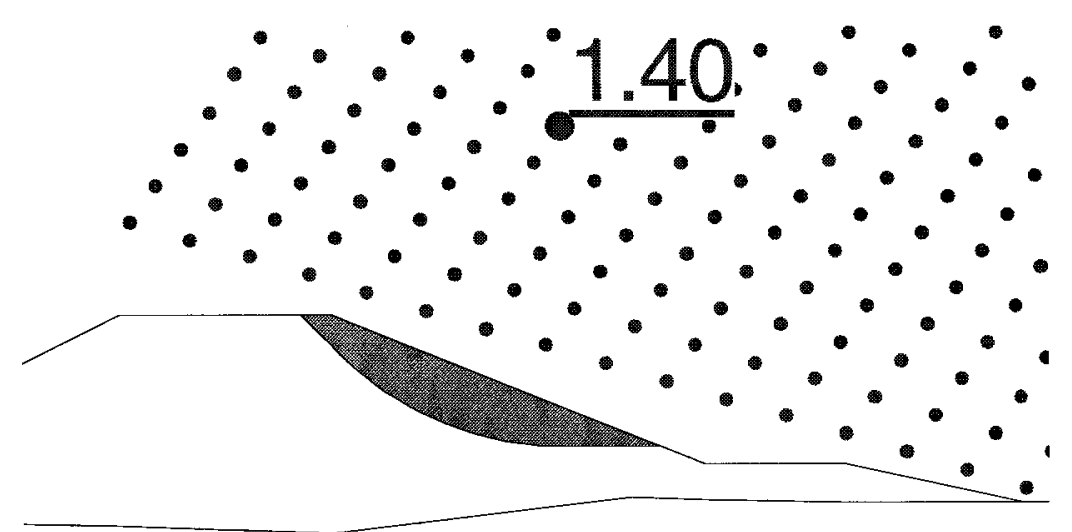

Figure 4.29 Factor of safety of the downstream side of the dam with the average liquefied strength from the Seed and Harder (1990) approach and based on the near-field ground motion

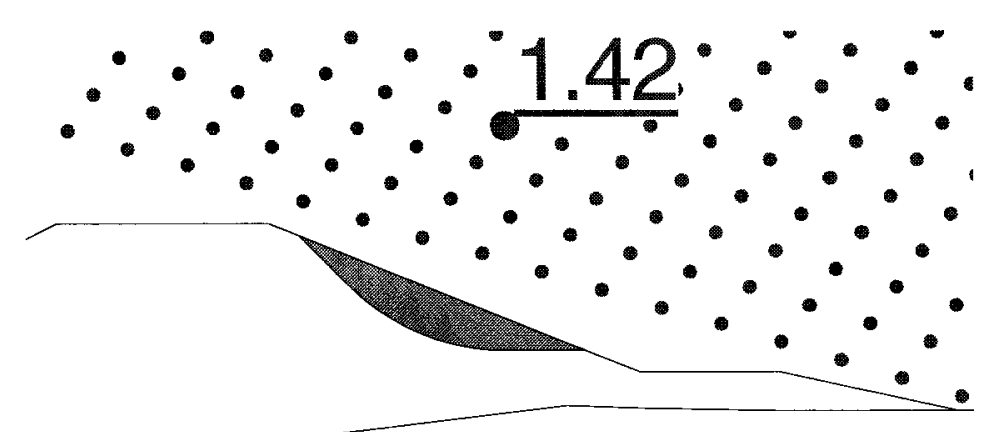

Figure 4.30 Factor of safety of the downstream side of the dam with the average liquefied strength from the Seed and Harder (1990) approach and based on the far-field ground motion 


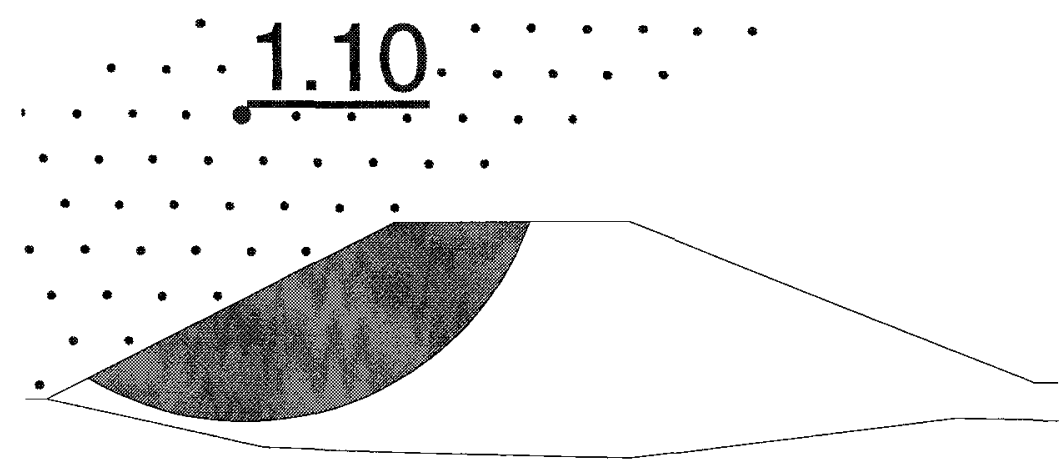

Figure 4.31 Factor of safety of the upstream side of the dam with the lower bound liquefied strength, according to the Seed and Harder (1990) approach, and based on the near-field ground motion

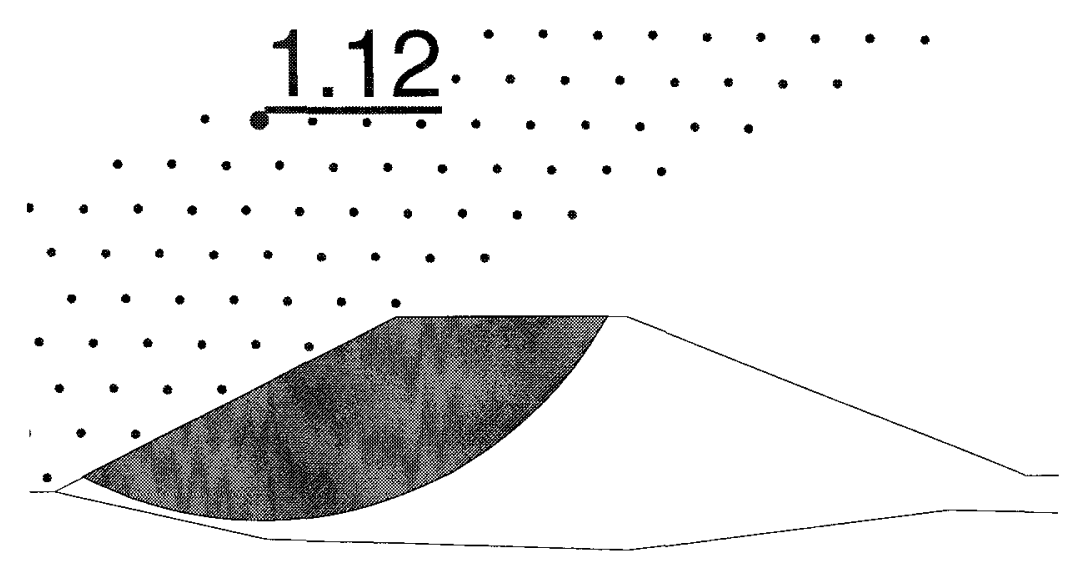

Figure 4.32 Factor of safety of the upstream side of the dam with the lower bound liquefied strength, according to the Seed and Harder (1990) approach, and based on the far-field ground motion 


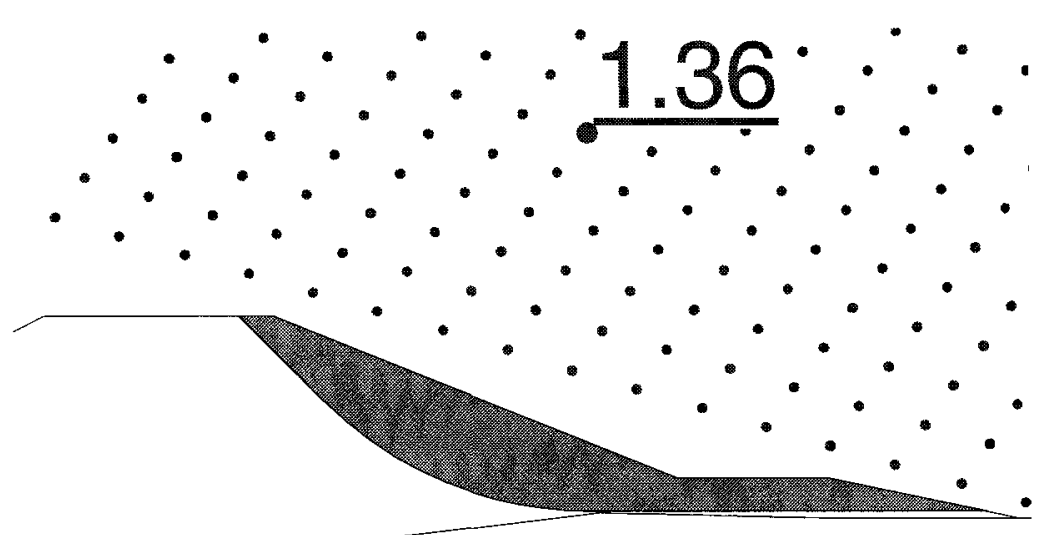

Figure 4.33 Factor of safety of the downstream side of the dam with the lower bound liquefied strength, according to the Seed and Harder (1990) approach, and based on the near-field ground motion

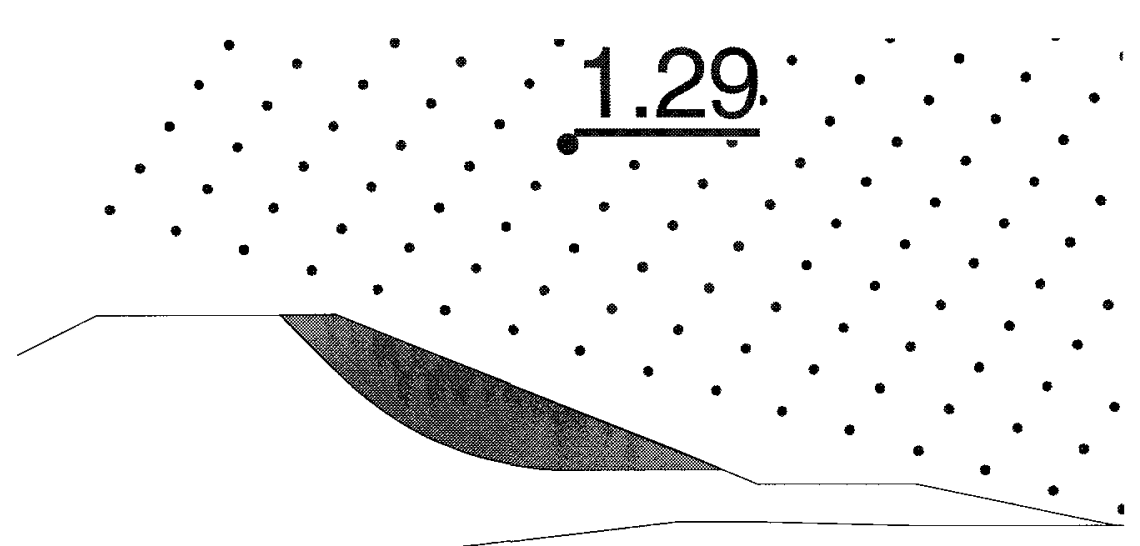

Figure 4.34 Factor of safety of the downstream side of the dam with the lower bound liquefied strength, according to the Seed and Harder (1990) approach, and based on the far-field ground motion 


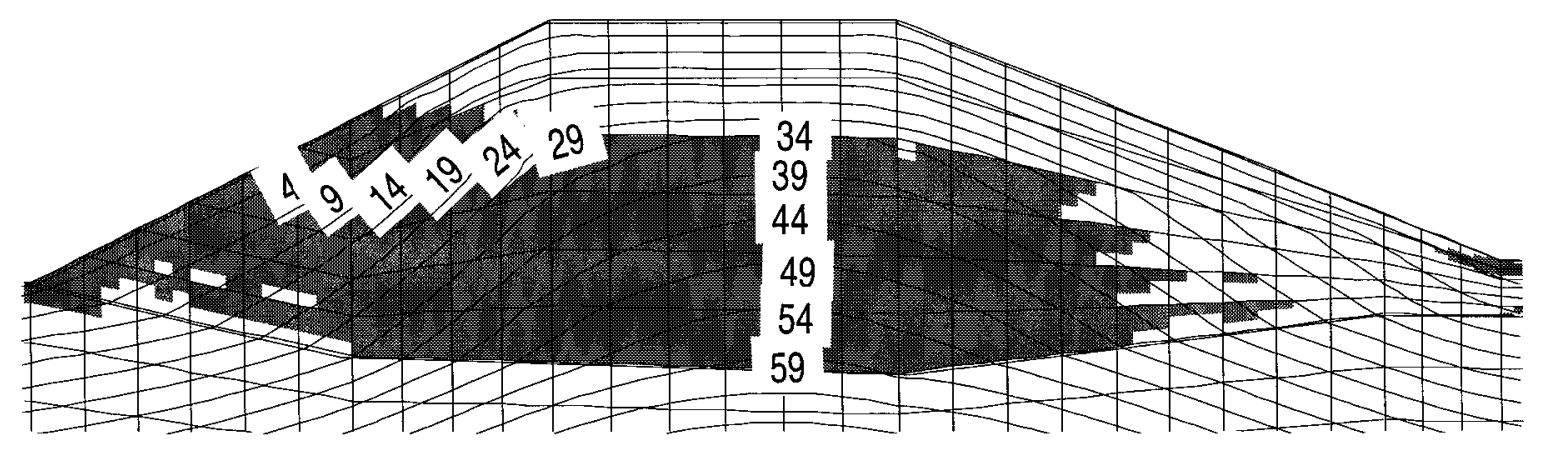

Figure 4.35 The pre-earthquake vertical effective stress and the liquefied area due to the far-field ground motion 


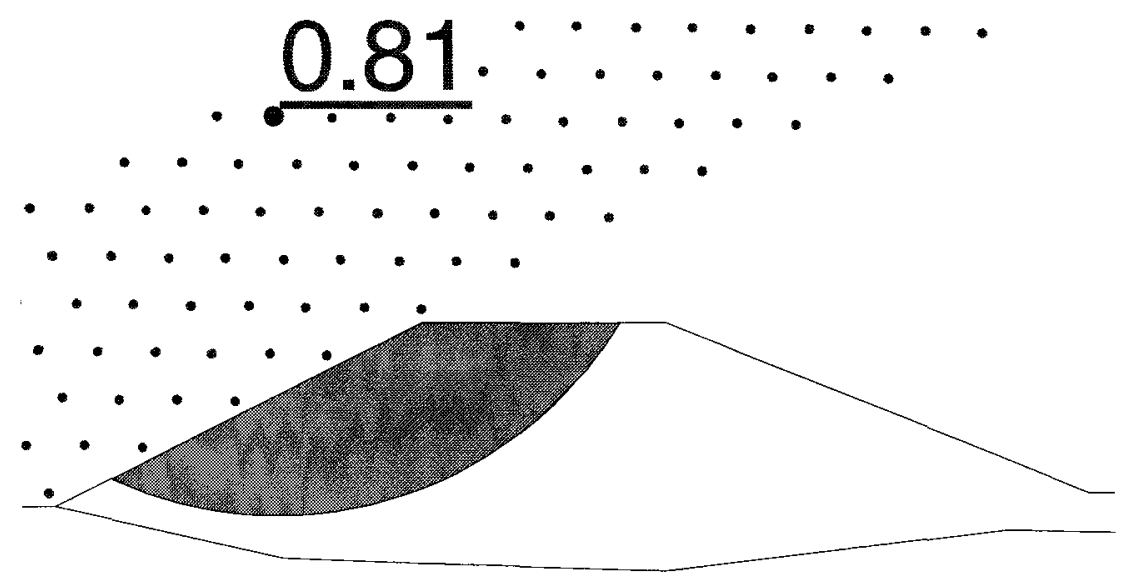

Figure 4.36 Factor of safety of the upstream side of the dam with the average liquefied strength, according to the Olson and Stark (2002) approach, and based on the near-field ground motion

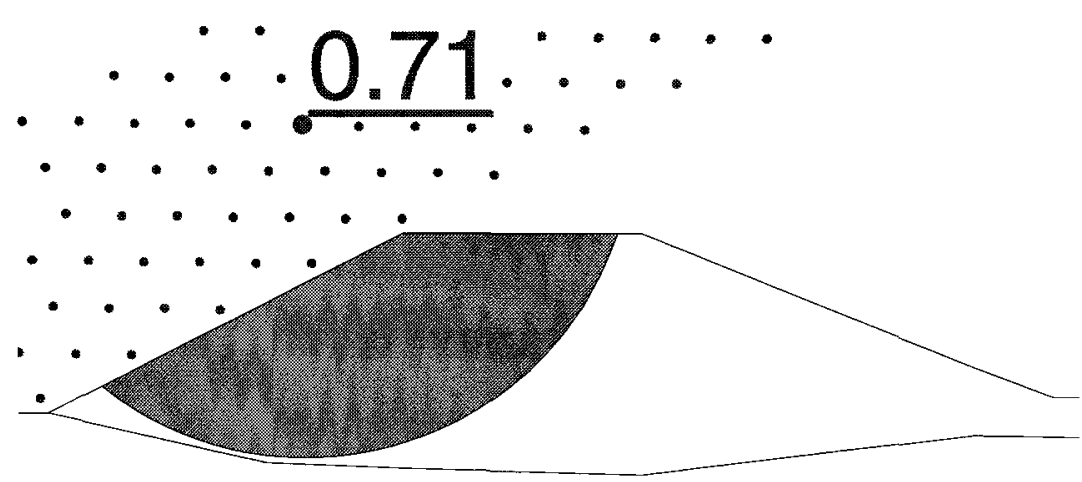

Figure 4.37 Factor of safety of the upstream side of the dam with the average liquefied strength, according to the Olson and Stark (2002) approach, and based on the far-field ground motion 


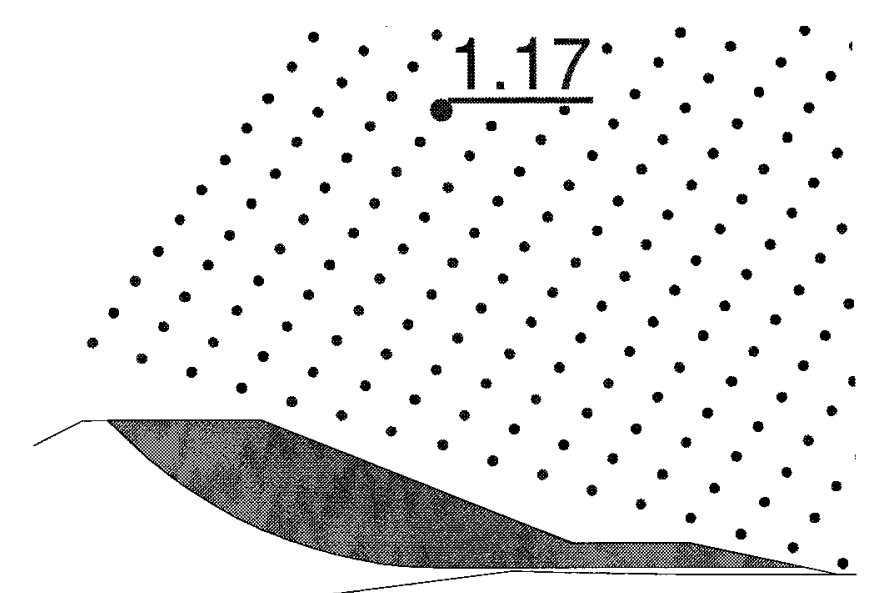

Figure 4.38 Factor of safety of the downstream side of the dam with the average liquefied strength, according to the Olson and Stark (2002) approach, and based on the near-field ground motion

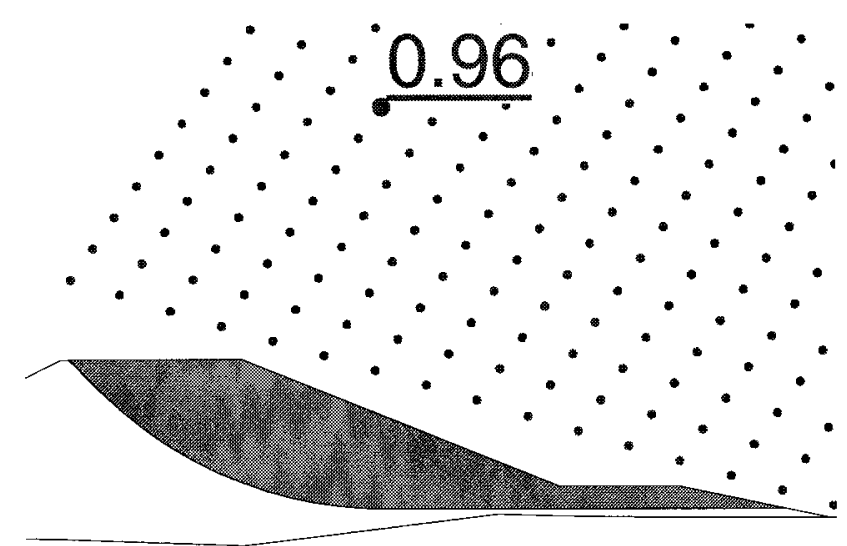

Figure 4.39 Factor of safety of the downstream side of the dam with the average liquefied strength, according to the Olson and Stark (2002) approach, and based on the far-field ground motion 


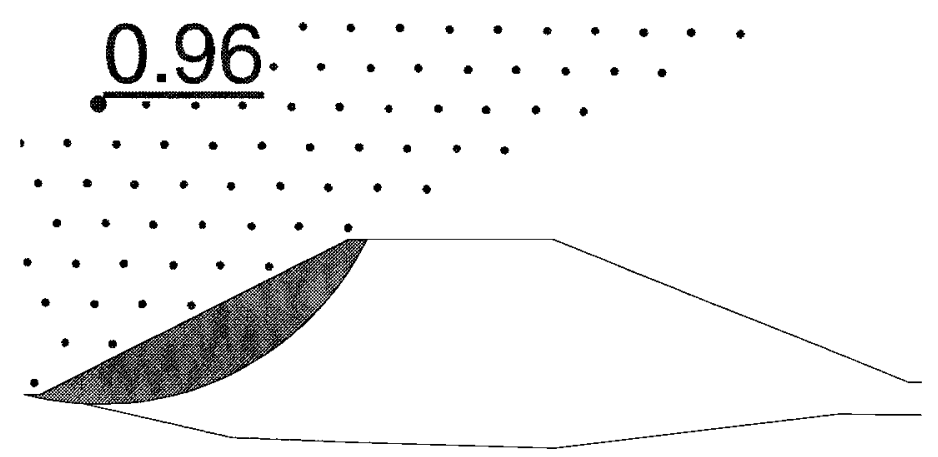

Figure 4.40 Factor of safety of the upstream side of the dam with the average liquefied strength, according to the Olson and Stark (2002) approach, and based on the short-period ground motion (M6)

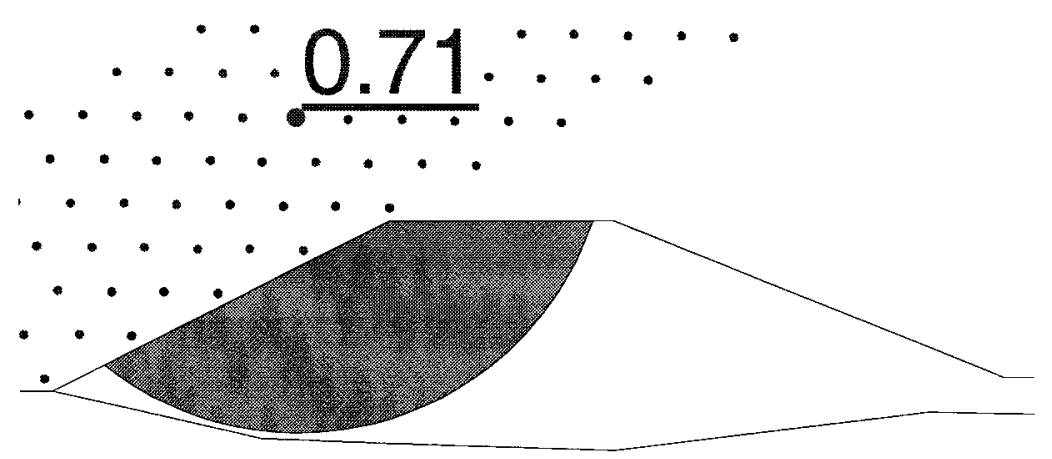

Figure 4.41 Factor of safety of the upstream side of the dam with the average liquefied strength, according to the Olson and Stark (2002) approach, and based on the long-period ground motion (M7) 


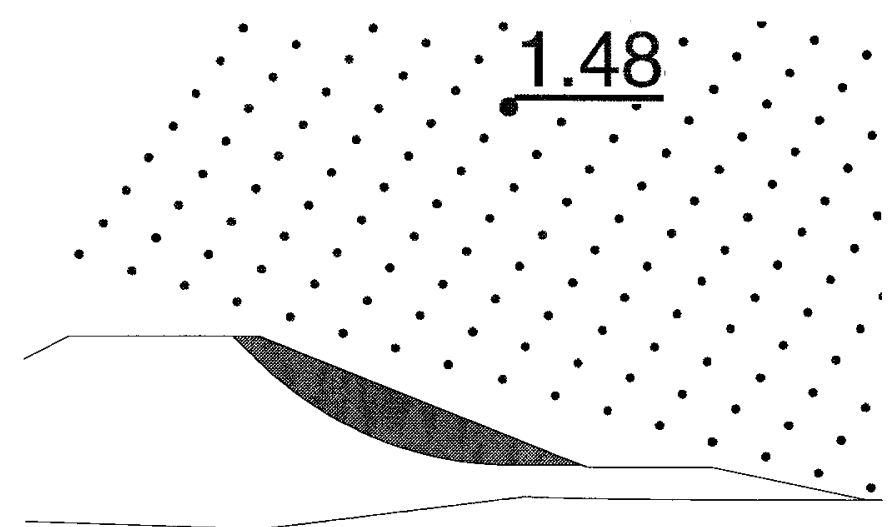

Figure 4.42 Factor of safety of the downstream side of the dam with the average liquefied strength, according to the Olson and Stark (2002) approach, and based on the short-period ground motion (M6)

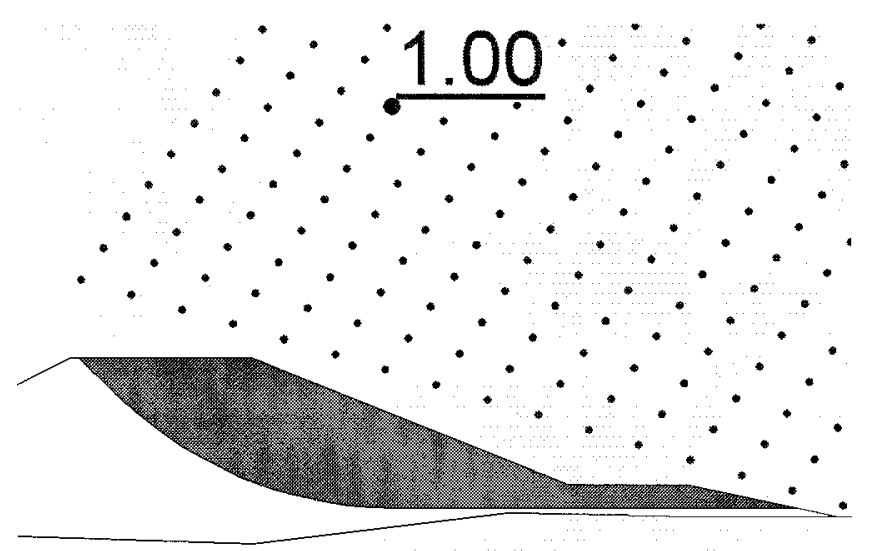

Figure 4.43 Factor of safety of the downstream side of the dam with the average liquefied strength, according to the Olson and Stark (2002) approach, and based on the long-period ground motion (M7) 


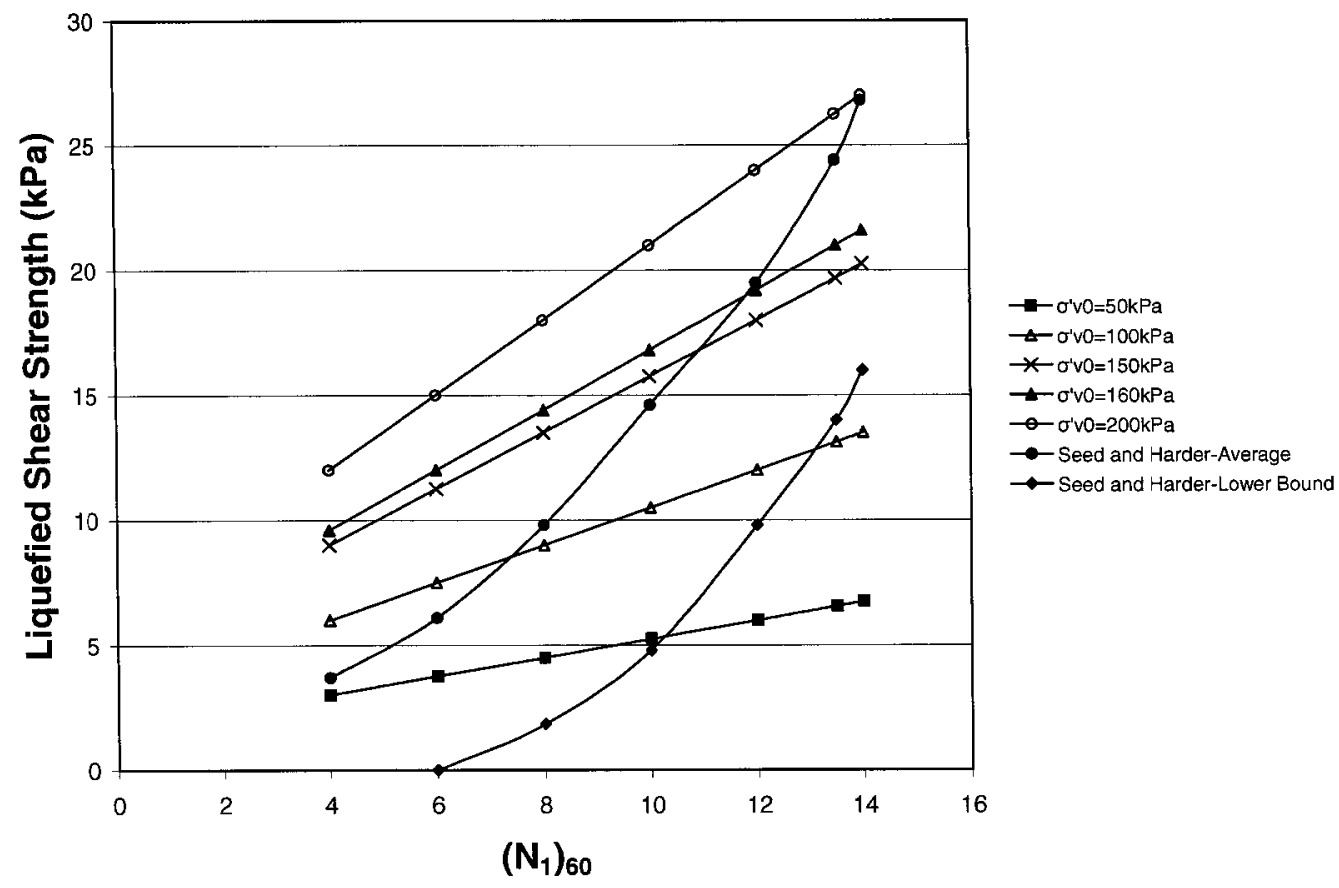

Figure 4.44 Comparing the liquefied shear strength based on approaches of Seed and Harder (1990) and Olson and Stark (2002) 


\section{CHAPTER 5}

\section{REMEDIATION OF THE TYPICAL LIQUEFIABLE DAM IN CANADA}

The results of the slope stability analyses based on Olson and Stark (2002) approach show that the Canadian dam has potential to a flow type of failure when it is subjected to the large magnitude ground motion with return period of either 2,500 or 10,000 years. This chapter deals with some possible remedial measures to prevent the failure. Use of stabilizing berms and recompaction of the original fill layer are two possible remedial measures.

\subsection{Use of stabilizing berms}

The design of stabilizing berms involves complete analysis of liquefaction initiation and the subsequent slope stability. The berms are assumed to be composed of granular materials compacted to the state that the SPT blow-counts N of 15 or 20 blows $/ 30 \mathrm{~cm}$. A certain berm size is first chosen for the evaluation of liquefaction initiation. Then, the results of this evaluation are applied in the subsequent stability 
analysis to estimate the factor of safety against flow slide. This procedure is repeated until a sufficiently high factor of safety is obtained.

The berms on the upstream and the downstream sides have the same slope of 1:2.5 and the unit weight of the berm material is assumed to be $20 \mathrm{kN} / \mathrm{m}^{3}$. Other soil parameters for the new fill of the berms are determined in similar ways to what has been described in the last chapter. Those parameters such as the damping ratio and its function, which are not correlated to $\mathrm{N}$ value, have been considered equal to what were applied for the original fill layer. The determination of these parameters is described in the following. $\left(\mathrm{N}_{1}\right)_{60}$ values and friction angle

Based on Equations 4.1 to 4.4 the standardized $\mathrm{N}$ values and the drained friction angels are determined and are shown in Table 5.1.

\section{Poisson's ratio and Modulus of elasticity}

The Poisson's ratio of the new fill is taken as 0.40 , identical to that of the original fill, and the modulus of elasticity is assumed equal to $40 \mathrm{MPa}$.

$\mathbf{K}_{2 \max }$

This parameter is dependent on the relative density and therefore, to the $\mathrm{N}$ value. The calculated values of this layer, with respect to the assumed $\mathrm{N}$ values, have been shown in Table 5.1.

\section{Damping ratio}

This parameter is assumed identical to the damping ratio of the original fill layer and is equal to $7 \%$. 


\section{$\mathbf{K}_{\sigma}$ and $\mathbf{K}_{\alpha}$ correction functions}

These parameters have been calculated for the associated relative densities and are shown in Figure 5.2 to Figure 5.4. The $\mathrm{K}_{\alpha}$ correction function for $\mathrm{N}=20$ blows $/ 30 \mathrm{~cm}$ is the same as the function which has been utilized for $\mathrm{N}=15$ because both presented functions correspond to a relative density of $70 \%$ or higher.

\section{Cyclic number functions}

Figure 5.5 and Figure 5.6 show the cyclic number functions corresponding to $\mathrm{N}$ equal to 15 and 20 blows $/ 30 \mathrm{~cm}$, respectively.

\section{Pore pressure, $\mathbf{G}$ reduction, and damping ratio function}

All these three functions are assumed the same as those that have been applied for the original fill layer.

\section{Liquefied shear strength}

Based on Olson and Stark (2002) the liquefied strength is related to $\left(\mathrm{N}_{1}\right)_{60}$ as shown in Equation 2.21. This equation, however, is based on $\left(\mathrm{N}_{1}\right)_{60}$ less than 12. For the new fill of the berms with $\left(\mathrm{N}_{1}\right)_{60}$ larger than 12 , the liquefied strength ratio is obtained by linearly extrapolating the existing data. Hence, the liquefied strength ratios for $\left(\mathrm{N}_{1}\right)_{60}$ of 15 and 20 blows $/ 30 \mathrm{~cm}$ are found to be 0.221 and 0.285 , respectively.

\subsubsection{Evaluation of liquefaction initiation}

The procedure of evaluating liquefaction initiation is the same as what has been applied in LSFD and the Canadian dam. Some analyses are conducted with different dimensions of the berms for the two assumed $\mathrm{N}$ values. The far-field ground motion with 10,000 -year return period is applied during the dynamic analysis because the factors of safety for both the upstream and the downstream sides are the most critical under this 
earthquake. After liquefaction analysis for each dimension of the berms, the associated stability analysis is conducted to obtain the factor of safety. The result of one of the liquefaction analyses is shown in Figure 5.7. The figure shows that zones of liquefaction are found in some parts of the upstream berm and in the original dam body. Therefore, the likelihood of slope failure of the dam with the berm and the upstream berm only has to be considered separately.

\subsubsection{Slope stability analysis}

Stability analyses are conducted after the evaluation of liquefaction initiation. The dynamic analyses show that part of the upstream berm will be liquefied at the end of the far-field ground motion. Therefore, liquefied shear strength should be applied to the liquefied zone for the stability analyses. Using the deduced liquefied strength ratio and determining the vertical effective stress in the mid depth of the liquefied area the liquefied strength of the berm can be estimated. The liquefied shear strength corresponding to each berm size has been shown in Table 5.1.

There is little guidance on the appropriate factor of safety for designing slopes involving the application of liquefaction strength to liquefied zones caused by earthquakes. For pseudo-static analysis based on the peak strength, past design experience suggests a safety factor ranging from 1.0 to 1.5 (Seed, 1979) with no regard to the nature of material in the dam and the foundation. For non-liquefiable material Seed (1979) further suggests a factor of 1.15 is adequate in the pseudo-static analysis.

In this thesis, it is recognized that flow slide failure occurs after the earthquake ground motions come to the halt. Therefore, a static slope stability analysis is used here, which takes into consideration that in the liquefied zone, only the liquefied strength can 
be mobilized. This is a transient situation and hence, a factor of safety of 1.3 is considered adequate. Based on this, therefore, the berm size of $\mathrm{W}=10.00 \mathrm{~m}, \mathrm{H}=3.30 \mathrm{~m}$ for the upstream side and $\mathrm{W}=3.50 \mathrm{~m}, \mathrm{H}=2.70 \mathrm{~m}$ for the downstream side with the material compacted to $\mathrm{N}=15$ blows $/ 30 \mathrm{~cm}$ will provide the necessary safety factor against flow slide failure in consequence to the development of liquefied zone caused by the design earthquake. The summary of the soil parameters and results of analyses for the upstream side are shown in Table 5.1. Because the stability analyses on the size of the upstream berm mentioned above show that there is little increase in the safety factor by increasing $\mathrm{N}$ from 15 to 20 blows $/ 30 \mathrm{~cm}$, the berm material corresponding to $\mathrm{N}=15$ blows $/ 30 \mathrm{~cm}$ is selected. The stability analysis with the mentioned size of the downstream berm gives the sufficient factor of safety for the material compacted to $\mathrm{N}=15$ blows $/ 30 \mathrm{~cm}$. Therefore, no analysis with the material with $\mathrm{N}=20 \mathrm{blows} / 30 \mathrm{~cm}$ is conducted for the downstream berm. The results of stability analysis corresponding to Figure 5.7 are shown in Figure 5.8 and Figure 5.9 for the upstream and the downstream sides, respectively.

Because the upstream berm is more critical than the downstream berm, a separate stability analysis was carried out for the upstream berm. The analysis shows that the factor of safety is 1.5 , higher than that of the dam with the berm.

\subsection{Dam recompaction}

The second method is to recompact the existing loose dam material to a certain resistance as indicated by the SPT N value. Analysis, therefore, have been conducted to determine what $\mathrm{N}$ value is required.

In this method, it is assumed that the loose fill of the dam is recompacted by first being excavated and placed back with appropriate compaction. The final dimension of 
the dam will remain unchanged. Analyses as demonstrated earlier in this chapter are conducted with three assumed $\mathrm{N}$ values corresponding to three different degrees of recompaction. The soil parameters for the analysis are shown in Table 5.2. The applied cyclic number function and the $\mathrm{K}_{\sigma}$ correction function corresponding to $\mathrm{N}=12$ blows $/ 30 \mathrm{~cm}$ are shown in Figure 5.10 and Figure 5.11, respectively. For the material with $\mathrm{N}=15$ and 20 blows $/ 30 \mathrm{~cm}$ the cyclic number function and the $\mathrm{K}_{\sigma}$ correction function of the berms are employed. The $\mathrm{K}_{\alpha}$ correction functions corresponding to these three degrees of recompaction are considered identical to the applied function for the berms analyses. The results are shown in Figure 5.12. To achieve a factor of safety of 1.3 , the results show that $\mathrm{N}$ is equal to 20 blows $/ 30 \mathrm{~cm}$.

\subsection{Choice of method}

While both remedial methods can provide the needed factor of safety, the choice of the method depends largely on the cost of individual method. No attempt is made here to conduct a cost analysis to arrive at the final choice as it is outside the scope of this thesis. However, recompacting the existing dam may require a cofferdam to prevent water running downstream. The cost therefore, may be higher than the placement of berms. 


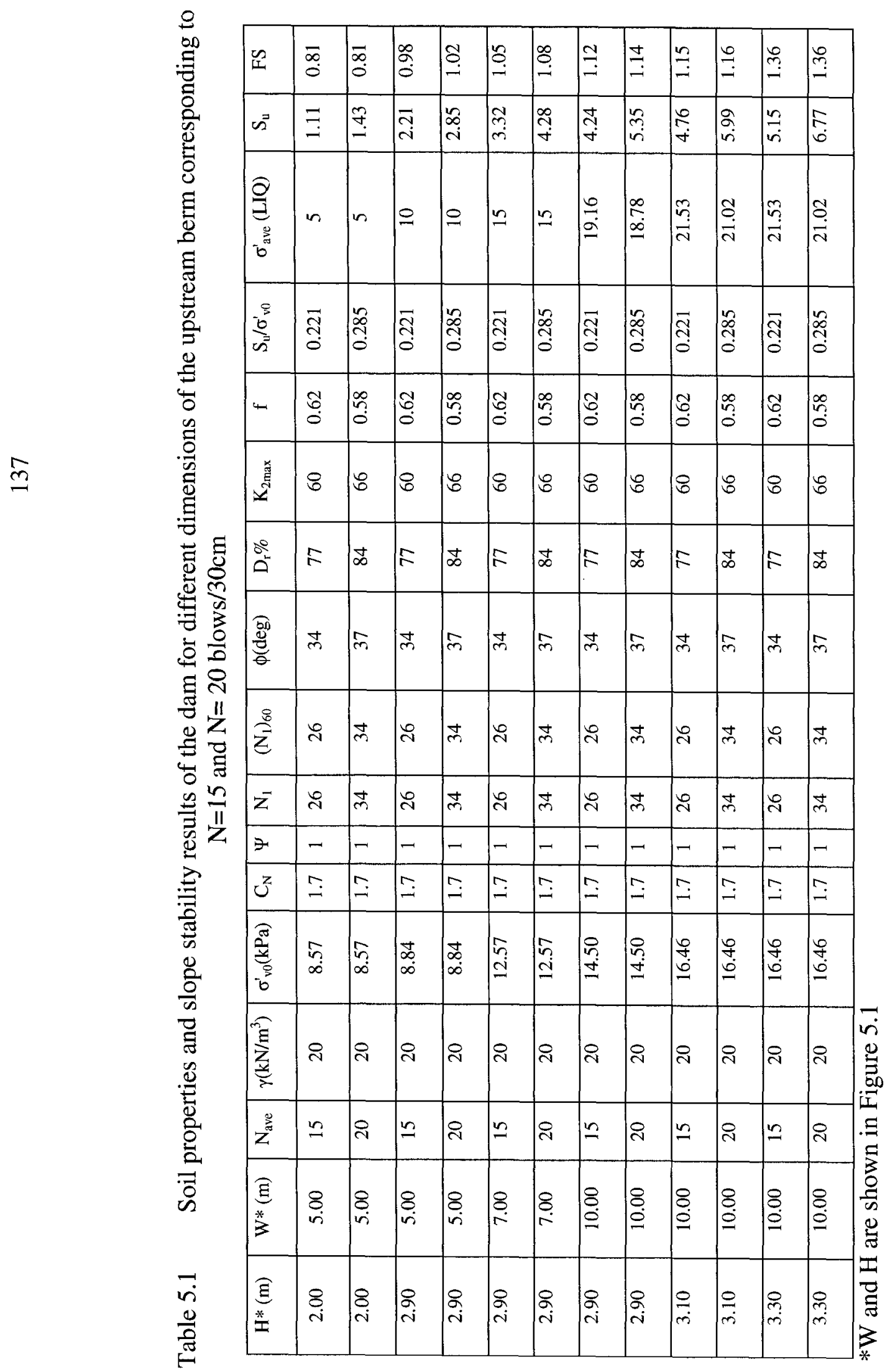


Table 5.2 Soil parameters for the material compacted to $\mathrm{N}=7,12,15,20$ blows $/ 30 \mathrm{~cm}$; $\mathrm{N}=7$ corresponds to the original loose fill.

\begin{tabular}{|c|c|c|c|c|c|c|c|c|c|c|}
\hline $\mathrm{N}$ & $\mathrm{C}_{\mathrm{N}}$ & $\Psi$ & $\mathrm{N}_{1}$ & $\left(\mathrm{~N}_{1}\right)_{60}$ & $\mathrm{D}_{\mathrm{r}} \%$ & $\mathrm{~K}_{2 \max }$ & $\phi$ & $218.8 \mathrm{~K}_{2 \max }$ & $\mathrm{f}$ & $\mathrm{S}_{\mathrm{u}} / \sigma_{\mathrm{v}}^{\prime}$ \\
\hline 7 & 1.55 & 1.00 & 12 & 12 & 54 & 48 & 31 & 10502 & 0.73 & 0.12 \\
\hline 12 & 1.55 & 1.00 & 19 & 19 & 63 & 53 & 32 & 11684 & 0.69 & 0.1696 \\
\hline 15 & 1.55 & 1.00 & 23 & 23 & 69 & 56 & 34 & 12297 & 0.66 & 0.2045 \\
\hline 20 & 1.55 & 1.00 & 31 & 31 & 80 & 63 & 36 & 13711 & 0.60 & 0.2627 \\
\hline
\end{tabular}




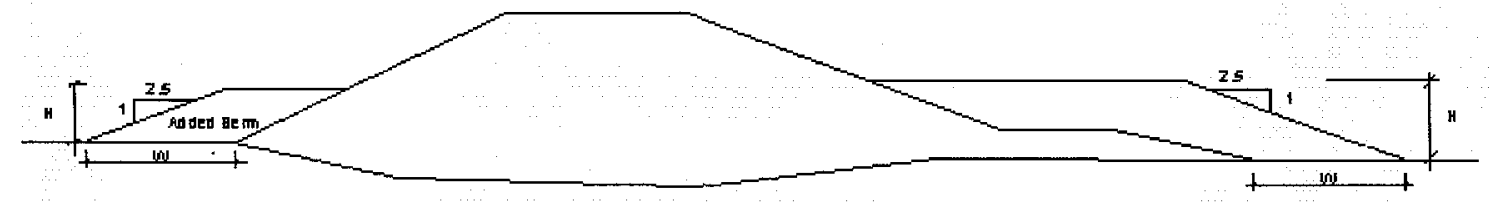

Figure 5.1 Geometry of the dam with the added berms

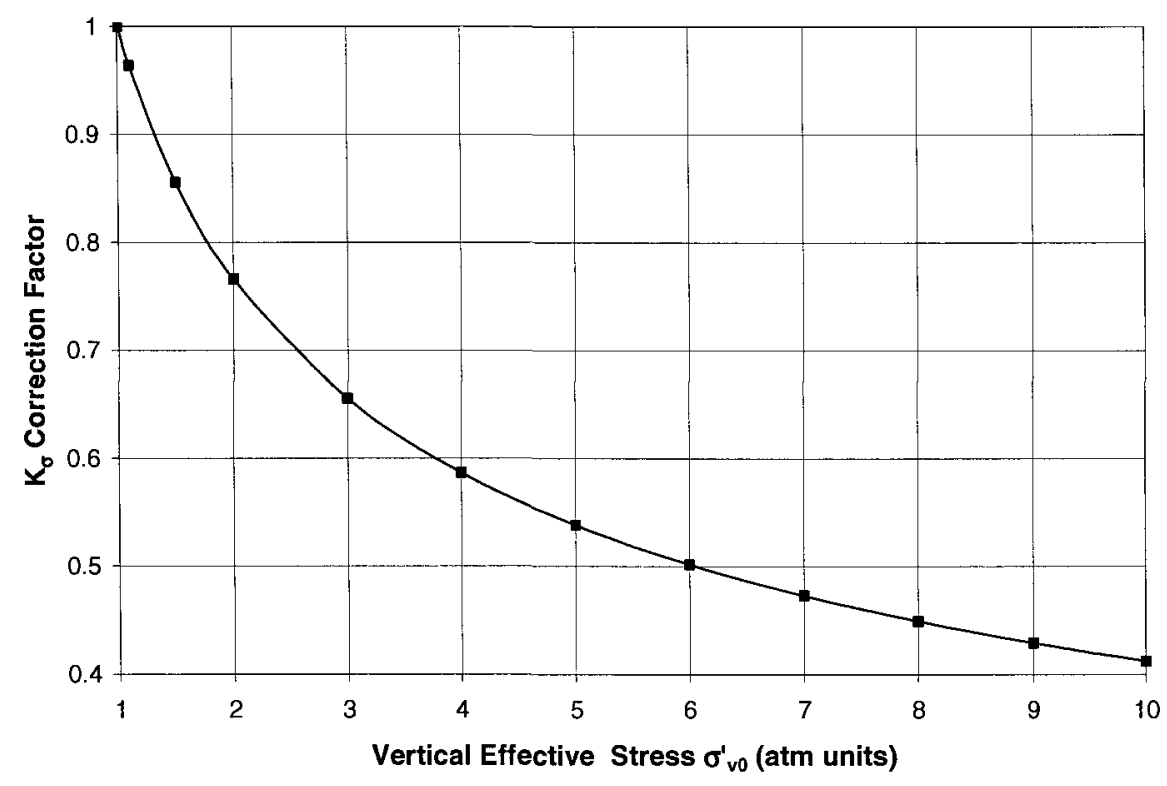

Figure 5.2 $\mathrm{K}_{\sigma}$ correction function for the berm material compacted to $\mathrm{N}=15$ blows $/ 30 \mathrm{~cm}$ 


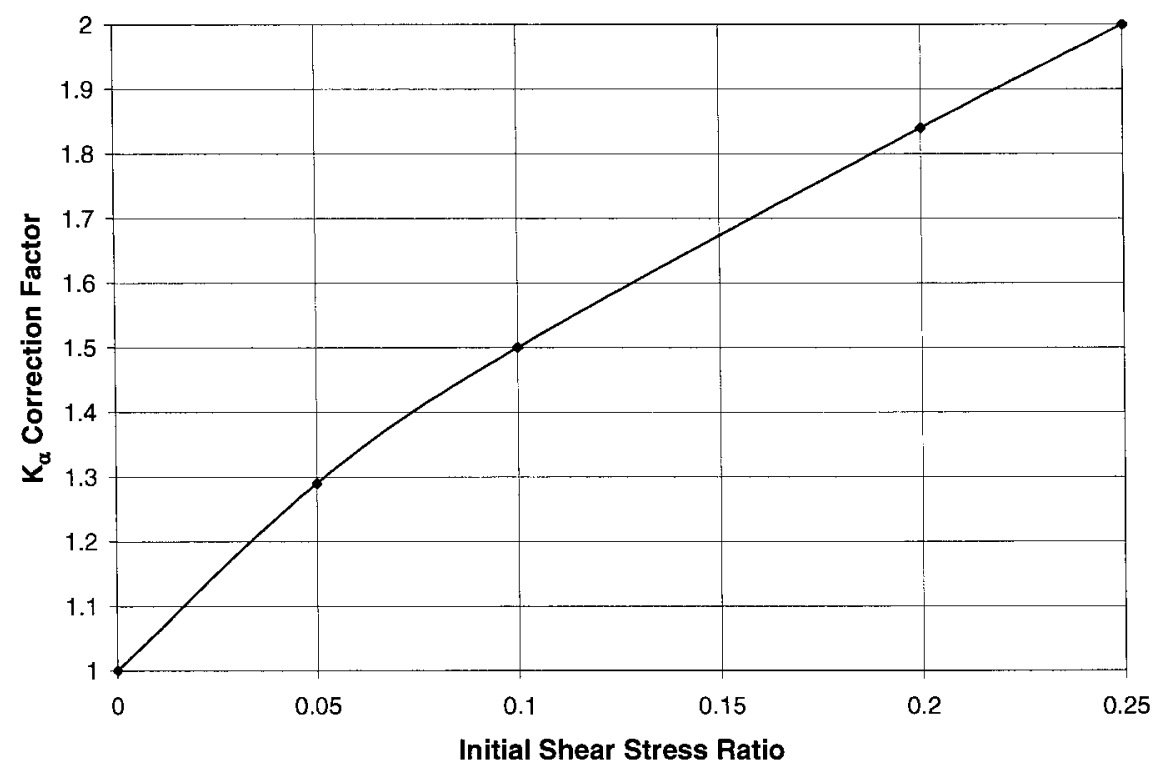

Figure 5.3 $\mathrm{K}_{\alpha}$ correction factor for the berm material compacted to $\mathrm{N}=15$ and $\mathrm{N}=20$ blows $/ 30 \mathrm{~cm}$

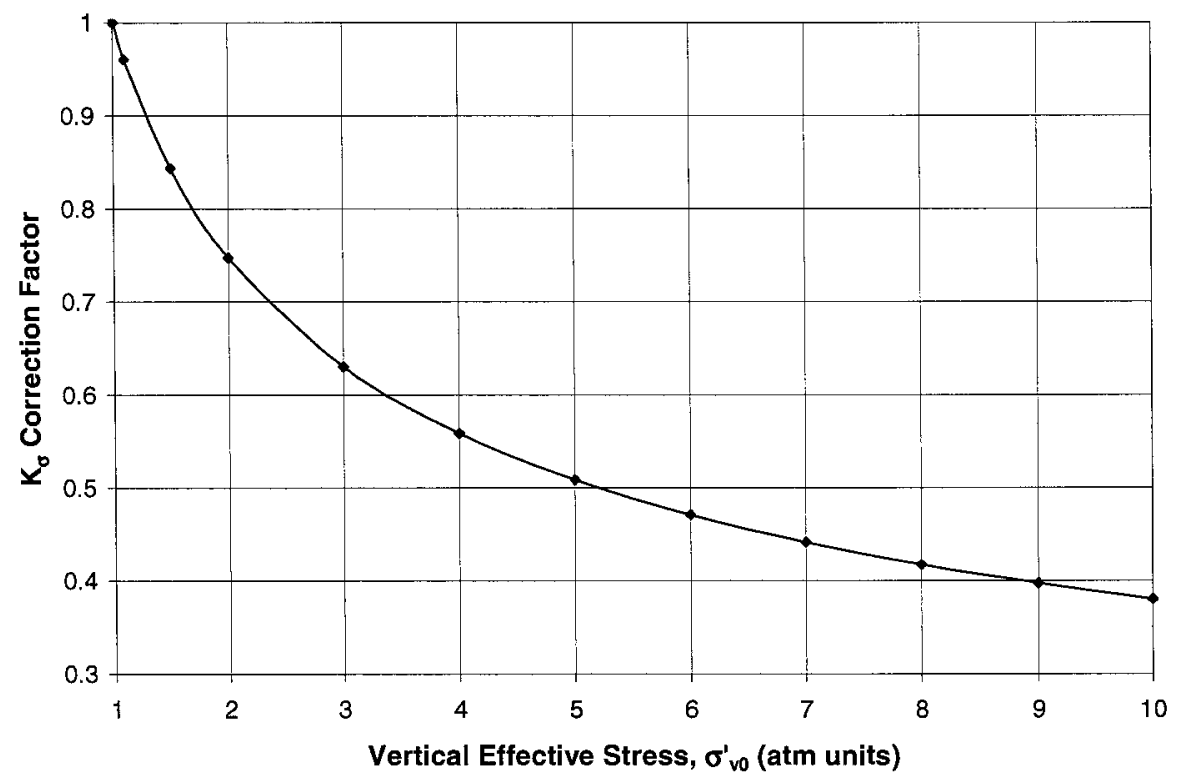

Figure 5.4 $\mathrm{K}_{\sigma}$ correction function for the berm material compacted to $\mathrm{N}=20$ blows $/ 30 \mathrm{~cm}$ 


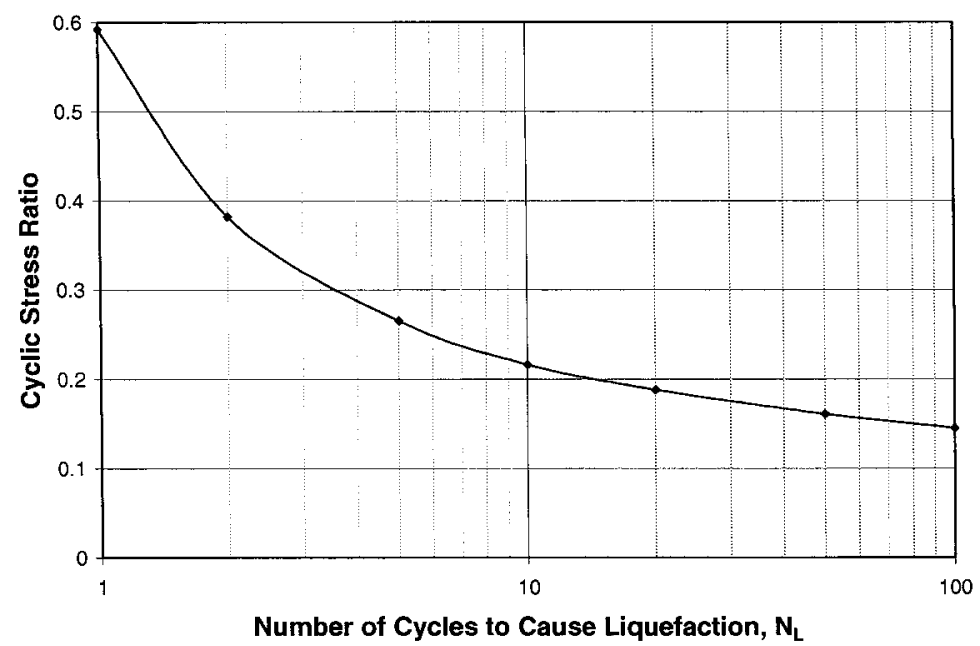

Figure 5.5 Cyclic number function of the berm material compacted to $N=15$ blows $/ 30 \mathrm{~cm}$

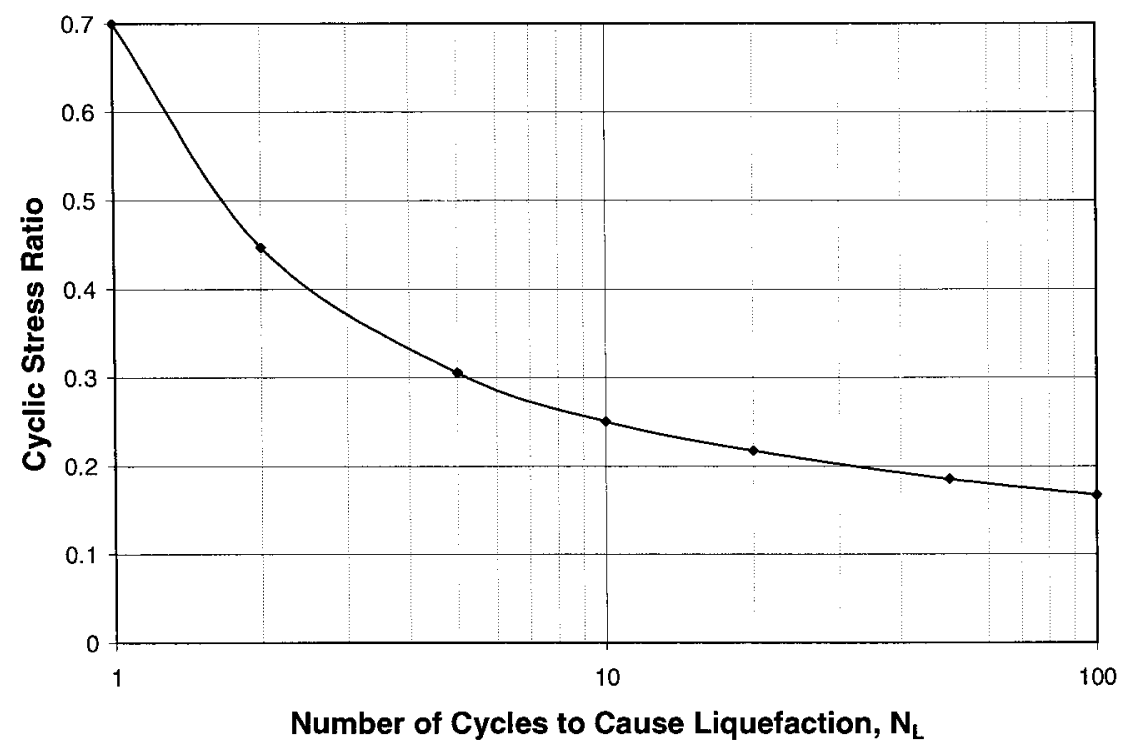

Figure 5.6 Cyclic number function of the berm material compacted to $\mathrm{N}=20$ blows $/ 30 \mathrm{~cm}$ 


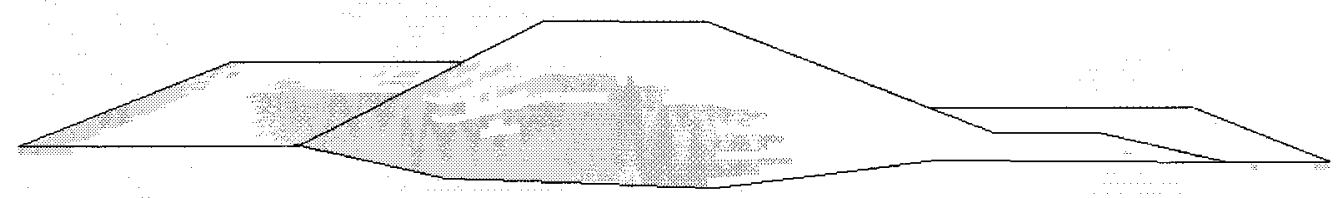

Figure 5.7 Dynamic analysis of the dam with the berm material compacted to $\mathrm{N}=15$ blows $/ 30 \mathrm{~cm}$

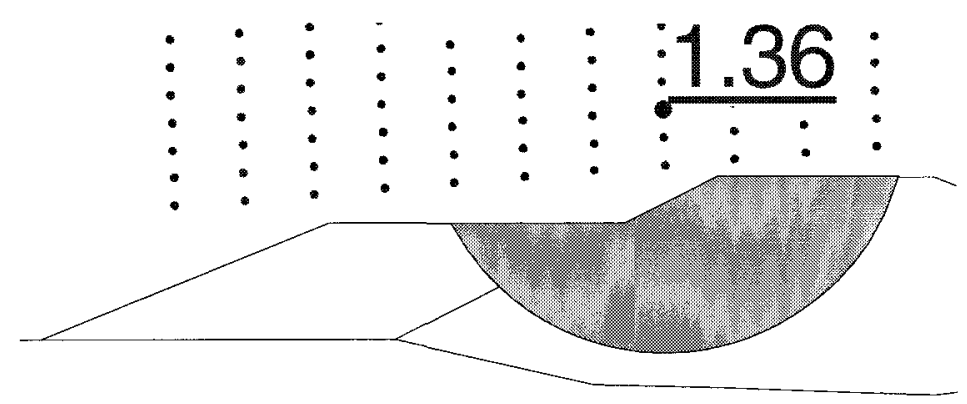

Figure 5.8 Result of slope stability analysis for the upstream berm with $H=3.30 \mathrm{~m}$, $\mathrm{W}=10.00 \mathrm{~m}$, material compacted to $\mathrm{N}=15$ blows $/ 30 \mathrm{~cm}$ 


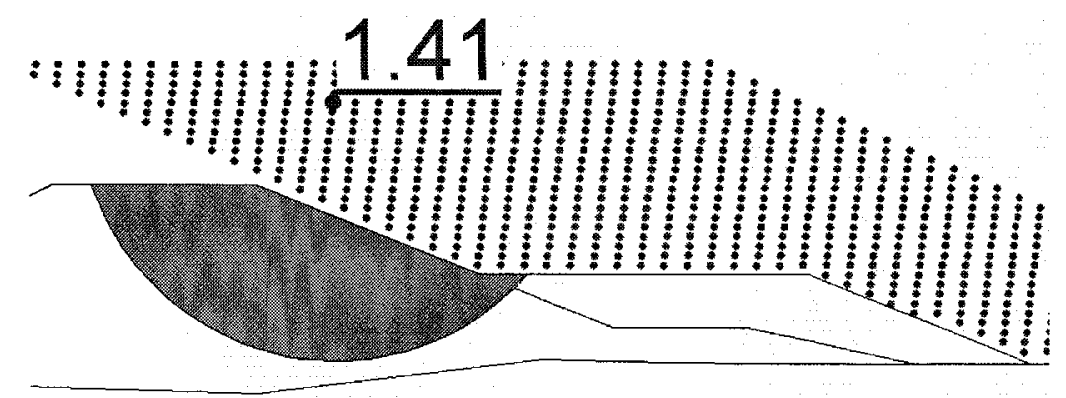

Figure 5.9 Result of slope stability analysis for the downstream berm with $\mathrm{H}=2.70 \mathrm{~m}$, $\mathrm{W}=3.50 \mathrm{~m}$, material compacted to $\mathrm{N}=15 \mathrm{blows} / 30 \mathrm{~cm}$

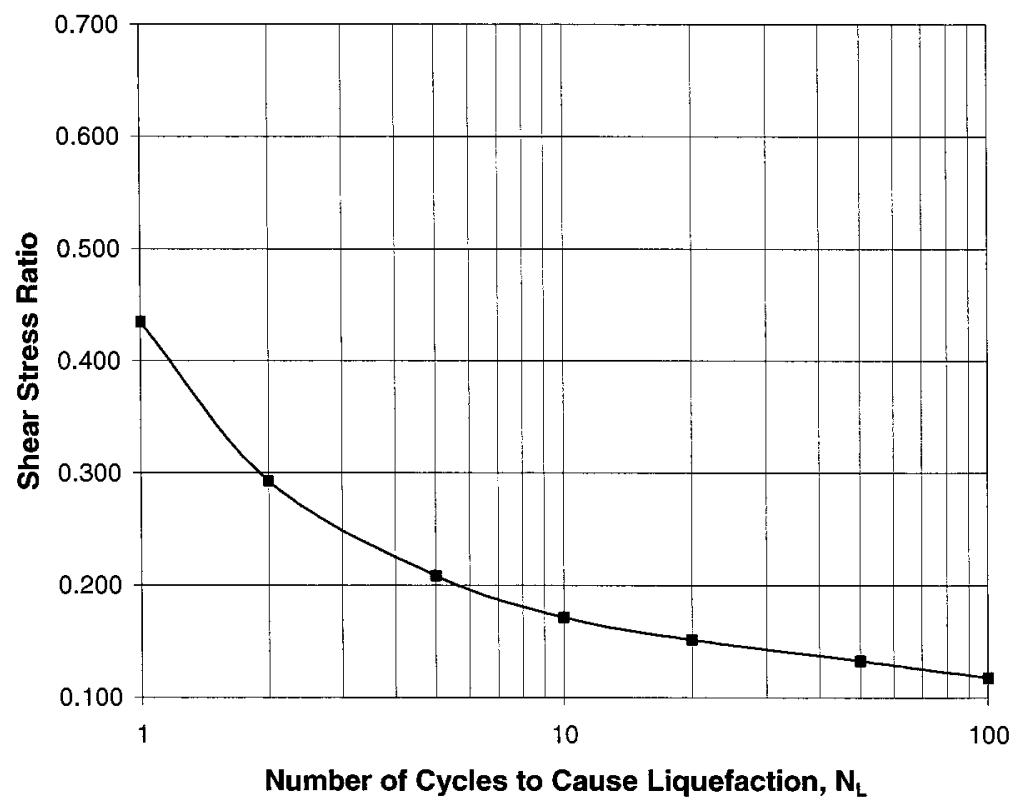

Figure 5.10 Cyclic number function of the soil with respect to $\mathrm{N}=12 \mathrm{blows} / 30 \mathrm{~cm}$ 


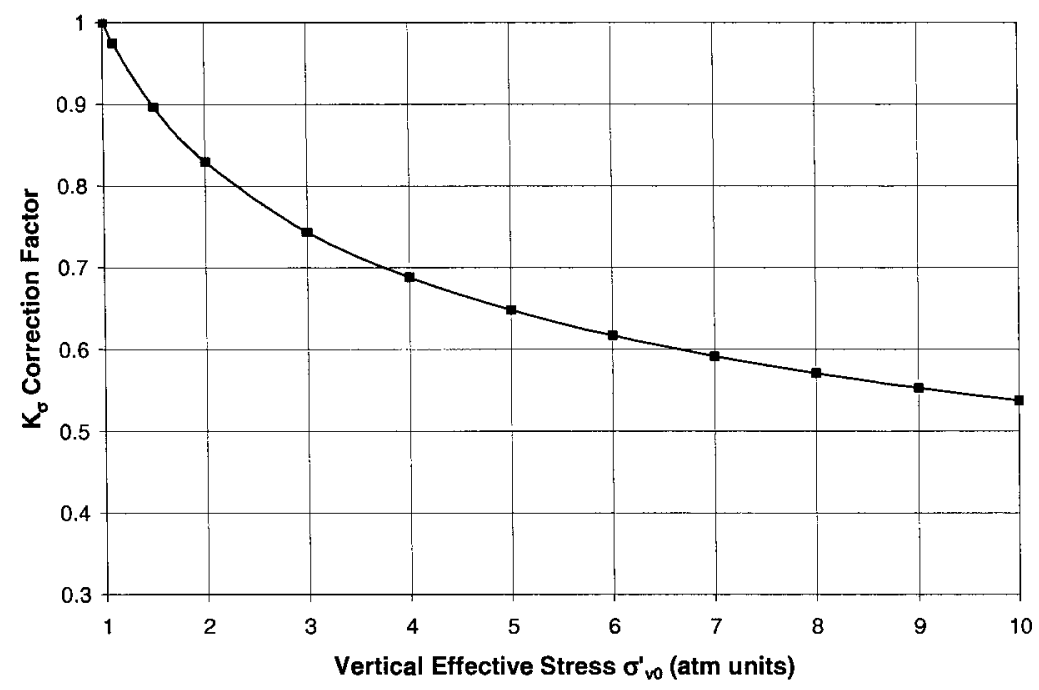

Figure $5.11 \mathrm{~K}_{\sigma}$ correction functions with respect to $\mathrm{N}=12$ blows $/ 30 \mathrm{~cm}$

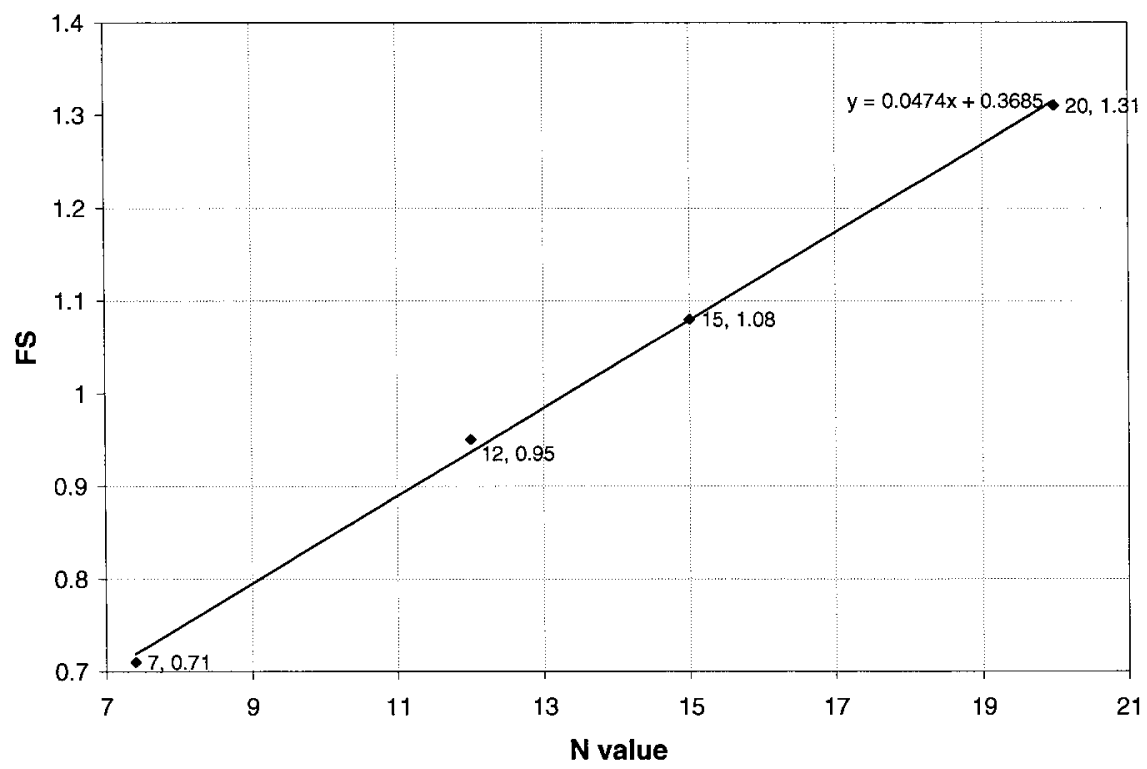

Figure 5.12 Variation of factor of safety of the fill layer of the dam with respect to SPT N values 


\section{CHAPTER 6}

\section{SUMMARY AND CONCLUSIONS}

\subsection{Summary}

A deterministic analysis was performed to evaluate the slope stability of liquefiable earthdams. Background information in the liquefaction hazard assessment, determination of residual strength of liquefied soils, and the use of suitable computer programs are required for appraising the overall stability of liquefiable earthdams. During this study, two approaches to determine the liquefied shear strength of soils were compared to arrive at a judgment on the stability of the dam. Some possible remediation techniques to prevent liquefaction-triggered flow failure of the dam were considered.

Lower San Fernando Dam (LSFD) was evaluated here before initiating the stability analysis of a Canadian dam. The purpose of this exercise is to establish, based on a well studied case, the methodology to analyze the potential of flow slide failure of a dam vulnerable to seismic liquefaction occurrence. The most essential data and soil parameters for analysing LSFD were obtained from the works of Seed et al. (1973), Lee et al. (1975), and Seed and Harder (1990). The pre-earthquake and post-earthquake 
stresses were determined through static and dynamic analyses using a commercial program, Quake/W. With this program, the liquefied zones in the dam were identified. The stability of LSFD with these liquefied zones was analysed under the static condition since the actual failure occurred after the termination of the earthquake. Another commercial program, Slope/W, has been used for assessing the static factor of safety of the dam. For the analysis, the liquefied strength considered mobilized in the liquefied zone and drained strength in the other zones which were granular in nature. Two approaches were used for determining the liquefied strength of the soil: Seed and Harder (1990) and Olson and Stark (2002). Based on these two approaches, two separate factors of safety against flow failure were calculated. The results of this exercise demonstrated that the proposed methodology in this thesis is established for studying the potential of flow slide failure as a consequence of seismic liquefaction occurrence.

By using the methodology that is successfully applied to LSFD, the overall slope stability of an existing dam in Canada was evaluated. The ground motions with return periods of 2,500 and 10,000 years were applied in the dynamic analysis. Based on Seed and Harder (1990) and Olson and Stark (2002) approaches the liquefied strength of the soil was determined and the factors of safety against flow failure were calculated. The calculated factor of safety based on Seed and Harder (1990) indicates that the dam remains stable even after large magnitude earthquake of seven. On the other hand, the factor of safety based on Olson and Stark (2002) shows that flow slide will occur at both sides of the dam.

To reach a reasonable judgment on the stability of the dam, the reliability of these two approaches were investigated. The proposed approach by Seed and Harder (1990) correlates the absolute value of liquefied strength to the standardized penetration 
resistance $\left(\left(\mathrm{N}_{1}\right)_{60}\right)$. The Olson and Stark (2002) approach, however, gives liquefied strength ratio based on $\left(\mathrm{N}_{1}\right)_{60}$. As it is more reasonable to relate the liquefied strength ratio to $\left(\mathrm{N}_{1}\right)_{60}$, the approach of Olson and Stark (2002) is considered more appropriate for this type of analysis. Hence, it is suggested that the Olson and Stark's approach be used. Consequently, the dam under study is found likely to suffer liquefaction during the design earthquakes of return periods of both 2,500 and 10,000 years, followed by a flow slide failure.

Since it is likely that the dam will suffer a flow slide type of failure under the design earthquakes, some remedial measures are considered. Two common techniques have been examined for stabilizing the dam: the use of stabilizing berms and recompaction of the loose fill of the dam. For the first technique, berms with different dimensions were tried to give sufficient factor of safety for stability. The analyses were conducted with two SPT N values of 15 and 20 blows $/ 30 \mathrm{~cm}$ for the berms. In the second technique, three $\mathrm{N}$ values of 12,15 , and 20 blows $/ 30 \mathrm{~cm}$, each representing a certain degree of compaction, were selected for reanalysing the stability of the dam. The value of $\mathrm{N}$ corresponding to the required factor of safety was estimated on the basis of the results of analysis.

\subsection{Conclusions}

The following conclusions can be drawn based on the study described in this thesis:

1. A method is proposed for analysing the seismic stability of liquefiable earthdams. The method consists of three main steps. First, the geometry and the maximum time history of the earthquake are determined. Second, pre-earthquake and post-earthquake 
stresses are determined through static and dynamic analyses to identify the liquefied regions of the dam and the foundation. Third, the stability of the dam with these liquefied zones is analysed under the static condition. For the stability analysis, the liquefied strength is considered operational in the liquefied zones and drained strength in the non-liquefied zones. Two approaches are used for determining the liquefied strength of the soil: Seed and Harder (1990) and Olson and Stark (2002).

2. The analysis of LSFD based on this method using the liquefied strength from the approach either by Seed and Harder (1990) or by Olson and Stark (2002) gives results nearly similar to what has been obtained by Seed et al. in 1973 . Therefore, this analysis suggests that the proposed method in this thesis is useful for studying the potential of flow slide failure as a consequence of seismic liquefaction occurrence.

3. The proposed method is then used for the analysis of the overall slope stability of a dam in Canada based on design ground motions with return periods of 2,500 and 10,000 years. The liquefied strength of the soil was determined based on Seed and Harder (1990) and Olson and Stark (2002) approaches.

4. The analysis of the dam with liquefied shear strength (either average or lower bound) based on Seed and Harder (1990) shows that the dam will remain stable even after large magnitude earthquake of seven. On the other hand, the analysis with liquefied shear strength based on Olson and Stark (2002) for the same earthquake shows that the flow slides will occur at the both sides of the dam after the design earthquakes.

5. The different results in stability analysis using different liquefied strength of the two different approaches have been examined. It is found that the approach by Olson and Stark (2002) is more reliable because this approach is more current, employs more 
case histories and more reliable data and more importantly, considers the effect of confining stress on liquefaction strength.

6. Hence, according to the Olson and Stark (2002) approach, both sides of the fill layer of the dam will likely fail in a flow slide type of failure under the design earthquakes with the return periods of 2,500 and 10,000 years.

7. Because of the likelihood of flow slide failure of the dam under the design earthquakes, two common techniques have been considered for remediation of the dam: the use of stabilizing berms and recompaction of the loose fill of the dam.

8. Using the method of analysis proposed in this thesis, it is found that for the first method of remediation, a berm with width $(\mathrm{W})$ of $10.00 \mathrm{~m}$ and a height $(\mathrm{H})$ of $3.30 \mathrm{~m}$ on the upstream side and another berm of $\mathrm{W}=3.50 \mathrm{~m}$ and $\mathrm{H}=2.70 \mathrm{~m}$ on the downstream side of the dam will provide sufficient stability to the dam under the design earthquake.

9. The same method of analysis also shows that for the second method of remediation, sufficient stability will be achieved during the design earthquake if the original fill in the dam is recompacted to give a standard penetration resistance of 20 blows $/ 30 \mathrm{~cm}$.

\subsection{Further studies}

To improve the reliability of the analysis of the dam under the design earthquake, the soil characteristics of the layers of the dam should be determined through more extensive in-situ and laboratory studies. A numerical analysis with non-linear soil modeling can be developed to assess the factor of safety of the dam against flow slide failure. A rigorous analysis should be performed to determine the build-up and redistribution of the pore pressure and its effect on the strength of non-liquefied soils. To 
improve the reliability of the design of the berms, the compressibility curve of the soils should be checked against the steady-state line. If these lines are parallel, the foregoing concept is applicable. If not, the liquefied strength ratio has to be re-determined. Further, the relative technical and economical merits of adding stabilizing berms and recompaction of the original fill layer should be assessed to arrive at a reasonable decision to mitigate the hazards caused by the design earthquake. 


\section{References}

Baziar, M.H. and Dobry, R. (1995), "Residual Strength and Large-Deformation Potential of Loose Silty Sands." Journal of Geotechnical Engineering, ASCE, Vol. 121, No. 12, pp. 896-906.

Budhu, M. (1999), "Soil Mechanics and Foundations," John Wiley and Sons, New York.

Casagrande, A. (1936), "Characteristics of Cohesionless Soils Affecting the Stability of Slopes and Earth Fills," Journal of the Boston Society of Civil Engineers, reprinted in Contributions to Soil Mechanics, Boston Society of Civil Engineers, 1940, pp. 257-276.

Castro, G. (1969), "Liquefaction of Sands", Ph.D. Thesis, Harvard University, Cambridge, Massachusetts.

Castro, G. (1975), "Liquefaction and Cyclic Mobility of Sands," Journal of the Geotechnical engineering Division, ASCE, Vol. 101, No. GT6, pp. 551-569.

Das, B.M. (1998), "Principles of Geotechnical Engineering," PWS, Boston, MA.

Day, R.W. (2002), "Geotechnical Earthquake Engineering Handbook," McGraw-Hill, New York, NY.

Dealba, P., Chan, C.K., and Seed, H.B. (1975), "Determination of Soil Liquefaction Characteristics by Large-Scale Laboratory Tests," Report EERC 75-14, Earthquake Engineering Research Center, University of California, Berkeley.

Dobry, R. and Ladd, R.S. (1980), Discussion to "Soil Liquefaction and Cyclic Mobility Evaluation for Level Ground During Earthquakes," by H.B. Seed and "Liquefaction potential: science versus practice," by R.B. Peck, Journal of the Geotechnical Engineering Division, ASCE, Vol. 106, No. GT6, pp. 720-724

Dobry, R., Ladd, R.S., Yokel, F.Y., Chung, R.M., and Powell, D. (1982), "Prediction of Pore Water Pressure Buildup and Liquefaction of Sands During Earthquakes by the Cyclic Strain Method," NBS Building Science Series 138, National Bureau of Standards, Gaithersburg, Maryland, 150pp.

Fear, C.E. and Robertson, P.K. (1995), "Estimating the Undrained Strength of Sand: a Theoretical Framework," Canadian Geotechnical Journal, Vol. 32, No. 4, pp. 859-870.

Finn, W.D.L., Pickering, D.J., and Bransby, P.L. (1971), "Sand Liquefaction in Triaxial and Simple Shear Tests," Journal of the Soil Mechanics and Foundations Division, ASCE, Vol. 97, No. SM4, pp. 639-659.

GEO-SLOPE, International Ltd. 2002, Quake/W manual. 
GEO-SLOPE, International Ltd. 2002, Slope/W manual

Harder, L.F. Jr. and Boulanger, R. (1997), "Application of $\mathrm{K}_{\sigma}$ and $\mathrm{K}_{\alpha}$ Correction Factors," Proc., NCEER Workshop on Evaluation of Liquefaction Resistance of Soils, T.L. Youd and I.M. Idriss, eds., NCEER-97-0022, pp. 167-190.

Ishibashi, I. and Zhang, X. (1993), "Unified Dynamic Shear Moduli and Damping Ratios of Sand and Clay," Soil and Foundations, Vol. 33, No. 1, pp. 182-191.

Ishihara, K. (1984), "Post-earthquake Failure of a Tailings Dam Due to Liquefaction of the Pond Deposit," Proc., Inter. Conf. on Case Histories in Geotechnical Engineering, Rolla, Missouri, May 6-11, Vol. 3, pp. 1129-1143.

Ishihara, K. (1985), "Stability of Natural Deposits During Earthquakes," Proc., 11th International Conference on Soil Mechanics and Foundation Engineering, San Francisco, CA, Vol. 1, pp. 321-376.

Ishihara, K. (1993), "Liquefaction and Flow Failure during Earthquakes," Geotechnique, Vol. 43, No. 3, pp. 351-415.

Konrad, J.M. and Watts, B.D. (1995), "Undrained Shear Strength for Liquefaction Flow Failure Analysis," Canadian Geotechnical Journal, Vol. 32, pp. 783-794.

Kramer, S.L. (1996), “Geotechnical Earthquake Engineering,” Prentice-Hall, Englewood Cliffs, NJ.

Kuerbis, R.H. (1989), "Effect of Gradation and Fines Content on the Undrained Response of Sand," M.A.Sc. Thesis, The University of British Colombia, Vancouver, Canada.

Lee, K.L. and Chan, K. (1972), "Number of Equivalent Significant Cycles in Strong Motion Earthquakes," Proceeding International Conference on Microzonation, Seattle, Washington, Vol. 2, pp. 609-627

Lee, K.L., Seed, H.B., Idriss, I.M., and Makdisi, F.I. (1975), "Properties of Soil in the San Fernando Hydraulic Fill Dams," Journal of the Geotechnical Engineering Division, ASCE, Vol. 101, No.GT8, pp. 801-821.

Marcuson, W.F. and Hynes, M.E. (1990), "Stability of Slopes and Embankments during Earthquakes," Proceedings, ASCE/ Pennsylvania Department of Transportation Geotechnical Seminar, Hershey, Pennsylvania.

Marcuson, W.F., III, Hynes, M.E., and Franklin, A.G. (1990), "Evaluation and Use of Residual Strength in Seismic Safety Analysis of Embankments," Earthquake Spectra, Vol. 6, No. 3, pp. 529-572. 
Mogami, T. and Kubo, K. (1953), “The Behaviour of Soil during Vibration,” Proceedings, $3^{\text {rd }}$ International Conference on Soil Mechanics and Foundation Engineering, Zurich, Vol. 1, pp. 152-155.

National Research Council of Canada, 2005, National Building Code of Canada, Volume 1, Ottawa, ON.

Olson, S.M. (2001), "Liquefaction Analysis of Level and Sloping Ground Using Field Case Histories and Penetration Resistance," $\mathrm{PhD}$. Thesis, University of Illinois at Urbana-Champaign, Urbana, Illinois.

Olson, S.M., and Stark, T.D. (2002), "Liquefies Strength Ratio from Liquefaction Flow Failure Case Histories," Canadian Geotechnical Journal, Vol. 39, pp. 629-647.

Olson, S.M., and Stark, T.D. (2003a), "Yield Strength Ratio and Liquefaction Analysis of Slopes and Embankments," Journal of Geotechnical and Geoenvironmental Engineering, ASCE, Vol. 129, No. 8, pp. 727-737.

Poulos, S.J., Castro, G. and France, W. (1985), "Liquefaction Evaluation Procedure," Journal of Geotechnical Engineering, ASCE, Vol.111, No. 6, pp. 772-792.

Scott, R.F. (1973), “The Calculation of Horizontal Accelerations from Seismoscope Records," Bulletin of the Seismological Society of America, Vol. 63, No. 5, pp. 16371661 .

Seed, H.B. (1979), "Considerations in the Earthquake-resistant Design of Earth and Rockfill Dams," Geotechnique, Vol. 29, No. 3, pp. 215-263.

Seed, H.B. (1987), "Design Problems in Soil Liquefaction," Journal of Geotechnical Engineering Division, ASCE, Vol. 113, No. 8, pp. 827-845.

Seed, H.B. and Idriss, I.M. (1970), "Soil Moduli and Damping Factors for Dynamic Response Analyses," Report EERC 70-10, Earthquake Engineering Research Center, University of California, Berkeley.

Seed, H.B. and Idriss, I.M. (1971), "Simplified Procedure for Evaluating Soil Liquefaction Potential", Journal of the Soil Mechanics and Foundation Division, ASCE, Vol. 97, No. SM9, pp.1249-1273.

Seed, H.B. and Lee, K.L. (1965), "Studies of Liquefaction of Sands under Cyclic Loading Conditions," Report TE-65-65, Department of Civil Engineering, University of California, Berkeley.

Seed, H.B. and Peacock, W.H. (1971), "Test Procedures for Measuring Soil Liquefaction Characteristics," Journal of the Soil Mechanics and Foundations Division, ASCE, Vol. 97, No. SM8, pp.1099-1119. 
Seed, H.B., Idriss, I.M., Lee, K.L., and Makdisi, F. (1975b), "Dynamic Analysis of the Slide in the Lower San Fernando Dam during the Earthquake of February 9, 1971," Journal of the Geotechnical Engineering Division, ASCE, Vol. 101, No. GT9, pp. 889911.

Seed, H.B., Idriss, I.M., Makdisi, F., and Banerjee, N. (1975), "Representation of Irregular Stress Time Histories by Equivalent Uniform Stress Series in Liquefaction Analyses," EERC 75-29, Earthquake Engineering Research Center, University of California, Berkeley.

Seed, H.B., Lee, K.L., Idriss, I.M., and Makdisi, F. (1973), "Analysis of the Slides in the San Fernando Dams during the Earthquake of Feb. 9, 1971," Earthquake Engineering Research Center 73-2, University of California, Berkeley, California.

Seed, H.B., Lee, K.L., Idriss, I.M., and Makdisi, F. (1975c), "The Slides in the San Fernando Dams during the Earthquake of February 9, 1971," Journal of the Geotechnical Engineering Division, ASCE, Vol. 101, No. GT7, pp. 651-688.

Seed, H.B., Tokimatsu, K., Harder, L.F., and Chung, R. (1985), "Influence of SPT Procedures in Soil Liquefaction Resistance Evaluations," Journal of Geotechnical Engineering Division, ASCE, Vol. 111, No. 12, pp. 861-878.

Seed, R.B. and Harder, L.F. Jr. (1990), "SPT-based Analysis of Cyclic Pore Pressure Generation and Undrained Residual Strength," Proc. H. Bolton Seed Memorial Symposium, Bi-Tech Publishing Ltd., Vol. 2, pp. 351-376.

Stark, T.D. and Mesri, G. (1992), "Undrained Shear Strength of Liquefied Sands for Stability Analysis," Journal of Geotechnical Engineering, ASCE, Vol. 118, No. 11, pp. 1727-1747.

Stark, T.D., Olson, S.M., Kramer, S.L., and Youd, T.L. (1998), "Shear Strength of Liquefied Soils," Proceeding, Workshop on Post-Liquefaction Shear Strength of Granular Soils, April 17-18, 1997, University of Illinois at Urbana-Champaign, Urbana, Illinois, 288 p. (Available only on the World Wide Web at http://mae.ce.uiuc.edu).

Tokimatsu, K. and Seed, H.B. (1987), "Evaluation of Settlements in Sands Due to Earthquake Shaking," Journal of Geotechnical Engineering, ASCE, Vol. 113, No. 8, pp. 861-878.

Vaid, Y.P. and Sivathayalan, S. (1996), "Static and Cyclic Liquefaction Potential of Fraser Delta Sand in Simple Shear and Triaxial Tests." Canadian Geotechnical Journal, Vol. 33, No. 2, pp. 281-289.

Vucetic, M. and Dobry, R. (1991), "Effect of Soil Plasticity on Cyclic Response," Journal of Geotechnical Engineering, ASCE, Vol. 117, No. 1, pp. 89-107. 
Wolff, T.F. (1989), "Pile Capacity Prediction Using Parameter Functions," in Predicted and Observed Axial Behaviour of Piles, Results of a Pile Prediction Symposium, sponsored by Geotechnical Engineering Division, ASCE, Evanston, Illinois, June 1989, ASCE Geotechnical Special Publication No. 23, pp. 96-106.

Youd, T.L. (1991), "Mapping of Earthquake-induced Liquefaction for Seismic Zonation," Proceedings, $4^{\text {th }}$ International Conference on Seismic Zonation, Earthquake Engineering Research Institute, Stanford University, Vol. 1, pp. 111-147.

Youd, T.L. (1993), "Liquefaction-induced Lateral Spread Displacement," Report TN1862, Naval Civil Engineering Laboratory, Port Hueneme, California, 44 pp.

Youd, T.L. and Hoose, S.N. (1977), "Liquefaction Susceptibility and Geologic Setting," Proceedings, $6^{\text {th }}$ World Conference on Earthquake Engineering, New Delhi, Vol. 3, pp. 2189-2194.

Youd, T.L. and Idriss, I.M. (2001), "Liquefaction Resistance of Soils: Summary Report from the 1996 NCEER and 1998 NCEER/NSF Workshops on Evaluation of Liquefaction Resistance of Soils," Journal of Geotechnical and Geoenvironmental Engineering, Vol. 127, No. 4, pp. 297-313. 